\title{
DECAY ENERGIES OF GASEOUS FISSION PRODUCTS AND THEIR DAUGHTERS FOR A-88 TO 93
}

\author{
Ph.D. Thesis Submitted to lowa State University, \\ November, 1972
}

\section{J. R. Clifford}

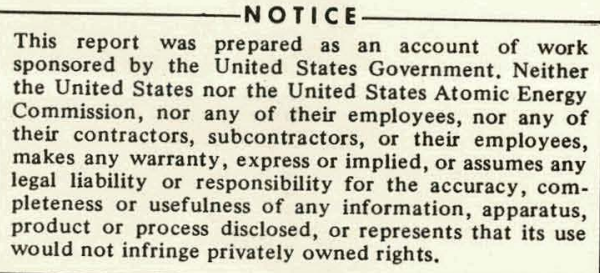

would not infringe privately owned rights.

\section{Ames Laboratory, USAEC \\ lowa State University}

Ames, lowa 50010

Date of Manuscript: November, 1972

PREPARED FOR THE U. S. ATOMIC ENERGY COMMISSION

DIVISION OF RESEARCH UNDER C.ONTRACT NO. W-740.5-eng-82 


\section{DISCLAIMER}

This report was prepared as an account of work sponsored by an agency of the United States Government. Neither the United States Government nor any agency Thereof, nor any of their employees, makes any warranty, express or implied, or assumes any legal liability or responsibility for the accuracy, completeness, or usefulness of any information, apparatus, product, or process disclosed, or represents that its use would not infringe privately owned rights. Reference herein to any specific commercial product, process, or service by trade name, trademark, manufacturer, or otherwise does not necessarily constitute or imply its endorsement, recommendation, or favoring by the United States Government or any agency thereof. The views and opinions of authors expressed herein do not necessarily state or reflect those of the United States Government or any agency thereof. 


\section{DISCLAIMER}

Portions of this document may be illegible in electronic image products. Images are produced from the best available original document. 


This report was prepared as an account of work
sponsored by the United States Government. Neither
the United States nor the United States Atomic
Energy Commission, nor any of their employees, nor
any of their contractors, subcontractors, or their
employees, makes any warranty, express or implied,
or assumes any legal liability or responsibility for the
accuracy, completeness or usefulness of any
information, apparatus, product or process disclosed,
or represents that its use would not infringe privately
owned rights.

Available from: National Technical Information Service Department A

Springfield, VA 22151

Price: Microfiche $\$ 0.95$ 
iii

Decay energies of gaseous fission products

and their daughters for $A=88$ to 93

by

Jerome Robert Clifford

A Dissertation Submitted to the

Graduate Faculty in Partial Fulfillment of

The Requirements for the Degree of DOCTOR OF PHILOSOPHY

Department: Physics

Major: Nuclear Physics

Approved:

W. L. Talbert, Jr. (RGB)

In Charge of Major Work

RG Barnes

For the Major Department

Chute ERodench

For the Graduate College

Iowa State University

Ames, Iowa

1972 
TABLE OF CONTENTS

$\begin{array}{lc}\text { ABSTRACT } \\ \text { PROLOGUE } \\ \text { INTRODUCTION AND THEORY } & \frac{\text { Page }}{v} \\ \text { EXPERIMENTAL ARRANGEMENT } & 18 \\ \text { RESPONSE AND CALIBRATION OF SCINTILLATOR } & 36 \\ \text { DATA ACCUMULATION } & 41 \\ \text { DATA ANALYSIS } & 48 \\ \text { RESULTS } & 84 \\ \text { DISCUSSION } & 95 \\ \text { CONCLUSIONS } & 97 \\ \text { REFERENCES } & 101 \\ \text { ACKNOWLEDGMENTS } & 9\end{array}$




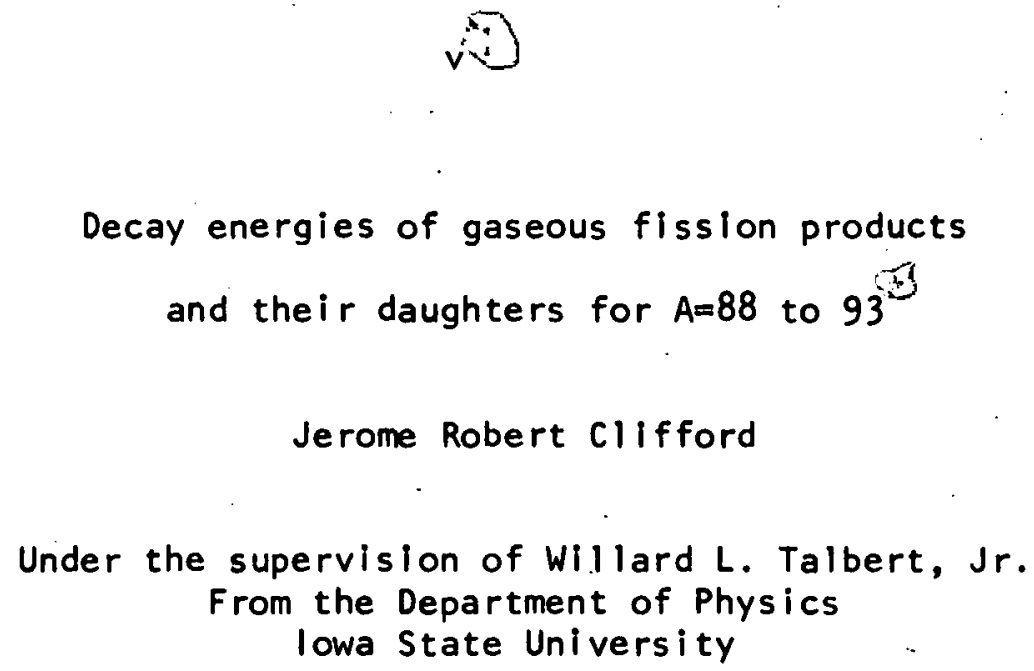

A systematic study of beta decay energies has been made for massseparated activities of $\mathrm{Kr}$ gaseous fission products and their daughters at the TRISTAN on-line separator facility at the Ames Laboratory Research Reactor. A Pllot B well-type plastic scintillator was used in coincidence with a $60 \mathrm{~cm}^{3} \mathrm{Ge}(\mathrm{LI})$ gamma detector as described by wohn et al. ${ }^{+}$The following beta decay end-point energles have been determined: ${ }^{88} \mathrm{Kr}$, $2.93 \pm 0.03 \mathrm{MeV} ;{ }^{88} \mathrm{Rb}, 5.30 \pm 0.06 \mathrm{MeV} ;{ }^{89} \mathrm{Kr}, 4.93 \pm 0.06 \mathrm{MeV} ;{ }^{90} \mathrm{Kr}$, $4.35 \pm 0.05 \mathrm{MeV} ;{ }^{90} \mathrm{Rb}, 6.32 \pm 0.06 \mathrm{MeV} ;{ }^{91} \mathrm{Kr}, 6.12 \pm 0.07 \mathrm{MeV} ;{ }^{91} \mathrm{Rb}$, $5.68 \pm 0.04 \mathrm{MeV} ;{ }^{92} \mathrm{Kr}, 5.97 \pm 0.08 \mathrm{MeV} ;{ }^{92} \mathrm{Rb}, 7.58 \pm 0.15 \mathrm{MeV}^{92} \mathrm{Sr}$, $1.93 \pm 0.03 \mathrm{MeV} ;{ }^{93} \mathrm{Kr}, 8.3 \pm 0.5 \mathrm{MeV}$; and ${ }^{93} \mathrm{Rb}, 7.23 \pm 0.10 \mathrm{MeV}$. The decay energles were compared with previous measurements, systematics predictions, and two currently accepted mass relations. The energies were used to predict the beta decay energies for thirteen additional nuclei by means of systematics.

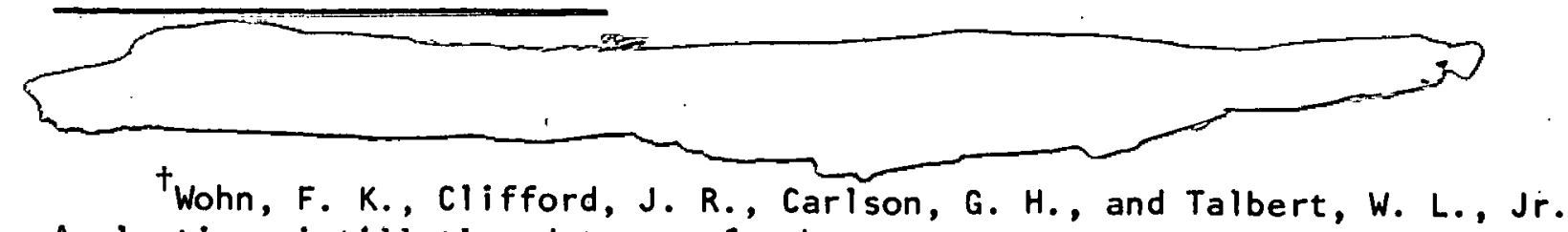
A plastic scintillation detector for beta-ray spectrum measurements. Nucl. Instr. Methods (In press) ca. 1972. 
Once upon a time there was a fellow named Harry Krypton. Everyone liked Harry and invited him to their parties; they all said that he was a gas. Harry came from a large family. His father had at least 103 relatives and he had heard that there were well over 1600 if you count all their daughters. (Harry had a weird family--only daughters.) Harry's parents were Fred Neutron and his wife Uranium. For years the nelghborhood thought that they would never get together. Harry, unfortunately, never got to know his parents because they split up just before he was born. Harry did hear stories about the folks from his older sisters, 93 and 94. 'Harry's parents were so lazy that they numbered the kids rather than name them.) Finally Harry decided to look up his family tree and discover the truth. The tree was like none he had ever seen; the whole family was a bunch of squares:

Harry was very much disturbed by this and became very unstable. His sisters said that he was decaying in front of their eyes, exponentially even. They sent him to the family doctor. Dr. Seeger said that the only thing wrong with Harry was that he was living in a shell. This was not unusual, however, because all his family lived in one shell or another. Dr. Seeger suggested that the only way out of his quandary was through pairing. Harry was to find a mate, which would be very difficult indeed, seeing as Harry was noble and found it hard to react.

Finally, discouraged and depressed, Harry went to a specialist, Dr. Garvey the shrink. Dr. Garvey belleved that to understand Harry's problems, 
he had to look at Harry's close relatives. The doctor determined that Harry was just another spin off the family tree. Hearing this Harry left. (Dr. Garvey's blll was very high for the amount of counseling since he felt that his work was charge independent.)

Completely dejected, Harry went for a quiet walk. He found his Way into the Woods where he met a fairy. She was really a magic number, in fact she was doubly magic, which almost put poor Harry into an excited state. The little falry told Harry what he had been searching for all the time, his value in life. Her line was that Harry was just as straight as the next guy. Harry was so relleved that he lived happily ever after, about a microsecond. 


\section{INTRODUCTION AND THEORY}

Since around 1935 when von Weizsäcker first developed a semlempirical mass relation (1), the study of nuclear masses has been of interest, especially in recent years, for element genesis theories in astrophysics and for predictions of decay properties of nuclei far from the line of beta stability. This work is concerned with the latter interest and attempts to extend our knowledge of the changes in the nuclear mass surface, as determined from beta-decay Q-values, for several nuclei far from the line of beta stability. The area of particular interest in this work is the neutron-rich region around the mass $A=90$, where decay is via the emission of a beta ray and an anti-neutrino.

The theory of beta decay describes the probability of emitting a beta ray of a given energy by

$$
T(W)=\sum_{i=1}^{n} A_{i} F(Z, W) \text { p W }(W,-W)^{2} s_{i}(W) \Delta_{i}
$$

where $A_{i}$ is the amplitude coefficient of the $i^{\text {th }}$ beta group, $F(Z, W)$ is the Fermi function, $S_{i}(W)$ is the spectrum shape factor, $p$ is the relativistic beta-ray momentum in units of $m_{e} c, W$ is the relativistic beta-ray energy in units of the electron mass, $\mathrm{m}_{\mathrm{e}} \mathrm{c}^{2}$, and $\mathrm{n}$ is the number of betaray groups. The step function $\Delta_{i}$ is unity for $w \leq w_{i}$ and zero for $w>w_{i}$, where $W_{i}$ is the end-point energy of the $i^{\text {th }}$ beta group. The amplitude coefficient $A_{i}$ is related to the intensity $I_{i}$ of the beta group by

$$
1_{i}=C A_{i} f\left(Z, w_{i}\right)
$$

where $f\left(Z, W_{i}\right)$ is the integral Fermi function and $c$ is the intensity 
normalization constant. The Fermi function accounts for the distortion of the beta-ray energy spectrum due to Coulomb effects by the nuclear charge on the emerging beta ray. The shape factor $s_{i}(W)$ is unity for allowed and most first-forbidden non-unique beta-ray spectra. For the first-forbidden unique transitions, the shape factor is

$$
s_{i}(w)=\frac{1}{12}\left(\lambda^{2} p^{2}-q_{i}^{2}\right)
$$

where $q_{i}=W_{1}-W$ and $\lambda$ is a slowly varying function of $W$. A complete study of the theory of beta decay is given by Konopinski and Rose in the compilation edited by siegbahn (2).

The Q-value for a beta decay, which is the energy avallable for the beta decay and is equivalent to the atomic mass difference of the initial and final nuclei, has been studied theoretically through mass relations that have parameters determined by using mass values for nuclei near the line of stability. The basic semi-empirical mass formula developed by von Weizsäcker utilizes the liquid drop model of the nucleus. Stimulated by an investigation of the astrophysical r-process (rapid neutron-capture process) (3), Seeger modified the liquid drop model by inclusion of shellmodel effects and pairing terms, and created one of the more accurate models currently being used. Seeger used this mass formula to calculate the solar system isotopic abundances of certain neutron-rich stable isotopes that resulted from the decay of extremely neutron-rich nuclides (20 to 40 units from the line of beta stability) formed in conjectured astrophysical environments. The features considered important in Seeger's mass formula are included for their possible role in r-process calculations 
and the results of this work would help to determine the extent to which the formula is applicable in calculating nuclear masses for the neutronrich region far from the line of beta stability.

Another highly regarded mass relation is that developed by Garvey and Kelson et al. (4). This mass relation is based on the single-particle model of the nucleus and utilizes symmetries impliclt in isospin formalism. Relationships between nuclidic masses that are valid, independently of the variation of mass with atomic number and charge, are used to formulate a simple mass relation, which is then fit to the known data. Though there are several other widely used mass formulas, these two are considered here to be the most acceptable since they have rather small deviations from experimentally determined masses. Furthermore, they are unique among the avallable formulas in their accuracy far from stability for neutron-rich nuclei since their predictions for the occurrence of delayed neutron precursors are in agreement with experimental observations $(5,6)$. The mass formulas have not, however, been subjected to a systematic test using mass differences experimentally determined for nuclei far from stability. This test is, in part, a justification for the work reported here.

An interesting systematic approach to the prediction of nuclear masses was taken by Way and Wood in 1954 (7). They developed a beta-decay systematics which exhibits linear relations for disintegration energies between the nuclei $(Z, N)$ and $(Z+1, N-1)$ when plotted as a function of $N$ wlth $Z$ constanc, where $Z$ is the proton number and $N$ is the neutron number. These linear relations have been used to predict the mass differences for 
nuclel far from the line of beta stablilty. Recently these predictions, as determined from presently aval lable experimental results, are reported in the 1971 Atomic Mass Evaluation by Wapstra and Gove (8). The measurement of masses far from stability in the present work should offer a critical test of these predictions and make possible several new predictions for nuclei even further away from the line of beta stability. The new predictions may also lead the way towards improving present mass formulas or developing new relations that are applicable far from the line of stability.

There are several experimental problems associated with the measurement of decay energies for nuclel far from the line of stability. It is necessary to have a system that produces a desired nucleus, separates it from any contaminant activities, and presents it to a detector, all before the nucleus decays. An isotope separator on-line to a fission product source, such as a ${ }^{235} \mathrm{U}$ sample in a reactor neutron beam, and a moving tape collector constitute such a system. Nuclei with mass numbers $A=88$ - $93^{\circ}$ were produced in this system and the gaseous fission products and their daughters were studied.

Two types of experiments are reported in this work: beta decay Qvalue measurements of singles beta-ray spectra and beta decay end-point energy measurements of beta-ray spectra in coincidence with gamma rays. A Ge(Li) gamma-ray detector and a plastic scintillator beta-ray detector, whose response and calibration were determined, were used with a pulseheight analyzer. The spectra obtained were analyzed to obtain beta decay end-point energies and relative beta feedings to levels in the daughter nucleus. 


\section{EXPERIMENTAL ARRANGEMENT}

The beta-ray spectrum measurements reported in this work we re per-. formed using the TRISTAN isotope separator on-line to the Ames Laboratory Research Reactor $(9,10)$. A layout of the TRISTAN system is illustrated in Figure 1. The reactor is a heavy water moderated and cooled, enriched ${ }^{235} \mathrm{U}$ fuel, research facility with a thermal power of five megawatts (11). Placed in one of the neutron beams emerging from the reactor is a fission product generator (FPG), which is a cylindrical aluminum can containing a cavity approximately $6 \mathrm{~cm}$ square by $2 \mathrm{~cm}$ deep in which $6.09 \mathrm{gm}$ of uranium stearate powder is placed on shelves. Figure 2 shows the FPG with one face removed to show the uranium stearate sample. The stearate is an excellent emanator of gaseous fission products, giving approximately $100 \%$ emanation in 1 second at room temperature $(12,13)$. The thermal neutron flux incident to the FPG is on the order of $3 \times 10^{9} \mathrm{n}_{\mathrm{th}} / \mathrm{cm}^{2}-\mathrm{sec}$.

From the FPG to the ion source of the separator, the emanated gaseous activities flow through a 2-m transport line, which is lined with teflon to minimize the gaseous fission product activity loss during transport (14). The transport time from the FPG to the lon source is thought to be less than 1 sec. A He support gas containing small amounts of $\mathrm{Kr}$ and $\mathrm{Xe}$ is swept through the FPG and transport line into the separator ion source. In addition to the possible sweeping action on fission product activities, the support gas provides stable ion beams of $\mathrm{Kr}$ and $\mathrm{Xe}_{e}$ for identification and tuning of the separator. The ions are accelerated through a potential of $50 \mathrm{kV}$ before introduction into a $90^{\circ}$ sector magnet having a mean radius of $160 \mathrm{~cm}(15)$. 


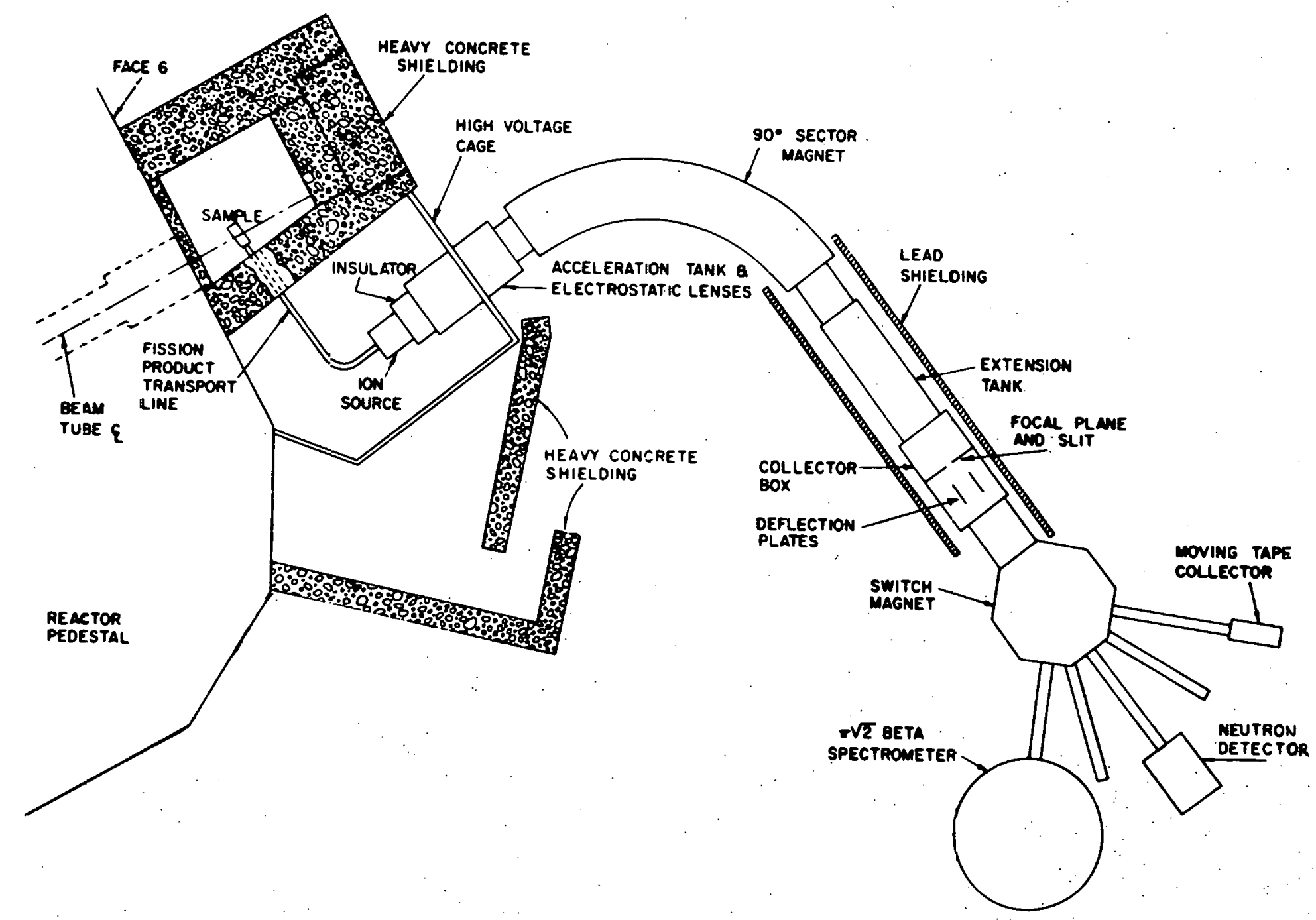

Figure 1. Layout of the TRISTAN isotope separator 


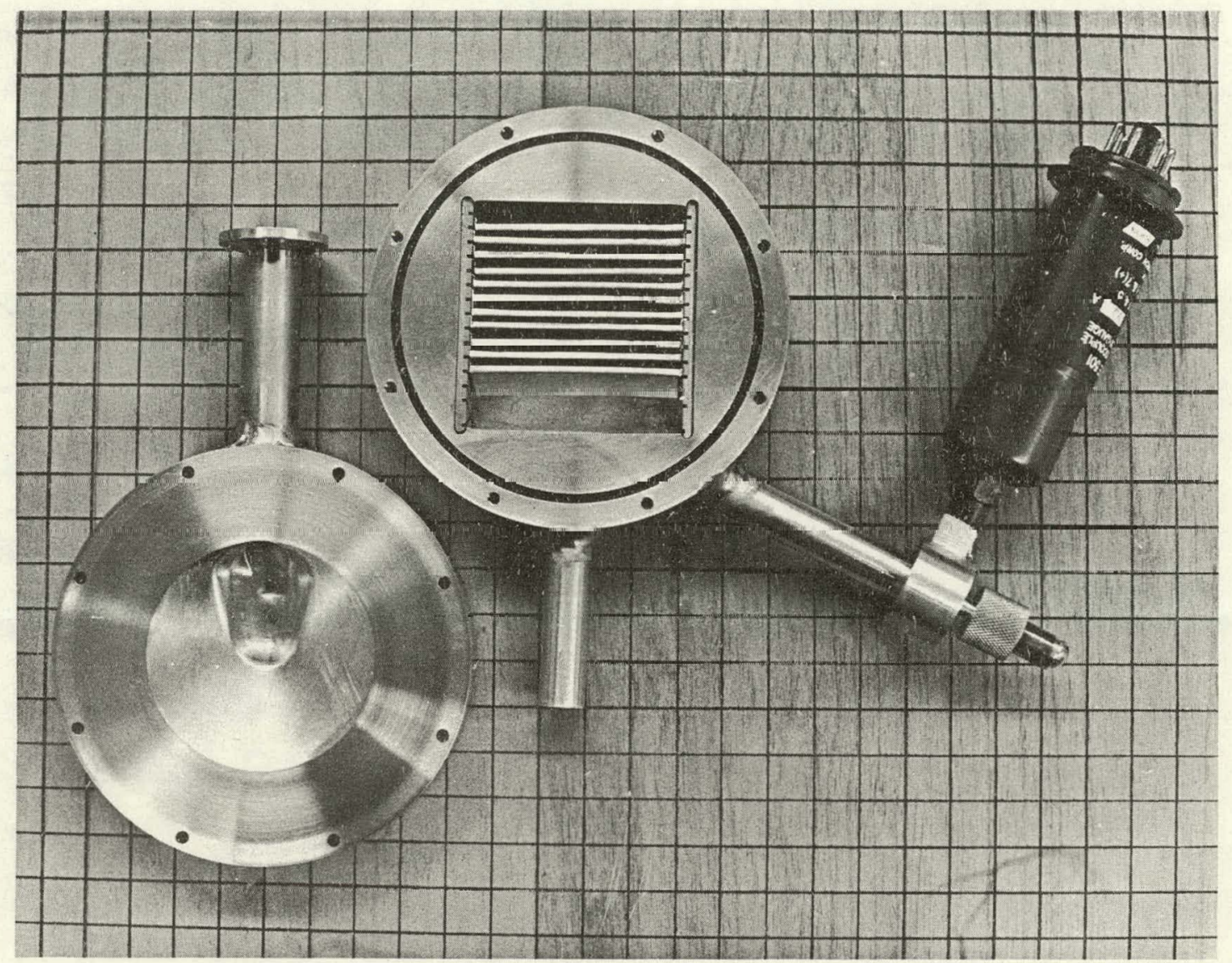

Figure 2. Fission product generator with one face removed 
The dispersion of the separator is such that ion beams of adjacent masses have focal plane spacings of about $1.8 \mathrm{~cm}$ for the $A=90$ region. Additional separation is achieved at the switching magnet, which directs the ions of a selected mass to the appropriate experimental apparatus. The contamination of adjacent masses found at the moving tape collector (MTC) due to incomplete mass selection in the separator is on the order of 1 part in $10^{7}$ (12). At the focal plane of the separator, the ion beams have profiles similar to that shown in Figure 3.

The ion beam from the mass separator strikes an aluminized Mylar tape mounted inside the MTC to produce a line source parallel to the direction of the tape motion (15). The MTC, shown in Figure 4, is used to provide isobaric separation between members of a decay chain with a given mass number. There are two detector ports in the MTC that are $46 \mathrm{~cm}$ apart, as measured along the tape. The upper port, which is at the beam deposition point, is used for the study of parent and short-lived daughter activities while the lower port is used for the study of the longer-lived daughter activities. The degree of separation, or enhancement, depends on the differences in half-life between the element under study and other elements of the same mass number as well as the manner in which the MTC and detection system are operated.

There are several modes of operation for the MTC. Depending on the half-life and the ancestry of the activity to be enhanced, the tape can be moved either continuously or intermittently in a stepping mode. Variation of such parameters as the tape speed, beam collection time, delay time, and count time determines the degree of enhancement of the activity 

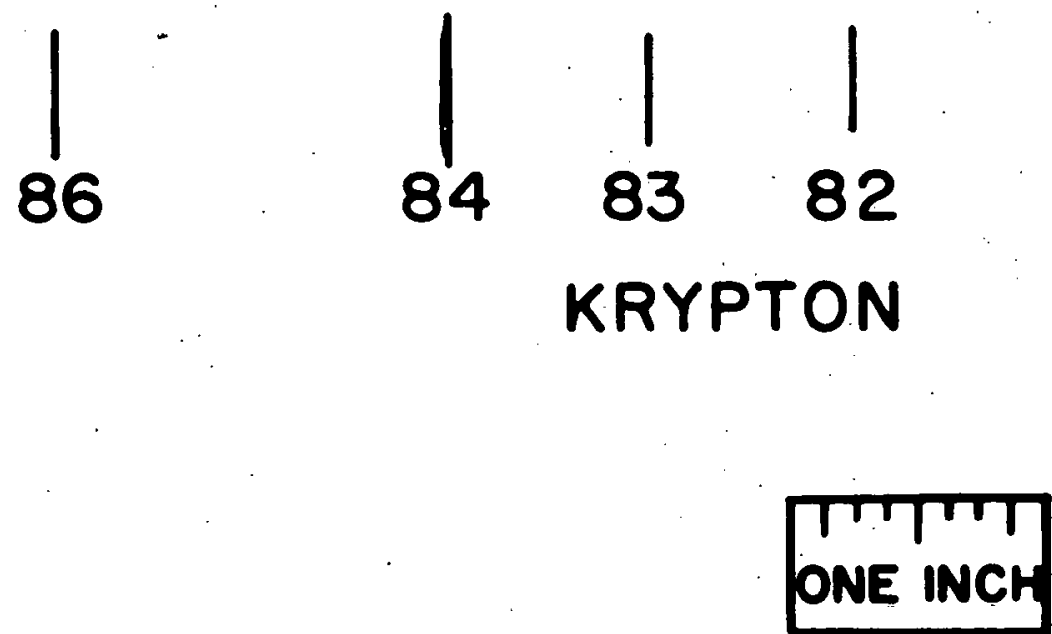

Figure 3. Ion beam profile at the focal plane of the separator 


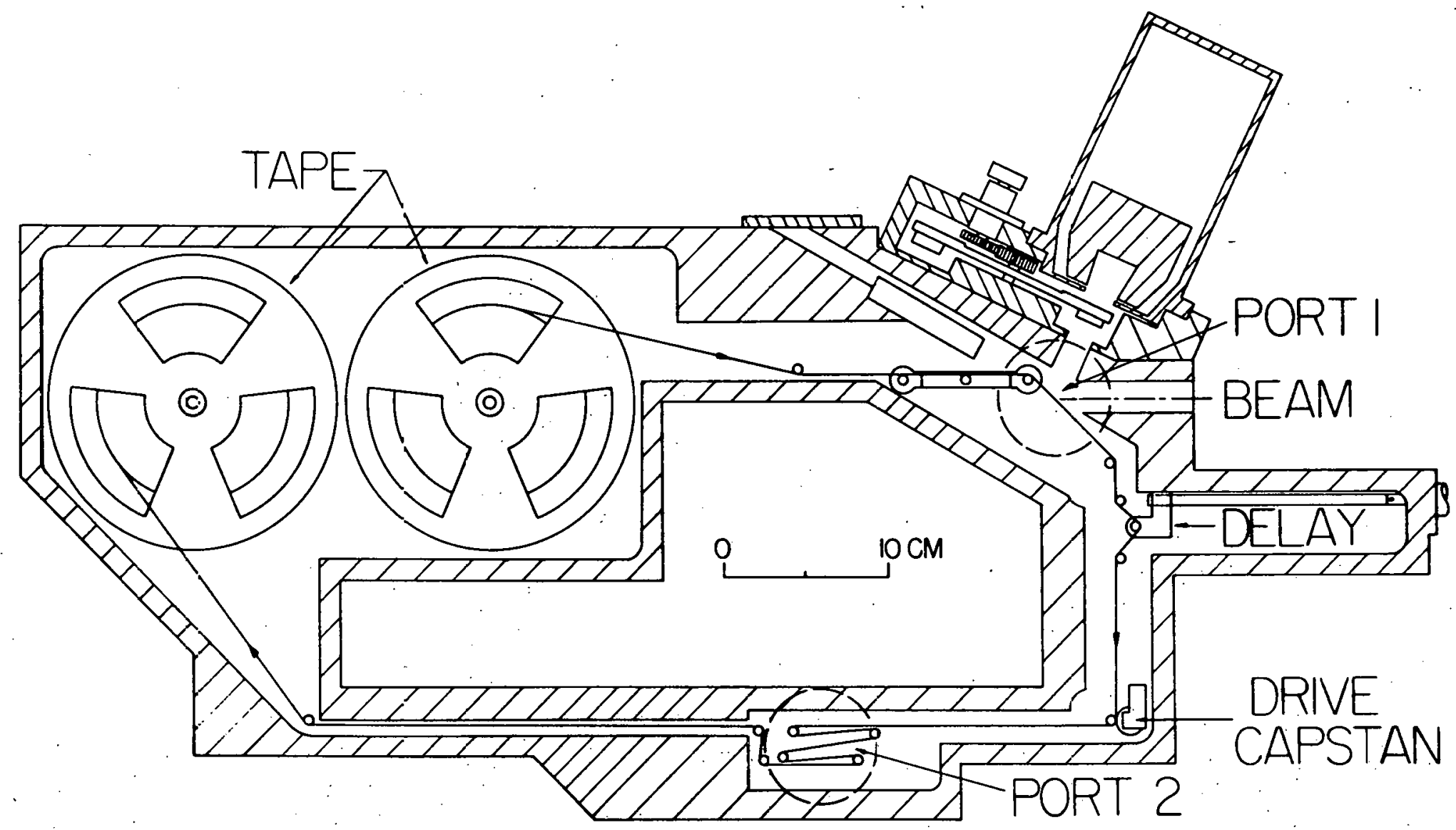

Figure 4. Moving tape collector 
of interest. The various modes of operation and the parameters involved are described in detail in a report by J. H. Norman et al. (16). Also described is a computer program called ISOBAR, which can be used to determine values of the parameters that yield the desired activity enhancement factor.

The beta-gamma coincidence detection system consists of a $\mathrm{Ge}(\mathrm{Li})$ gamma-ray detector and a plastic scintillator beta-ray detector. The Ge(Li) detector is a $60 \mathrm{~cm}^{3}$, coaxial type detector having an $11 \%$ efficiency compared to a $7.6 \mathrm{~cm}$ by $7.6 \mathrm{~cm} \mathrm{Nal}(\mathrm{TI})$ detector. It has a FWHM resolution of approximately $2.8 \mathrm{keV}$ and a peak-to-Compton ratio of $28: 1$ at the $1.33-$ $\mathrm{MeV}{ }^{60} \mathrm{Co}$ line. The plastic scintillator, shown in cross-section in figure 5, is made of Pilot B plastic and has cylindrical symmetry with a diameter of $6.5 \mathrm{~cm}$. The side and front surfaces of the scintillator are coated with a titanium dioxide reflective coating. The scintillator contains a well in the front face having the shape of a truncated cone. The well has an entrance diameter of $1.9 \mathrm{~cm}$ and a depth of $2.3 \mathrm{~cm}$. The plastic scintillator has a "depth" of $3.5 \mathrm{~cm}$ (the distance from the bottom of the well to the photomultiplier surface) that is equal to the range of a 7-MeV beta ray in the Pilot $B$ plastic, where the range is determined by extending the linear portion of the range curve to the zero counts axis.

The detector is mounted so that the source is positioned at the vertex of the cone, a distance of $5.7 \mathrm{~cm}$ from the front of the well. With respect to the source position, the solid angle subtended by the well is $0.7 \%$ of $4 \pi$. The well reduces the backscattering of beta rays by an order of magnitude compared to a flat scintillator. The decreased backscattering 


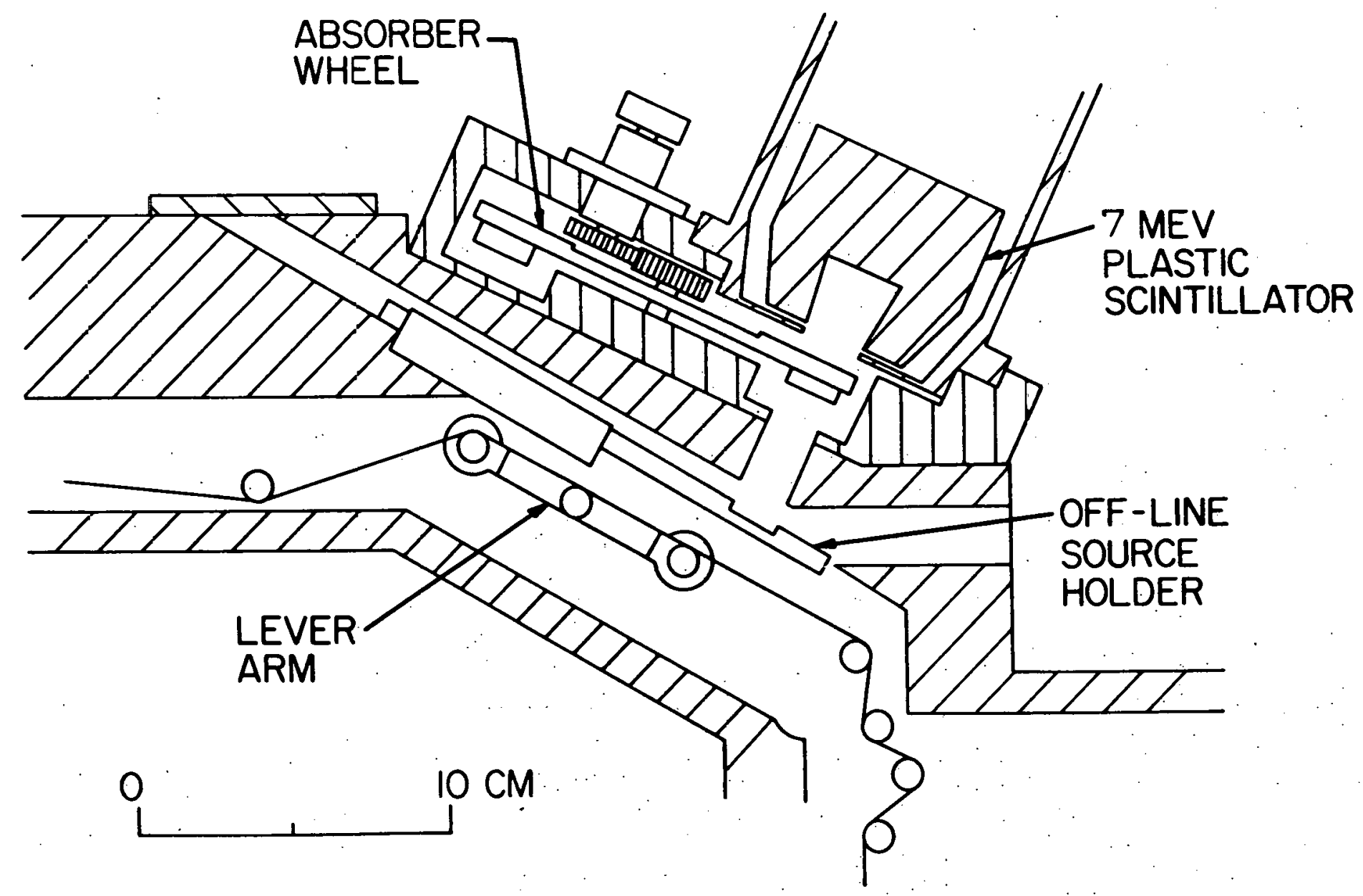

figure 5. Plastic scintillator, absorber wheel, and external source holder shown in cross-section on the MTC 
is at the expense of some non-linearity introduced into the calibration curve for low-energy beta rays due to an increased light collection efficiency for low-energy beta rays.

The plastic scintlllator is mounted on an EMI 9708KR photomultiplier (PM), which is shielded from magnetic and electrostatic fields that can distort the PM response by a mu-metal shield. The PM is a nine stage, "venetian blind" type tube operated at $+1,800$ volts. The PM supplies two signals; one for coincidence determination, the other for energy analysis. The timing signal is a negative pulse taken from the anode while the energy signal is a positive signal taken from the eighth dynode. The PM resistor chain has been modified to incorporate a Zener diode for greater voltage stability between the cathode and first dynode. The Zener diode assures that the important first stage of amplification in the PM is independent of the anode current. Despite the precautions taken to reduce gain shifts, there were still some shifts due to fluctuations in the scintillator-photomultiplier system, since the associated electronics have been used often with $\mathrm{Ge}(\mathrm{Li})$ systems without exhibiting shifts. These slight gain shifts encountered during a run were taken into account in the analysis of the data.

To determine the energy calibration of the plastic scintillator, several sources of known conversion-electron and beta-ray end-point energles were used. Some of these sources were available from the on-line separator system. Other sources produced off-line were contained in an external source holder, which can slide into the MTC. The moving tape can be pivoted out of the way and an external source can be located in the same 
position occupied by the tape during collection. A thin Mylar window covers the opening between the MTC and the scintillator in order to protect the detector from possible contamination.

The plastic scintillator is separated from the MTC by a wheel containing absorbers that are required for the analysis of beta-ray measurements, which is described below. A close-up view of the absorber wheel, plastic scintillator and external source holder is shown in Figure 5. The absorber wheel has five Aluminum and seven Beryllium discs which range in thickness from $3.2 \mathrm{~mm}$ to $22.2 \mathrm{~mm}$, as well as an "open" position. A beta-ray spectrum can be derived from the spectrum observed with no absorber by subtracting a normalized gamma-ray spectrum obtained by stopping the beta rays in the absorber whose thickness slightly exceeds the maximum beta-ray range. The thickness of the absorber was determined by range formulas for beta rays in the appropriate media. The gamma-ray spectrum was normalized to approximate the unattenuated gamma-ray spectrum, as will be described later.

A block diagram of the coincidence timing arrangement used in the coincidence measurements is shown in Figure 6. Emphasis during the arrangement of the coincidence electronics was placed on obtaining an energy-independent coincidence determination. Constant Fraction Timing Discriminators were used to produce an energy-independent timing spectrum, i.e., a spectrum of the number of events versus the time between the detection of beta-ray and gamma-ray pulses. With one fast and one slow detector used to start and stop the timing pulse, the time spectrum appeared slightly skewed from a Gaussian shape on the Ge(Li) detector side, with a FWHM of 


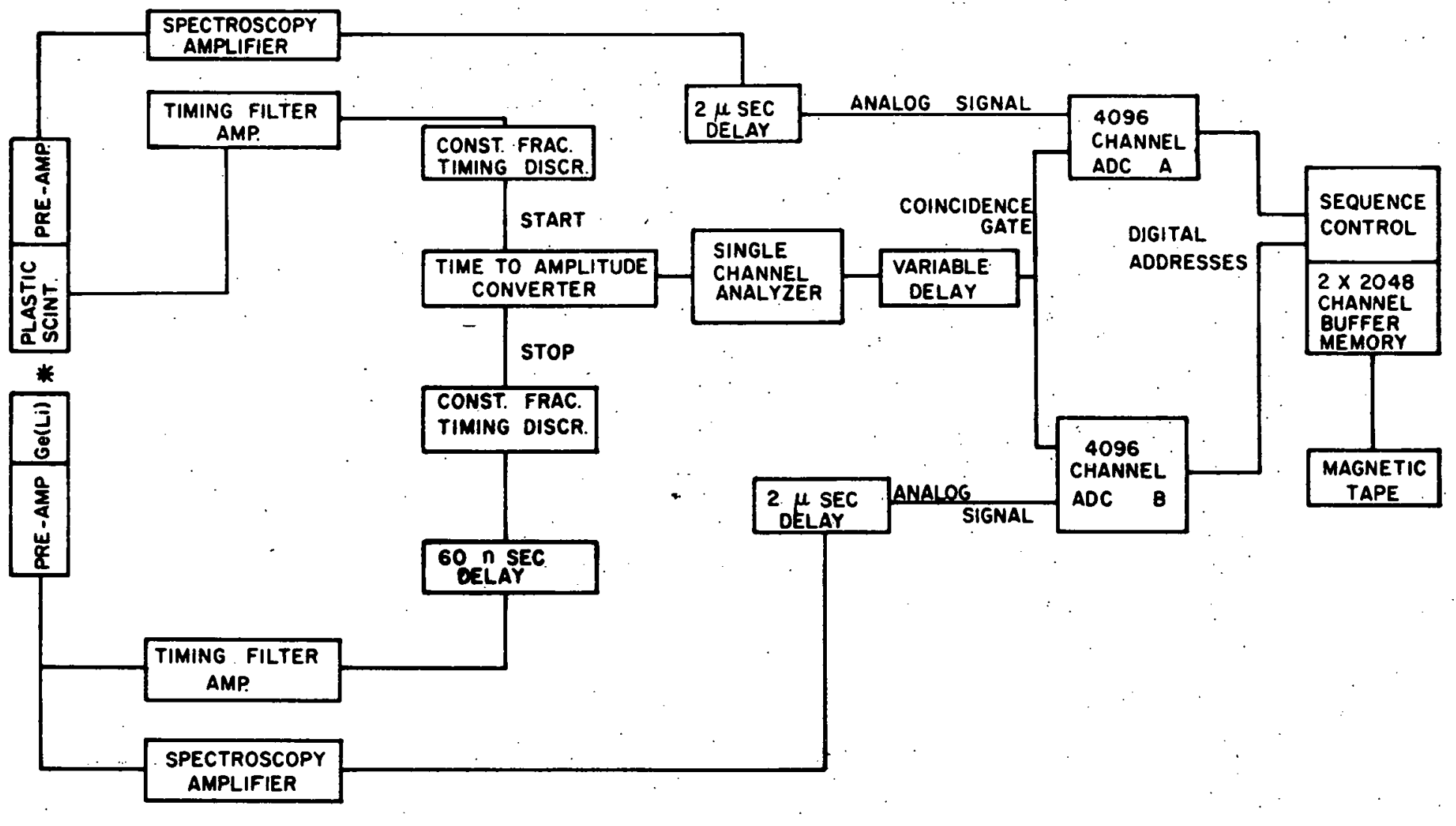

Figure 6. Block diagram of the coincidence timing arrangement 
14.5 nsec. The skewness had little effect on the data if a timing window of $24 \mathrm{nsec}$ was used, which then includes over $95 \%$ of the coincidence events. The beta-ray and gamma-ray energy pulses were shaped and amplified using linear amplifiers. The amplified beta-ray energy pulse, which had a rise time of a few nsec, was introduced into the analog-to-digital converter $(A D C)$ of a pulse-height analysis system, in which a timing gate was opened for pulses above a set threshold amplitude. A coincidence event was recorded if a coincidence timing pulse arrived while the timing gate was open. For the gamma-ray pulse, the fast coincidence pulse opened the linear gate of the gamma-ray $A D C$ and the event was recorded if the energy pulse arrived before the gate closed. This mode was necessary for the slower $\mathrm{Ge}(\mathrm{L} i)$ detector pulses, which had non-uniform pulse rise times. It was determined that, using these $A D C$ modes, the coincidence criteria were energy independent.

All experimental data were processed through a two parameter format Selector constructed at the Ames Laboratory Research Reactor. The Format Selector is a routing unit linked to two 4096-channel ADCs, a 16384-channel pulse-height analyzer and a buffer tape unit. The Format Selector can be used to route the beta-ray events directly to the pulse-height analyzer during beta-ray singles experiments. A seven-track magnetic tape unit records the beta-ray spectra directly from the analyzer memory for later computer analysis to determine the beta-decay Q-value. The Format Selector can also be used to transfer data from either or both ADC's to any memory subsection of the analyzer and/or to the buffer tape unit, while in a coincidence mode. The buffer tape unit stores the ADC addresses for 2048 
pairs of colncidence events, i.e., the channel number associated with the beta ray and the gamma ray for each colncidence event, and records them on a magnetic tape. The Format Selector has a final use of transferring the data back from the buffer tape into the memory to reassemble the data into beta-ray or gamma-ray spectra. In a singles playback mode, the gamma-ray spectrum consists of events that are in coincidence with any beta ray. This gamma-ray spectrum is used to set the gates for the coincidence beta-ray spectra. In the gated or coincidence playback mode, the beta-ray spectra consist of events that are in colncidence with the selected gamma ray. These beta-ray spectra are recorded on to seventrack magnetic tape for later computer analys is to determine the endpoint energies of the beta-ray spectra in coincidence with the gated gamma rays. 


\section{RESPONSE AND CALIBRATION OF SCINTILLATOR}

The use of a scintillation detector for the study of continuous beta-ray spectra requires a knowledge of the response of the scintillator to monoenergetic beta rays. The determination of the response for the scintillation detector used in this work has been described in detail by F. K. Wohn et al. (17). Some features of this report, however, are summarized below to reveal the approach taken in the analysis of the data for this work.

The analysis of the spectra is limited by the distortion of the measured spectra; the greater the distortion, the greater the difficulty in determining the end-point energies. There are two major distortion effects caused by the scintillation detector. One effect is due to the inherent ly low resolving power of the scintillator, which causes the measured spectrum to extend beyond the maximum energy of the beta-ray spectrum. The other effect results from the backscattering of the beta rays out of the detector, which causes the measured spectrum to contain excess counts in the low-energy part of the spectrum. These distortions cause the beta-ray response, or pulse-height spectrum for monoenergetic beta rays, to consist of a broad peak with a flat backscatter tail extending from the peak down to zero energy.

The distorted beta-ray spectrum $D(W)$ is related to the true betaray spectrum $T(W)$ by the response function, $R\left(W, W^{\prime}\right)$ through the relation

$$
D(W)=\int_{1}^{\infty} T\left(W^{\prime}\right) \quad R\left(W, W^{\prime}\right) d W^{\prime}
$$


where $W$ is the total energy in units of $m_{e} c^{2}$. If the detector had a delta function response, then the observed spectrum $D(W)$ would be identical to the true spectrum $T(W)$. The response function $R\left(W^{\prime} W^{\prime}\right)$ can be interpreted, however, as the fraction of beta rays observed with energy $W$ for beta rays of energy $W^{\prime}$ incident on the scintillator. The normalization of the response function,

$$
\int_{1}^{\infty} R\left(W, W^{\prime}\right) d W=1
$$

insures that the area under the distorted spectrum equals the area under the true spectrum, which is appropriate since all electrons incident to the detector are present in the measured spectrum.

The response function of the well scintillator was determined directly by observing the spectrum of monoenergetic beta rays. An intermediate image magnetic spectrometer (18) with a source of ${ }^{144} \mathrm{Ce}$ was used to provide beta rays with energies between 0.1 and $2.5 \mathrm{MeV}$. A source of $88 \mathrm{Kr}$, produced by the TRISTAN facility, was used in the spectrometer for the energy range $2.5-5.0 \mathrm{MeV}$. The spectrometer current limit did not allow measurements for beta-ray energies above $5 \mathrm{MeV}$. The small background contribution to the observed spectrum was subtracted out. The resulting beta-ray spectrum was also corrected for the $1.8 \%$ resolution of the spectrometer (19) giving the response for truly monoenergetic beta rays.

The detector response for each electron energy $w_{0}$ was least-square fit, using a computer program called LINE, to the following functional 
form:

$$
\begin{array}{rlrl}
R\left(W, W_{0}\right) & =H \exp \left(-x^{2}\right) & W_{0}<W \\
& =H\left[(1-A) \exp \left(-x^{2}\right)+A\right] & W_{0}-W_{c}<W<W_{0} \\
\therefore & =H\left[\left(1-A+B\left(x-x_{c}\right)^{5}\right) \exp \left(-x_{c}\left(2 x-x_{c}\right)\right)+A\right] \quad W<W_{0}-W_{c}
\end{array}
$$

where

$$
x=\frac{\left(w_{0}-W\right)}{\sigma \sqrt{2}} \text { and } x_{c}=\frac{W_{c}}{\sigma \sqrt{2}}
$$

The energy $W_{0}$ is the Gaussian centroid (or peak energy), $\sigma$ is the Gaussian width and $H$ is the peak height parameter. At energy $W_{c}$ below the centroid the function changes from Gaussian to exponential in the energy $w$, slightly modified by the term involving the skewness parameter B. The backscatter tail parameter $A$ is contained in the response function for all energies below the peak energy. This functional form for $R\left(W, W_{0}\right)$ is empirical; its justification is that it provides a good fit to the observed beta-ray response of the scintillator.

For a given peak energy $W_{0}$ the response function depends on the four parameters $\sigma, W_{c}, A$ and $B$ (the helght parameter $H$ is determined by the normalization condition). Since these parameters vary smoothly with $W_{0}$, they are interpolated by fitting each parameter to a simple analytical function of $W_{0}$. The parameters are given by 


$$
\left.\begin{array}{l}
A=2.383 \times 10^{-3}\left(1+0.649 W_{0}{ }^{2}\right) \\
B=0.0309\left(W_{0}+0.8536 / W_{0}\right)-0.0525 \\
W_{C}=\sigma\left[\left|0.15\left(W_{0}-1.9\right)\right|^{1.035}+1.405\right]
\end{array}\right]-W_{0}>0.2 \mathrm{MeV}
$$

with $\mathrm{W}_{0}$ in MeV. The skewness parameter $B$ increases with energy, but is small enough at all energies so that it contributes littile to the area of the response function. The Gaussian width $\sigma$ is due to the statistical fluctuations in the photoelectron conversion process and, therefore, is proportional to the square root of the peak energy $w_{0}$ for $w_{0}>0.2 \mathrm{MeV}$. The normalized response function for three different beta-ray energies is shown in Figure 7.

The analysis of the measured spectra depends not only on the accuracy with which the beta-ray response function is known but also on the accuracy with which the energy calibration is known. The plastic scintillator was calibrated using off-line and on-line sources giving both conversion electron peaks and continuous beta-ray spectra. off-line sources of ${ }^{32} p$ and ${ }^{38} \mathrm{Cl}$ were produced by irradiation in the Ames Laboratory Research Reactor while sources of ${ }^{137} \mathrm{Cs},{ }^{144} \mathrm{Ce}$, and ${ }^{207} \mathrm{Bi}$ were obtained commerclally. The off-line sources were prepared by atmospheric evaporation of the radioactive solution onto an aluminized Mylar tape, similar to that used in the MTC. On-line sources of $85 \mathrm{~m}_{\mathrm{Kr}},{ }^{88_{\mathrm{Rb}}}, 137_{\mathrm{Xe}}$, and ${ }^{141_{\mathrm{La}}}$. were produced using TRISTAN to complete the range of calibration energies. Representative calibration spectra are shown in Figures 8-11; a onegroup fit for the beta-ray spectrum of ${ }^{144} \mathrm{Ce}$ in Figure 8 , a two-group 


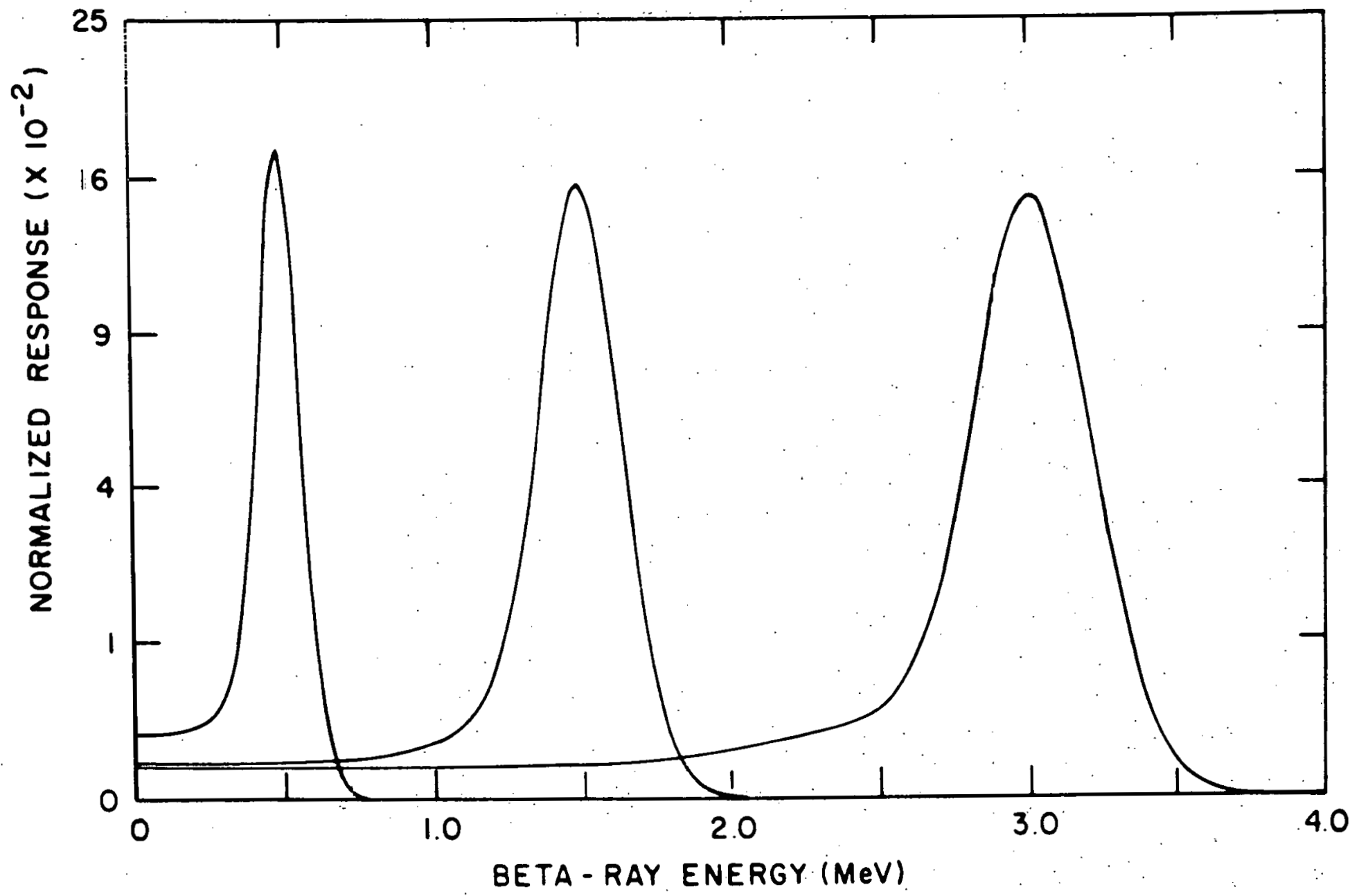

Figure 7. Normalized response function for three different beta-ray energies 

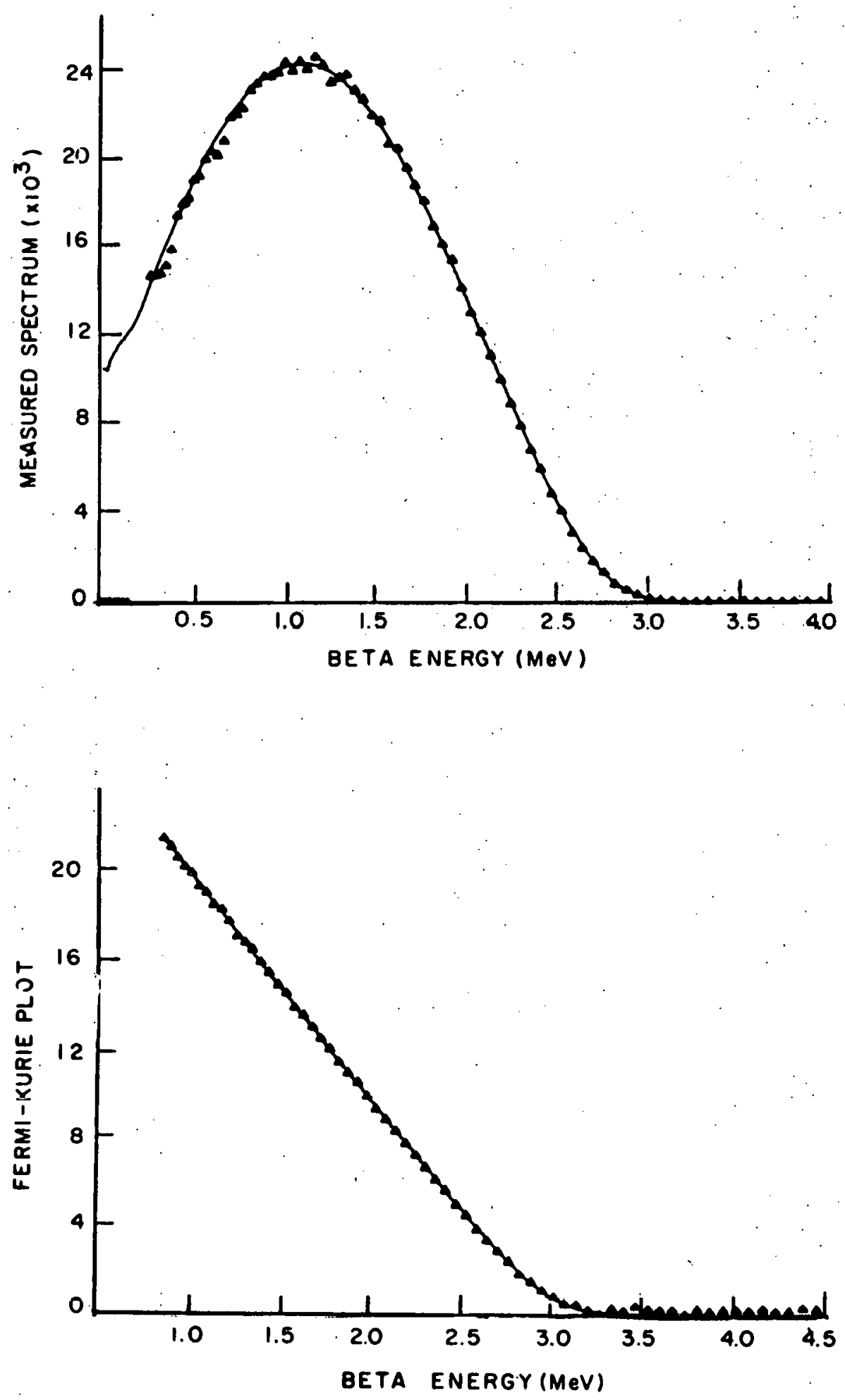

Figure 8. One-group fit for the beta-ray spectrum of ${ }^{144} \mathrm{Ce}$ 

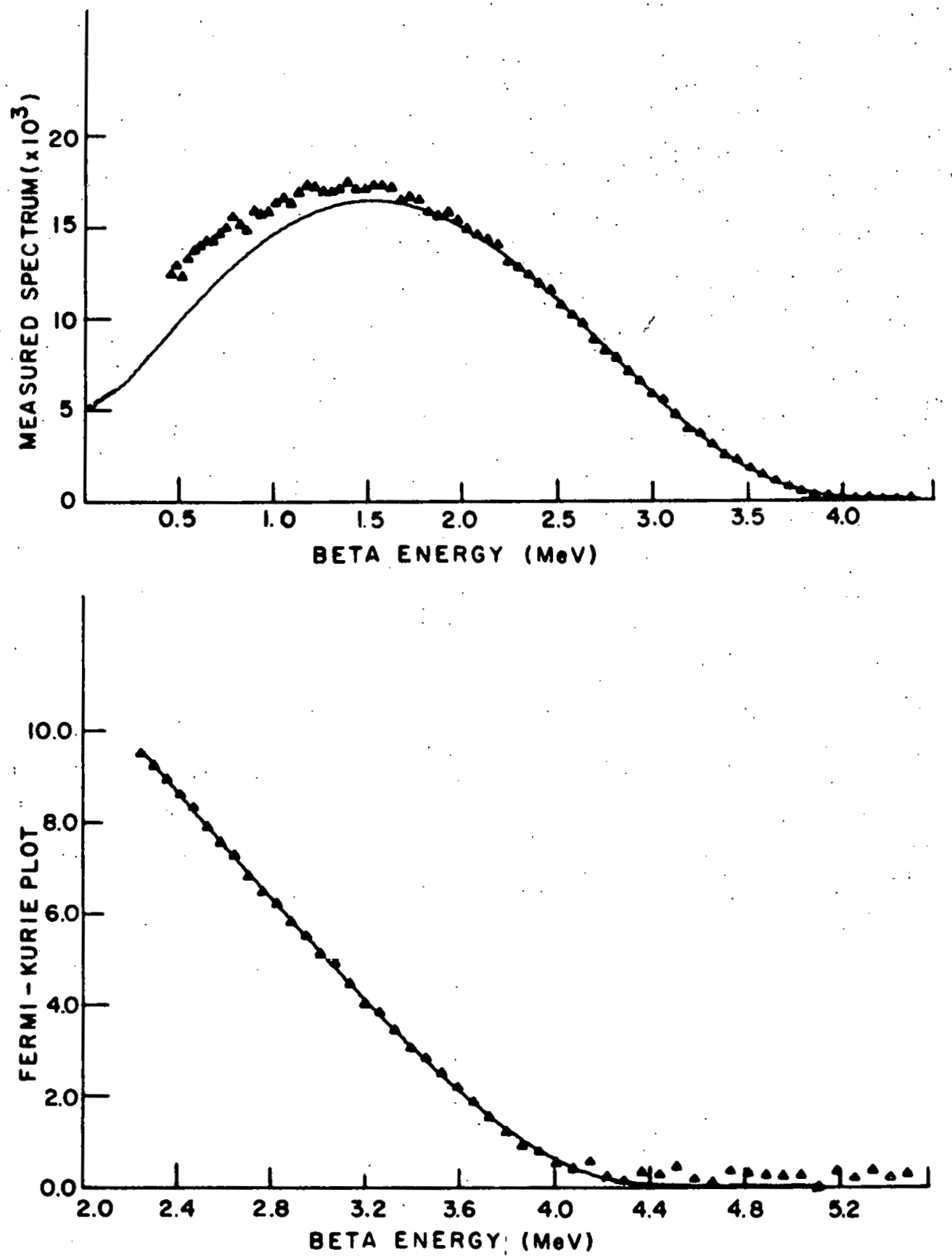

Figure 9. Two-group fit for the beta-ray spectrum of ${ }^{137} \mathrm{Xe}$ 

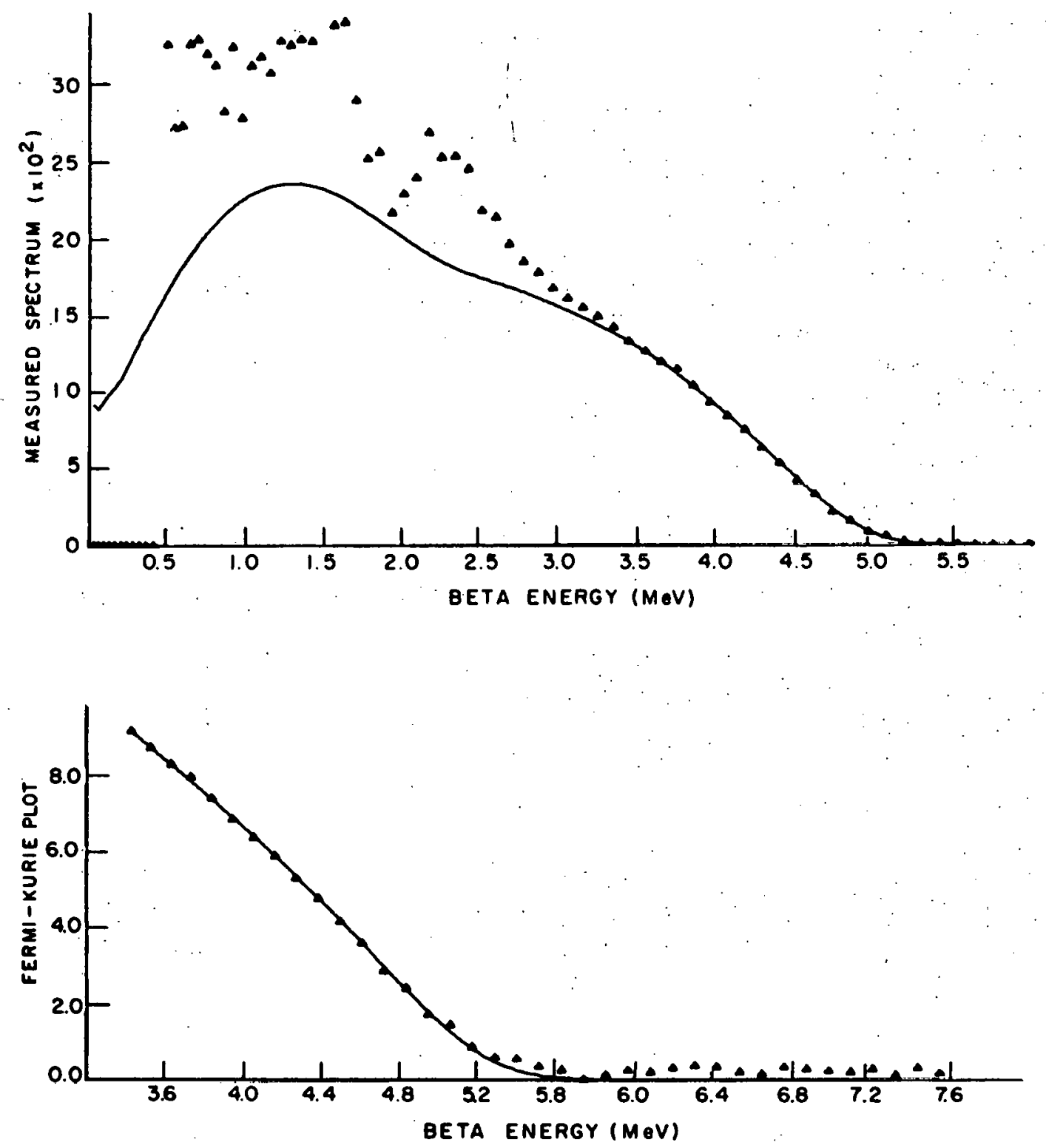

Figure 10. Three-group fit with a unique shape factor for the groundstate group for the beta-ray spectrum of ${ }^{88} \mathrm{Rb}$ 

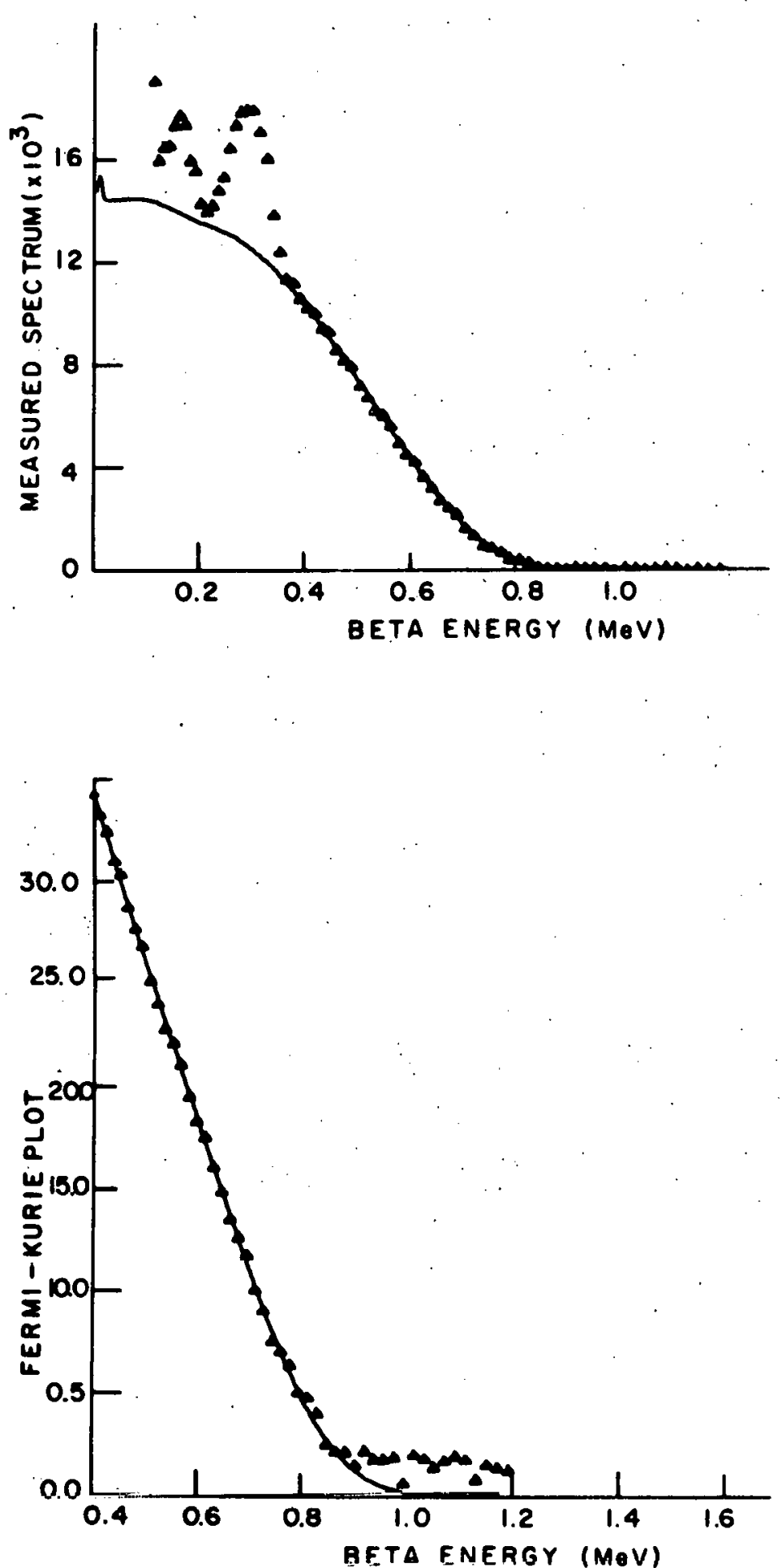

Figure 11. One-group fit for the beta-ray spectrum with an internal conversion electron peak for $85 \mathrm{~m}_{\mathrm{Kr}}$ 
fit for the beta-ray spectrum of 137 Xe in Figure 9, a three-group fit with a unique shape factor for the ground-state group for the beta-ray spectrum of ${ }^{88} \mathrm{Rb}$ in Figure 10 , and a one-group fit for the beta-ray spect-rum with an internal conversion electron peak for ${ }^{85 m_{K r}}$ in Figure 11 . A summary of the calibration sources used, along with the welghted averages of the reported end-point energy values with the rms deviations from the weighted averages, and the percent branching to the daughter energy levels, is presented in Table 1. The internal conversion electron energies listed are averages of the $K, L$, and $M$ energies, weighted by the subshell intensities.

Several collection and counting techniques had to be employed during calibration of the plastic scintillator. For the short-lived ${ }^{137} \mathrm{Xe}$ source, the sample was collected continuously unt il equillbrium was established. Spectra were accumulated for a short count time without an absorber, then with one absorber, and finally with another absorber (as described below), and the cycle was repeated in order to minimize the effect of any changes in the deposition rate of the activity. The source activity was continuously monitored and no significant deviations were noticed from the start to the finish of the counting. For the shortlived $37.2-\mathrm{min}{ }^{38} \mathrm{Cl}$ source, which could not be produced while being counted, the count time for each cycle was recorded so that the sample decay rate could be used in normalizing the gamma-ray spectra. To make the ${ }^{141}$ La source, ${ }^{141}$ Xe activity was collected for two hours and allowed to decay through the isobaric chain to ${ }^{141}$ La for three hours to eliminate any significant contamination from the shorter-lived precursors. 
Table 1. Beta-ray callibration data

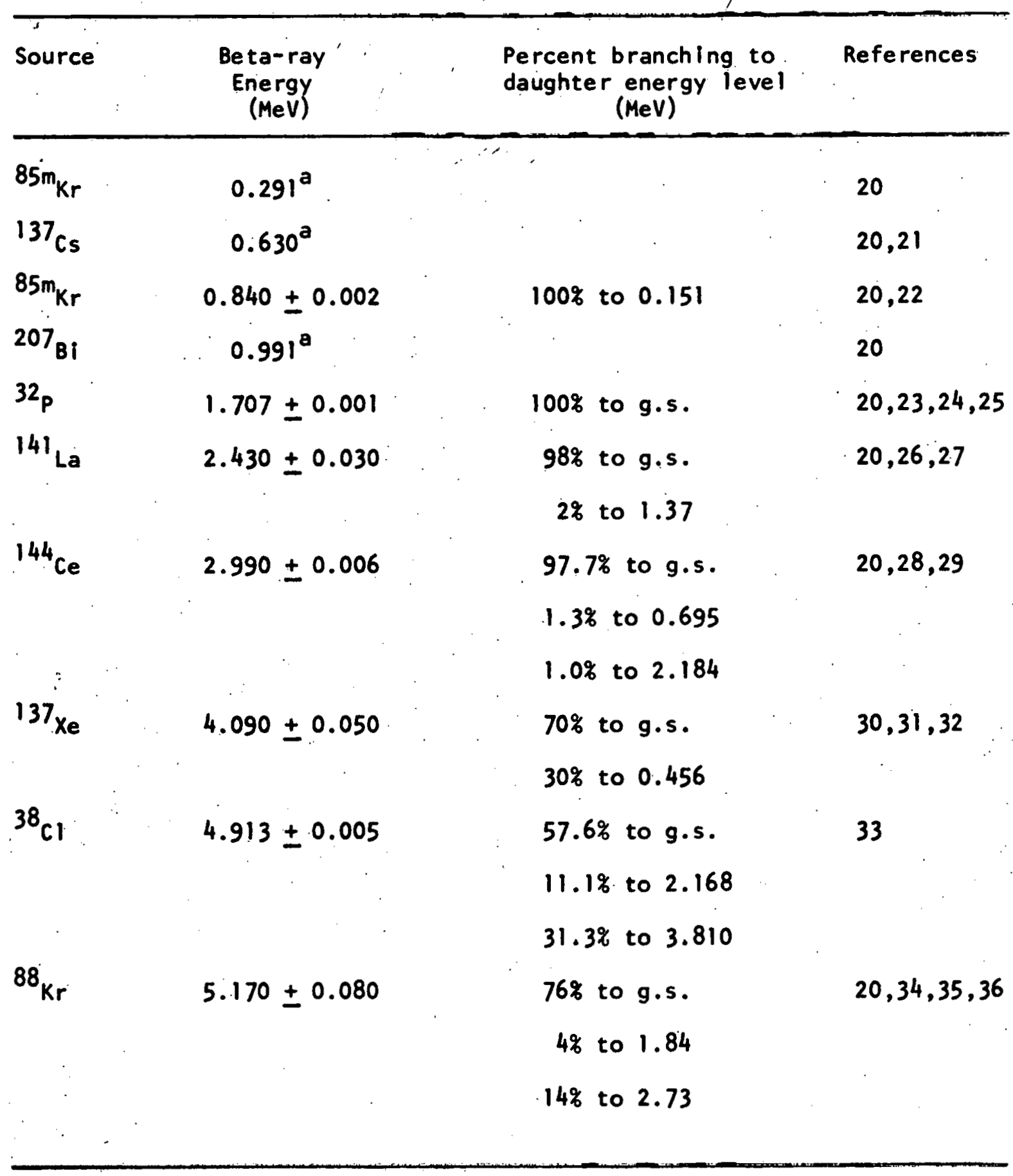

'Weighted average of $K, L$, and $M$ internal conversion electron energies. 
A two-absorber method was used to approximate the unattenuated gamma-ray spectrum which must be subtracted from the beta-plus-gamma spectrum collected without an absorber in order to obtain the distorted beta-ray spectrum. An absorber just thick enough to stop the most energetic beta ray and the next larger absorber were used during the scintillator calibration. The exponential absorption of gamma rays through an absorber can be approximated by a straight line over a small absorber thickness, as illustrated in Figure 12. Using the straight line approximation, the gamma-ray spectrum for zero absorber thickness is given by

$$
\gamma_{0}=\frac{t_{2} \gamma_{1}}{t_{2}-t_{1}}-\frac{t_{1} \gamma_{2}}{t_{2}-t_{1}}
$$

where $t_{1}$ and $t_{2}$ are the absorber thicknesses, and $\gamma_{1}$ and $\gamma_{2}$ are the gamma-ray spectra accumulated using these two absorbers. The twoabsorber approximation gives $98.8 \%$ of the true, unat tenuated gamma-ray spectrum at $1 \mathrm{MeV}$, and $99.7 \%$ of the unattenuated gamma-ray spectrum at $5 \mathrm{MeV}$, using the $1.588 \mathrm{-cm}$ and $1.905-\mathrm{cm}$ absorbers, which stop a $5-\mathrm{MeV}$ beta ray. Since the measured beta-ray spectra were usually fit over the region between the end-point energy and an energy 2 MeV back from the end-point energy, the approximation appears to give a valid correction for gamma-ray cont ributions.

Spectra of Compton-scattered electrons were also accumulated for calibration purposes by using encapsulated gamma-ray sources that have strong, well-separated gamma peaks. The observed Compton distributions 


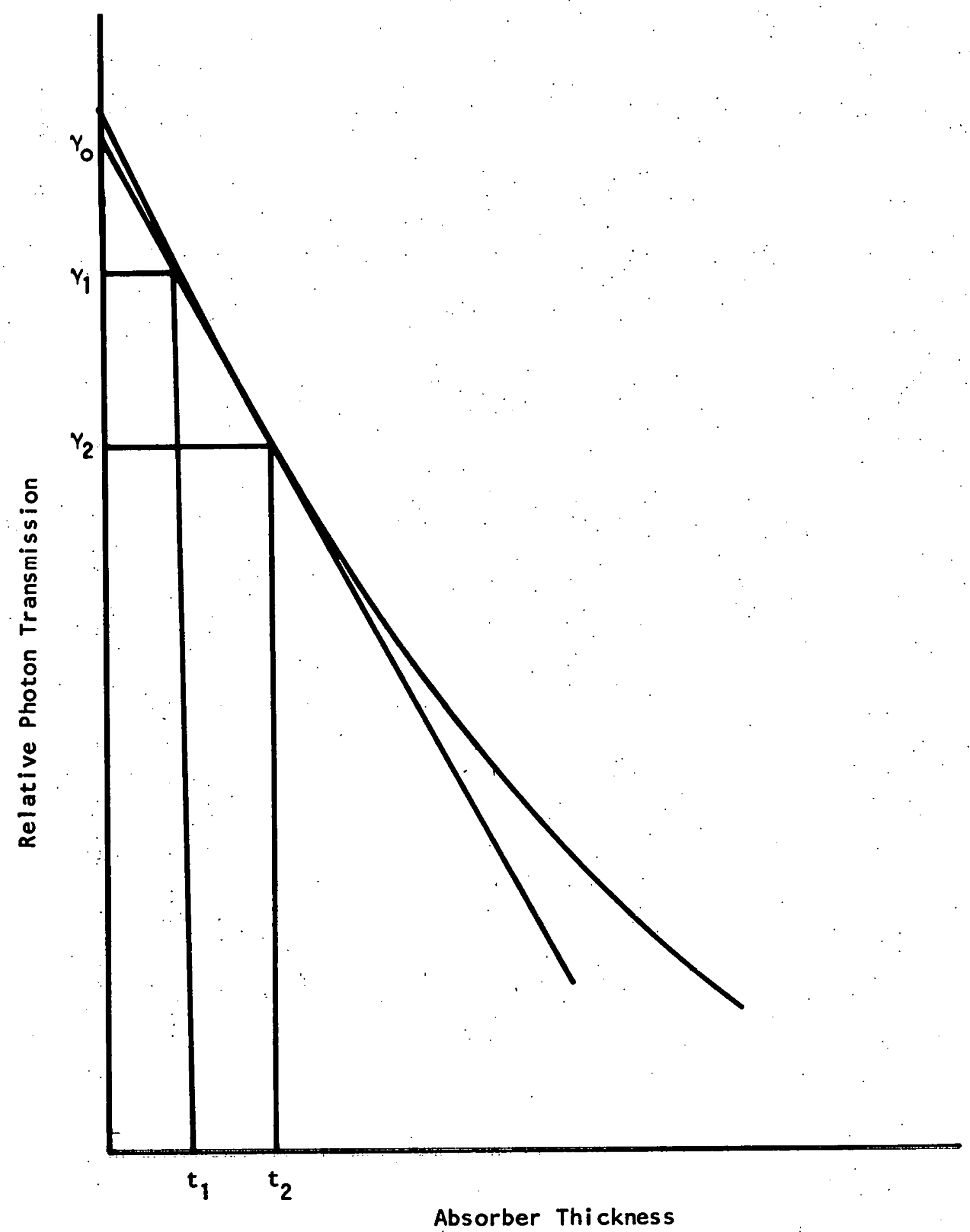

Figure 12. Exponential absorption curve and linear approximation for gamma rays through an absorber 
are distorted by the response of the scintillator giving broad peaks rather than sharp Compton edges, as shown in Figure 13. It was hoped that the energies of the Compton edges could be determined internally using the beta-ray spectra and then used as a more convenient callibration. The peak shape and energy, however, were found to vary with the energy calibration, making them useless for calibration. The Compton spectra were used, therefore, only to observe gain shifts during the experiment.

The spectra for each calibration source were combined using the computer program CARD such that the gamma-ray contribution was subtracted from the beta-plus-gamma spectrum. Each spectrum was also compressed so that it was no larger than 128 channels, the limit on the matrix size in the FERMI spectrum fitting program, which is described below. The computer output from CARD contains both a printout of the data and a plot of the spectrum. Peak channels of conversion electron spectra were determined by hand. In the treatment of cont inuous beta-ray spectra, a. straight line fit to the upper end of each spectrum was used as a first estimate to the end-point channel number. The resulting channel numbers and respective energies were used as the initial parameters in determining the calibration function given by

$$
\begin{array}{rlrl}
W(N) & =a N+W_{b}\left[1-\left(\frac{N^{\prime}-N}{N^{\prime}}\right)^{2}\right] & & W<W^{\prime} \\
& =a N+W_{b} & W>W^{\prime}
\end{array}
$$

where $W^{\prime}=a N^{\prime}+W_{b}$. The function is linear in the channel number $N$ for energies above the cross-over energy $W^{\prime}$, is quadratic in $N$ below $W^{\prime}$, and 


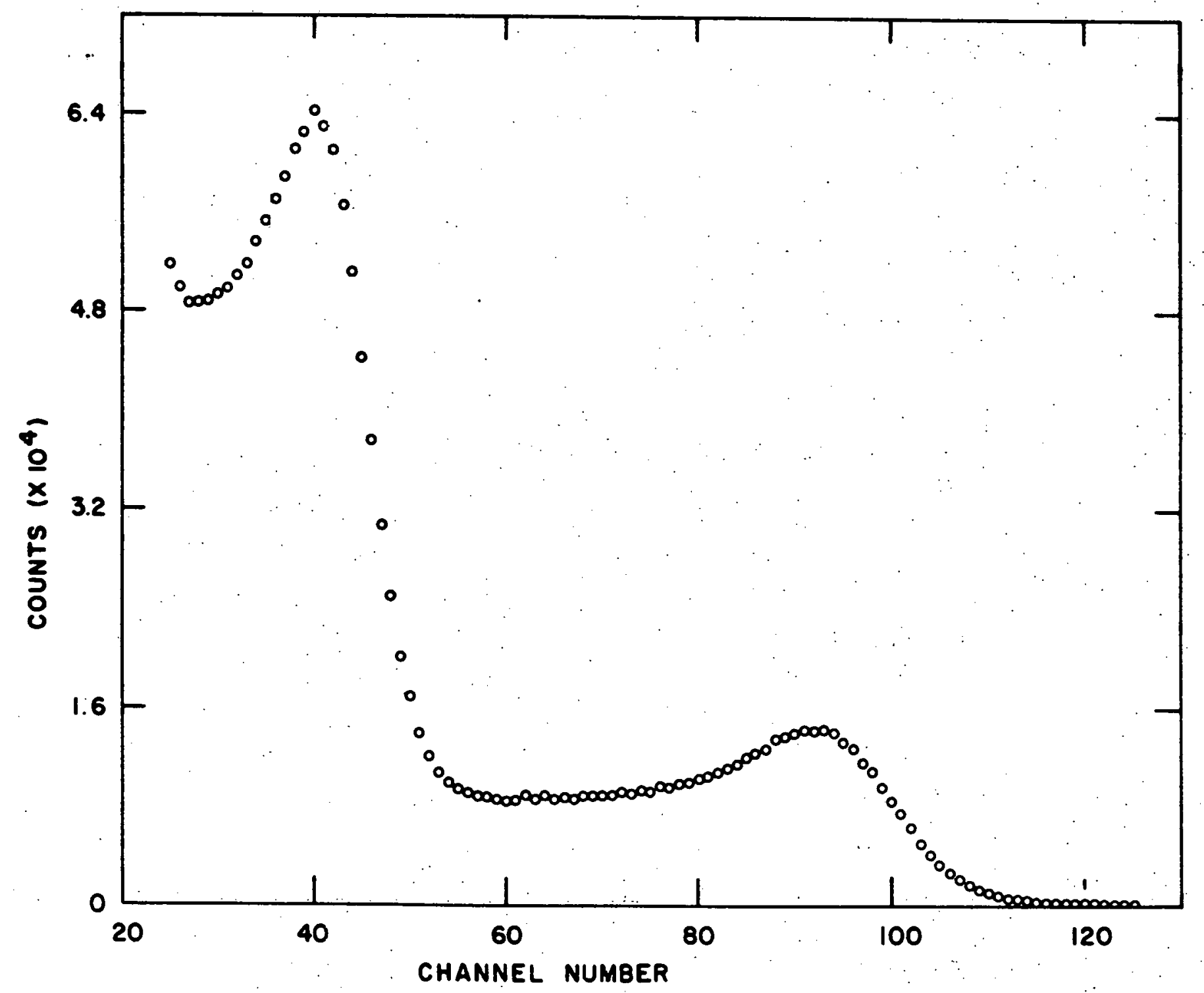

Figure 13. Spectrum distorted by response of scintillator of Compton-scattered electrons for ${ }^{22} \mathrm{Na}$ 
is required to approach zero energy as the channel number $N$ approaches zero. The non-linear character of the calibration function is due to the effect of the well in the plastic scintillator, and the function chosen is justified simply by the fact that it describes the data. The calibration function contains three parameters: slope, a, and intercept, $W_{b}$, of the linear portion and the cross-over energy, $W^{\prime}$. A value for the quadratic parameter $\mathrm{N}^{\mathrm{I}}$. Was assumed, and then the best values for the linear parameters, $a$ and $W_{b}$, were calculated by least-square minimization. The process was repeated for increasingly smaller increments of $N^{\prime}$ until N' was known to within 0.005 channel.

The final energy calibration was obtained by an iterative procedure since end-point energies of continuous beta-ray spectra were used as part of the calibration. The channel number corresponding to the known endpoint energy of a single beta-ray group was determined from a folding technique, where the fit required apriori knowledge of the energy calibration. An estimate of the three parameters of the calibration function was used to analyze each measured spectrum. The channel numbers from the analysis and the respective energies were used to determine a better estimate of the three parameters. An iterative cycle was used unt $i$ adequate convergence was obtained; the convergence criterion was that the end-point energy channel numbers change by less than 0.3 channel between successive iterations. The use of conversion electron peaks reduced the number of iterations required to about three since the channel number of each peak was determined by the centroid of the peak and remained unchanged during the iterative determination of the calibration parameters. A typical 
resultant calibration curve is shown in Figure 14a, where the extrapolated linear part is a dashed line. The uncertainty in the calibration curve is due to the uncertainties in the energy values for the sources and the uncertainties in the determination of the channel numbers assoclated with these energies. Figure $14 b$ shows the uncertainty in the calibration curve as a function of energy, to be interpreted as the $68 \%$ confidence limit in the measurement. 


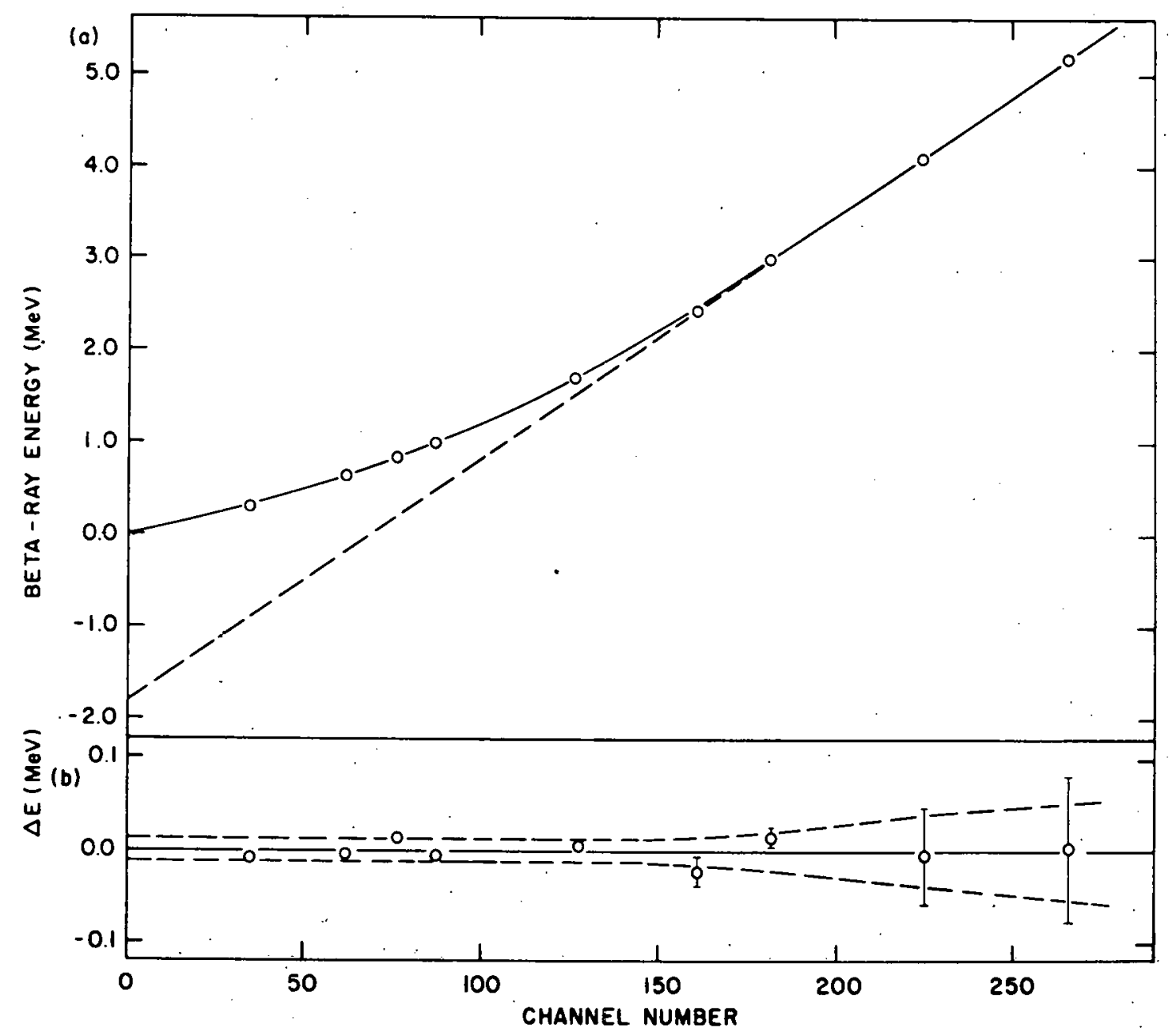

Figure 14. Calibration curve and uncertainty for plastic scintillator 
DATA ACCUMULATION

The isotopes studied during this experiment were the short-lived gaseous fission products and their daughters for $A=88$ - 93 . Knowing the half-lives of the members of each isobaric decay chain, a guess was made of the sample collect time, delay time, and data accumulation time. These values were used in the program ISOBAR to obtain the isobaric integrated activity ratios. Changes in these parameters were made until the desired isobaric activity enhancement was obtained. Table 2 lists the nuclei studied, and for each, the type of experiment (coincidence or singles), the MTC mode, and the integrated activity ratio. The MTC mode listed is either continuous, with the tape speed given in $\mathrm{cm} / \mathrm{sec}$, sequential for the upper port or high-duty-factor for the lower port, with the collect, delay, and accumulate tlmes given in seconds. For the more abundant activities, the ion beam intensity had to be reduced so that the live time of the plastic scintlllation detector electronics remained above $60 \%$ with no absorber. The Ge(LI) detector could be positioned or the source could be collimated so that the live time of this detector was also approximately $60 \%$.

A one-absorber method was used for the colncidence experiments to obtain the gamma-ray contribution which must be subtracted from the spectrum accumulated without an absorber in order to find the distorted beta-ray spectrum. During the experiment, data were taken with and without an absorber whose thickness slightly exceeded the range of beta rays. having energies equal to previous measurements or theoretical predictions 
Table 2. Integrated activity ratios

\begin{tabular}{|c|c|c|c|c|c|}
\hline $\begin{array}{l}\text { Decaying } \\
\text { Nucleus }\end{array}$ & $\begin{array}{l}\text { Coincidence or } \\
\text { Singles } \\
\text { Experiment }\end{array}$ & $\begin{array}{l}\text { Moving Tape } \\
\text { Collector } \\
\text { Mode }\end{array}$ & $\begin{array}{l}\text { ntegrated A } \\
\qquad \mathrm{Kr}\end{array}$ & ivity & $\begin{array}{c}\text { Ratios }(\%) \\
\text { Sr }\end{array}$ \\
\hline${ }^{88} \mathrm{Kr}$ & coin & stationary tape & 50.0 & 50.0 & -- \\
\hline${ }^{88}{ }_{R b}$ & $\operatorname{coin}$ & stationary tape & 50.0 & 50.0 & -- \\
\hline${ }^{89}{ }_{K r}$ & coin & $0.10^{a}$ & 99.5 & 0.5 & -- \\
\hline${ }^{89} 9_{K r}$. & sing & 0.77 & 100.0 & -- & -- \\
\hline $90 \mathrm{Kr}$ & coin & $40,0,40^{b}$ & 84.0 & 16.0 & -- \\
\hline $90 \mathrm{Kr}$ & sing & 1.02 & 99.8 & 0.2 & -- \\
\hline${ }^{90} \mathrm{Rb}$ & $\operatorname{coin}$ & $60,200,190$ & 3.0 & 97.0 & -- \\
\hline $90 \mathrm{Rb}$ & sing & $60,200,190$ & 3.0 & 97.0 & -- \\
\hline $91 \mathrm{Kr}$ & $\operatorname{coin}$ & 0.43 & 98.3 & 1.7 & -- \\
\hline $91_{K r}$ & sing & 0.77 & 99.0 & $i .0$ & -- \\
\hline $91_{\mathrm{Rb}}$ & coin & $30,40,60$ & 5.0 & 95.0 & -- \\
\hline $92 \mathrm{Kr}$ & coin & 0.41 & 82.0 & 18.0 & -- \\
\hline${ }^{92} \mathrm{Kr}$ & sing & 4.42 & 97.8 & 2.2 & -- \\
\hline${ }^{92} \mathrm{Rb}$ & sing. & $10,10,10$ & 4.0 & 96.0 & -- \\
\hline${ }^{92} \mathrm{Sr}$ & coin & $1500,1830,1665$ & -- & -- & 88 \\
\hline $93 \mathrm{Kr}$ & $\operatorname{coin}$ & & 49.0 & 51.0 & -- \\
\hline${ }^{93} \mathrm{Kr}$ & sing & 5.06 & 98.6 & 1.4 & $\cdots$ \\
\hline $93_{\text {Rb. }}$ & $\operatorname{coin}$ & & 49.0 & 51.0 & -- \\
\hline $93_{\mathrm{Rb}}$ & sing & $5,2,5$ & 26.7 & 72.5 & -- \\
\hline
\end{tabular}

${ }^{a}$ Tape speed in $\mathrm{cm} / \mathrm{sec}$.

${ }^{b}$ Collect time, delay time, accumulate time in sec. 
of the Q-value. The data could be taken while the source activity varied as long as the MTC mode was unchanged, since this determined the activity ratios for the elements in the decay chain. The relative amount of data taken with and without the absorber was determined by the time taken to fill one buffer memory in the two-parameter system. The timing of the buffers was done while the source had an integrated activity over the timing cycle with an absorber the same as that over the cycle without an absorber. The number of gamma-ray events accumulated for a specified live time could be considered independent of the absorber used, within the assumption that gamma-ray absorption was negligible. Thus, in order to correctly subtract out the gamma-ray contribution from a gamma-plusbeta spectrum, data were taken with the ratio of the number of buffers using no absorber to the number of buffers using an absorber inversely proportional to the ratio of the time to fill one buffer using no absorber to the time to fill one buffer using an absorber.

This one-absorber technique assumes that there is little attenuation of the gamma rays through the absorber. Though this assumption is not strictly true, the gamma-ray attenuation is small, typically $5 \%$ over the region in which the measured spectrum is fit. Moreover, the fact that the attenuation is energy dependent partially compensates for the reduction in gamma-ray counts at higher energies where the beta-ray spectrum analysis is concentrated, since the number of high-energy gamma rays compared to the number of low-energy gamma rays accumulated in a given live time is enhanced by the absorber. 
The scintillator-photomult iplier system was rèlatively stable over long periods of time but galn shifts of less than $0.1 \mathrm{MeV}$ were noticed ôver the three to four days taken to study one nuclei. One possible cause for gain shift is the saturation of the detector; either from the activity or from excess light entering the MTC. Often during an experiment, the moving tape needed replacing. A tape change required that the ent ire' MTC be covered with a sheet of black plastic to reduce the light incident on the scintillator while the side of the MTC was removed: To account for póssible gaín instabilities; a second calibration was taken after the study of each nucleus and compared to the first calibration. The data were analyzed using eact calibration and the end-point energies determined were usually within the energy uncertaint ies.

por Â coincidence events counted during the experiments were stored on magnetic tapes so that the experiment could be replayed in a fraction ouf the time taken in accumulating the data. A beta spectrum in coincidence with a gamma ray was extracted from the gross data by select ing beta-ray events recorded in coincidence with the gamma ray. A band was set to include the appropriate gamma ray in the gamma-ray spectrum and then the dâta tapes were played back and the associated beta-ray spectrum recorded in the analyzer memory. A background band was set adjacent to the gammaray band to include the Compton tails of gamma rays having energies above that of the gated gamma ray. During the experiment playback, the data taken using an absorber were subtracted from those taken with no absorber, employing the same counting system used to take the data with and without absorber. Usually three or four tapes totalling approximately ten million 
coincidence events were obtained and analyzed for each nucleus studied in this work. The beta-ray spectrum in coincidence with a gamma ray and that from the adjacent background band were combined using the com-. puter to give the measured beta-ray spectrum in coincidence with a given gamma ray.

The gamma rays on which gates were placed were chosen by examining the gamma-ray spectra obtained during the coincidence run and using the level schemes developed previously in gamma-ray decay studies for the nucleus studied, when available. Gain shifts observed in the gamma-ray spectra during an experiment were considered in setting the bands. Gammaray gates were chosen to try to include both of the following: several gamma rays depopulating one intensely beta-fed level, and gamma rays depopulating all significantly-fed levels.

Beta-ray singles measurements were taken for most nuclei to obtain a second determination of the beta-decay energy and to identify any strong ground-state feeding. The two-absorber method for gamma-ray, correction was used for the singles experiments, because of the greater accuracy possible. These experiments, which took approximately an hour each, were taken directly after a calibration was completed. The beta-ray singles data were analyzed in a manner similar to that used for calibration measurements. 
DATA ANALYSIS

The analysis of the experimental data used a "folding" technique described by Rogers and Gordon (37). The technique involves first distorting the theoretical beta-ray spectrum, then least-square fitting this distorted spectrum to the measured spectrum. The distorted theoretical spectrum $D(W)$ is obtained by folding the theoretical beta-ray spectrum, given previously, into the response function giving:

$$
D(W)=\sum_{i=1}^{n} \int_{1}^{W_{i}} A_{i} R\left(W^{\prime} W^{\prime}\right) F\left(Z, W^{\prime}\right) p W^{\prime}\left(W_{i}-W^{\prime}\right)^{2} s_{i}\left(W^{\prime}\right) d W^{\prime}
$$

in energy units of $m_{e} c^{2}$. The shape factor $s_{i}\left(W^{\prime}\right)$ also depends on the end-point energy $w_{i}$ when the transition is not al lowed or first-forbidden non-unique. $D(W)$ is a function of the $2 n$ parameters $A_{i}$, the amplitudes, and $w_{i}$, the end-point energies, of the $n$ beta groups. Values of the $2 n$ parameters are obtained by least-square fitting $D(W)$ to the measured spectrum $M(W)$. The main advantage of this technique is that the endpoint energies and intensities are obtained by a direct fit to the data. Possible spectrum distortions that can result in the intermediate step of calculating an unfolded spectrum are avoided. A disadvantage in the technique is that the least-square fitting procedure can result in more than one set of the $2 n$ parameters when $n$ is a large number.

The folding technique is most useful when constraints are applied to some of the $2 n$ parameters. If the energy level scheme of the daughter nucleus is known, then the number of free parameters in the least-square fitting procedure can be reduced from $2 n$ to as few as two or three. 
Constraining the differences between end-point energies to equal the appropriate differences in daughter energy levels leaves only one endpolnt energy as a free parameter. Knowing the relative beta-ray branching to the excited states of the daughter nucleus allows all but one of the amplitude coefficients for the excited state beta groups to be fixed relative to one amplitude coefficient. The amplitude coefficient for the ground-state beta group, observed in singles measurements only, would be the third free parameter. Such constraints result in a unique leastsquare fit and thus greatly simplify the application of this folding technique.

A computer program named FERMI was used to least-square fit the distorted theoretical beta-ray spectrum to the measured beta-ray spectrum. In FERMI the theoretical spectrum is written as a sum over the beta groups. of equations quadratic in the end-point energies of the groups. The terms in the equation also include integrals whose limits are the end-point energies. The expression is simplified by summing over the beta groups while fixing the relative end-point energies and the percent beta feedings for the various groups. In the program the integrals involving the endpoint energies are solved by assuming a $Q$-value for the decay. The remaining quadratic equation is linearized and solved by matrix inversion for the amplitude and Q-value. The procedure is iterated unt il the neglected quadratic term is negligible. The resultant Q-value is compared to the input $Q$-value to determine if it changed enough to warrant recalculating the integral with the new $Q$-value and starting the process again. 
- In FERMI the distorted theoretical beta-ray spectrum for one group is

$$
D_{i}(W)=A_{i}\left[W_{i}^{2} g_{1 i}(W)-2 w_{i} g_{2 i}(W)+g_{3 i}(W)\right]
$$

where

$$
g_{j i}(W)=\int_{i}^{W_{i}} R\left(W^{\prime} W^{\prime}\right) F\left(z, W^{\prime}\right) p\left(W^{\prime}\right)^{j} s_{j}\left(W^{\prime}\right) d W^{\prime}
$$

A direct least-square method would be difficult because the equation is quadratic in $w_{i}$ and includes $w_{i}$ as the limit of the integral. The endpoint energy is given by the difference between the $Q$-value and the energy level of the populated state $E_{\mathbf{i}}$.

$$
W_{1}=Q-E_{1} \cdot
$$

The FERMI program uses an iterative technique employing two loops. In the outer loop, an initial $Q$-value $Q_{0}$ is assumed and the $g(W)$ integrals are calculated. This initial value must be within approximately $300 \mathrm{keV}$ of the final Q-value or the program may not converge since the neglected quadratic term in the linearization becomes significant. In the inner loop, the distorted theoretical spectrum is

$$
D_{k i}(W)=A_{k i}\left[\left(Q_{k}-E_{i}\right)^{2} g_{1 i}(W)-2\left(Q_{k}-E_{i}\right) g_{2 i}(W)+g_{3 i}(W)\right]
$$

where $k=1$ for the first iteration. Linearization of the equation is achieved through a first-order Taylor expansion of $Q_{k}$ about $Q_{0} \cdot D_{k i}(W)$ can then be written as 


$$
D_{k i}(W)=A_{k i} G_{1 k i}(W)+B_{k i} G_{2 k i}(W)
$$

where

$$
B_{k i}=A_{k i} \delta_{k} \text { and } \delta_{k}=Q_{k}-Q_{k-1}
$$

The relative beta feeding for the $n$ beta groups is fixed such that

$$
\sum_{i} A_{k i} G_{1 k i}=A_{k} \sum_{i} a_{1} G_{1 k i}=A_{k} G_{1 k} \text {. }
$$

Similarly the relative end-point energies for the $n$ beta groups are fixed such that

$$
\sum_{i} B_{k i} G_{2 k i}=B_{k} G_{2 k}
$$

Summing over the number of beta groups produces an equation which is a function of $A_{k}$ and $B_{k}$ only:

$$
D_{k}(W)=A_{k} G_{1 k}(W)+B_{k} G_{2 k}(W) \text {. }
$$

The least-square fitting is obtained by minimizing Chi-squared, given by

$$
x^{2}=\sum_{N}\left(\frac{1}{\sigma_{N}^{2}}\right)\left[M_{N}-A_{k} G_{1 N}-B_{k} G_{2 N}\right]^{2}
$$

with respect to the two linear parameters, $A_{k}$ and $B_{k^{*}} M_{N}$ is the measured spectrum, $\sigma_{N}$ is the statistical uncertainty in $M_{N}$, and $N$ is the channel number. The spectrum is fit over a region determined by a choice of the groups included and by an inspection of the spectrum plots and the fermi plots. A standard matrix inversion yields the best values of the two 
parameters (38). The uncertainty in the parameters is a product of the statistical uncertainty in the data point and the change in the variable with respect to the data point. If $\delta_{k}>10^{-4} Q_{o}$, then $Q_{k+1}=Q_{k}+\delta_{k}$ and the inner loop is repeated. If $\delta_{k} \leq 10^{-4} Q_{0}$, then $Q_{k}-Q_{0}$ is calculated. If $Q$ changes by more than the equivalent of one channel, then the new $Q$ is used to recalculate the $g(W)$ integrals and the outer loop is repeated. When $Q$ changes less than the equivalent of one channel, the final result is determined.

The input parameters for the FERMI program include the three calibration parameters, the end-point energy differences, and the relative branching to the levels of the daughter nucleus. The three calibration parameters have been discussed previously. The end-point energy differences are equal to the energy differences between the energy levels with beta feeding that contribute to the distorted theoretical beta-ray spectrum. Figure 15 illustrates a simplified beta decay with feeding to three excited states and gamma-ray transitions between all levels. A gate set on the transition from the first excited state to the ground state would have beta contributions from all three excited states. The total beta contribution for this gate is the sum of the direct beta feeding to the first excited state, the beta feeding to the second excited state scaled by the relative gamma-ray intensity leaving that state and feeding the first excited state, and the beta feeding to the third excited state scaled by the relative gamma-ray intensities leaving that state and feeding the second and first excited states. The scale factor is the fraction of transition intensities leaving the beta-fed level 


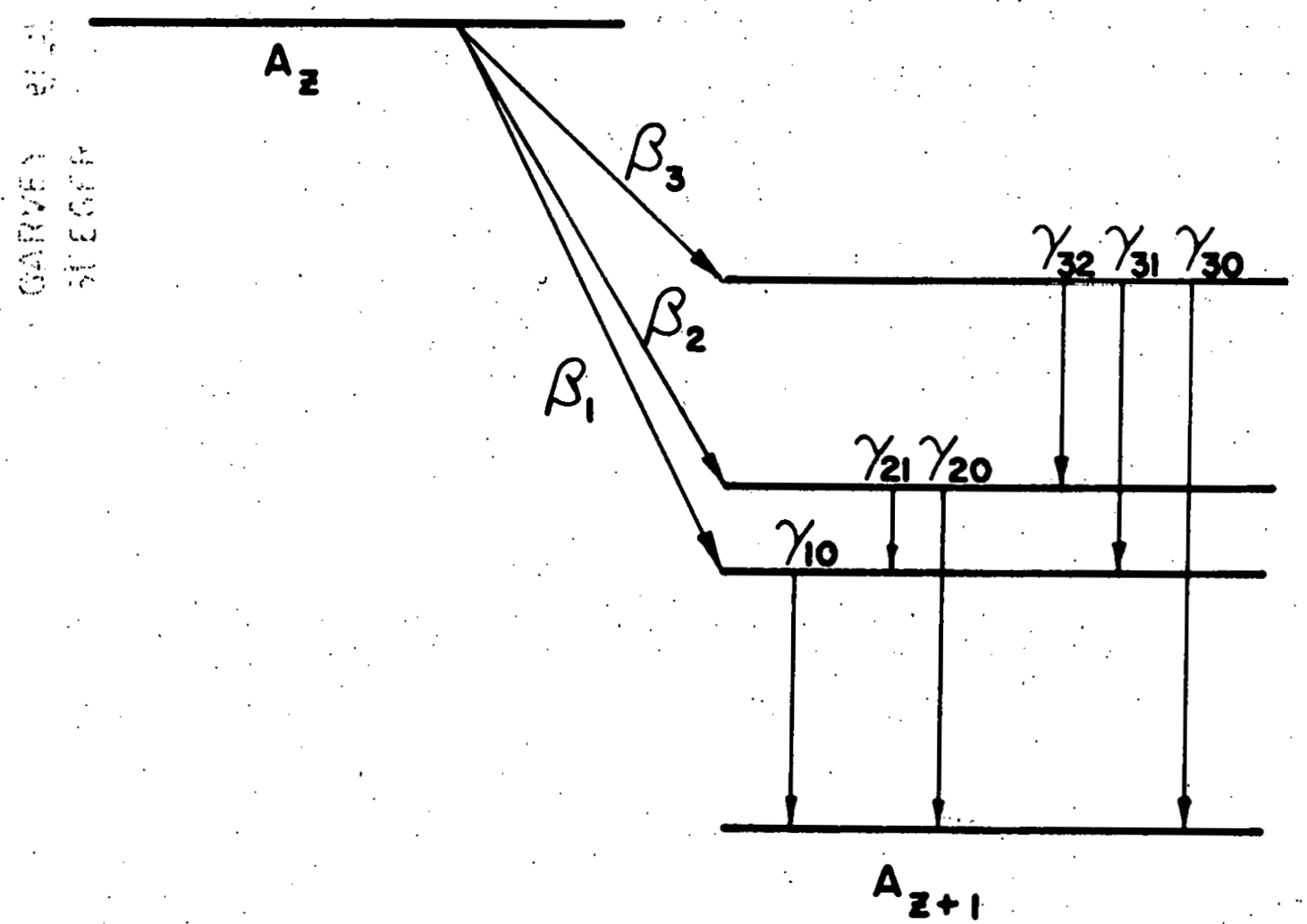

Figure 15. Simplified gamma-ray decay scheme with beta feeding to three exci ted $s$ tates 
which cascade through the gated gamma-ray transition. For the gated gamma ray; $\gamma_{10}$, shown in Figure 15 , the scale factor for the second excited level is the intensity of $\gamma_{21}$ divided by the sum of the intensities of $\gamma_{21}$ and $\gamma_{20}$. The scale factor for the third excited level is the intensity of $\gamma_{32}$ times the scale factor for the second excited level plus the intensity of $\gamma_{31}$ all divided by the total intensity of gamma rays depopulating the third exclted state.

The FERMI program is capable of fitting the measured spectrum to as many as five beta groups. In order to include as many beta contributions as possible into the fitting, the relative beta feedings to several closelying, poorly fed levels can be summed and considered to go to an intermediate level. If the percent beta feedings to the various levels in the daughter nucleus have not been calculated, then the total gamma-ray intensity populating a level must be subtracted from the total gammaray intensity depopulating the level to obtain the relative beta feeding to the level. 


\section{RESULTS}

The results of the analysis of the beta-ray spectra for the eleven nuclei studied are reported in Tables 3 through 11 . The tables for the nuclei with mass numbers $A=88$ - 93 list the gating gamma rays, the levels depopulated by these gamma rays, and the $Q$-values deduced from the end-point energies of the coincident beta-ray spectra with their uncertainties. The uncertainties in the $Q$-values are a combination of the uncertainties in the least-square fitting procedure and the uncertainties in the calibration function for the given energies. The Q-values are a weighted average of the two values determined using calibrations from both the start and end of a run. Also included in the tables are the beta-fed levels that depopulate through the gating transition and the percentage beta-ray spectrum contributions from these levels to the fits of the coincident beta-ray spectra. A weighted average of the $Q$-values and uncertainties for the coincident beta-ray spectra is listed at the end of each table. The table for the $A=93$ nuclei, for which the energy level schemes have not been determined, includes only the gating gamma-ray energies and the end-point energies, and uncertainties, of the coincident ${ }^{93} \mathrm{Kr}$ and $93_{\mathrm{Rb}}$ beta-ray spectra. In the discussion below on the individual decay results, several figures are presented that illustrate some of the more interesting features of the beta-ray spectra obtained during the course of this work.

\section{${ }^{88} \mathrm{Kr}$ Decay}

The Q-value for the ${ }^{88} \mathrm{Kr}$ beta decay is $2.93 \pm 0.03 \mathrm{MeV}$, determined from seven coincldence beta-ray spectra. This value is in agreement with 
the value of $2.9 \pm 0.1 \mathrm{MeV}$ reported by Lycklama, et al. (34). The decay scheme used in selecting the gating gamma-ray transitions and in determining percent beta feeding to the varlous daughter energy levels was determined by R. L. Bunting (39). Table 3 lists the seven individual Qvalues and the decay scheme information used in fitting the beta-ray spectra. The 0.196-MeV gamma-ray transition is in coincidence with a beta-ray spectrum, shown in Flgure 16, that has an end-point energy of $0.54 \mathrm{MeV}$ for an Intense group feeding the $2.39-\mathrm{MeV}$ level in ${ }^{88} \mathrm{Rb}$. and an end-point energy of $5.3 \mathrm{MeV}$ for a much weaker group. (The Fermi-Kurie plot in Figure 16 shows an end-point energy of $5.4 \mathrm{MeV}$, which uses the energy calibration determined after the beta-gamma run.) The intense group gives a $Q$-value consistent with that determined for the beta decay of ${ }^{88} \mathrm{Kr}$. The 5.3-MeV end-point energy is, however, close to the value measured for the decay of ${ }^{88} \mathrm{Rb}$. This high-energy tail in the beta-ray spectrum may be due to chance coincidence events, which are proportional to the area of the background contribution and not completely subtracted out in the buffer tape playback. The $A=88$ decay chain contains nuclei wlth prominent gamma-ray transitions, $0.587 \mathrm{MeV}$ in ${ }^{88} \mathrm{Sr}$ and $0.834 \mathrm{MeV}$ in ${ }^{88} \mathrm{Rb}$, Lhal pruduce distinct backscatter peaks at $0.199 \mathrm{MeV}$ and $0.196 \mathrm{MeV}$, respectively. With the $0.196-\mathrm{MeV}$ gamma-ray band set on the se backscatter peaks and the background band set above the peaks, there could be a chance coincidence contribution from ${ }^{88} \mathrm{Rb}$ decays to the beta-ray spectrum that is not masked by true coincldence events. There could also be events in true coincidence with the $0.587-\mathrm{MeV}$ and $0.834-\mathrm{MeV}$ transitions that produce the structure appearing in the beta-ray spectrum. 
Table 3. Values of beta decay energies for ${ }^{88} \mathrm{Kr}$

\begin{tabular}{|c|c|c|c|c|}
\hline $\begin{array}{c}\text { Gating } \\
\text { transit ion } \\
\text { (MeV) }\end{array}$ & $\begin{array}{c}\text { Level } \\
\text { depopulated } \\
(\mathrm{MeV})\end{array}$ & $\begin{array}{c}\text { Beta decay } \\
\text { Q-value } \\
\text { (MeV) }\end{array}$ & $\begin{array}{l}\text { Grou } \\
\text { Level } \\
\text { (MeV) }\end{array}$ & $\begin{array}{l}\text { ps. Included } \\
\text { Cont ribution } \\
(\%)\end{array}$ \\
\hline 0.196 & 0.196 & $5.28 \pm 0.05^{a}$ & $\begin{array}{l}1.182 \\
1.715 \\
2.232 \\
2.392 \\
2.548\end{array}$ & $\begin{array}{r}3 \\
10 \\
18 \\
66 \\
3\end{array}$ \\
\hline 0.500 & 0.864 & $2.94 \pm 0.03$ & $\begin{array}{l}0.864 \\
2.232 \\
2.392 \\
2.548\end{array}$ & $\begin{array}{r}2 \\
12 \\
84 \\
2\end{array}$ \\
\hline 0.835 & 0.864 & $2.97 \pm 0.04$ & $\begin{array}{l}0.864 \\
2.232 \\
2.392 \\
2.548\end{array}$ & $\begin{array}{r}2 \\
12 \\
84 \\
2\end{array}$ \\
\hline 1.353 & 1.353 & $2.91 \pm 0.03$ & $\begin{array}{l}1.353 \\
2.232 \\
2.392\end{array}$ & $\begin{array}{r}32 \\
4 \\
64\end{array}$ \\
\hline 1.530 & 2.392 & $2.93 \pm 0.03$ & 2.392 & 100 \\
\hline 2.196 & 2.392 & $2.92 \pm 0.03$ & 2.392 & 100 \\
\hline 2.232 & 2.232 & $2.92 \pm 0.03$ & 2.232 & 100 \\
\hline \multirow[t]{2}{*}{2.392} & 2.392 & $2.92 \pm 0.03$ & 2.392 & 100 \\
\hline & welghted average & $2.93 \pm 0.03$ & & \\
\hline
\end{tabular}

${ }^{Q_{Q} \text {-value for }}{ }^{88} \mathrm{Rb}$ contaminant activity. 

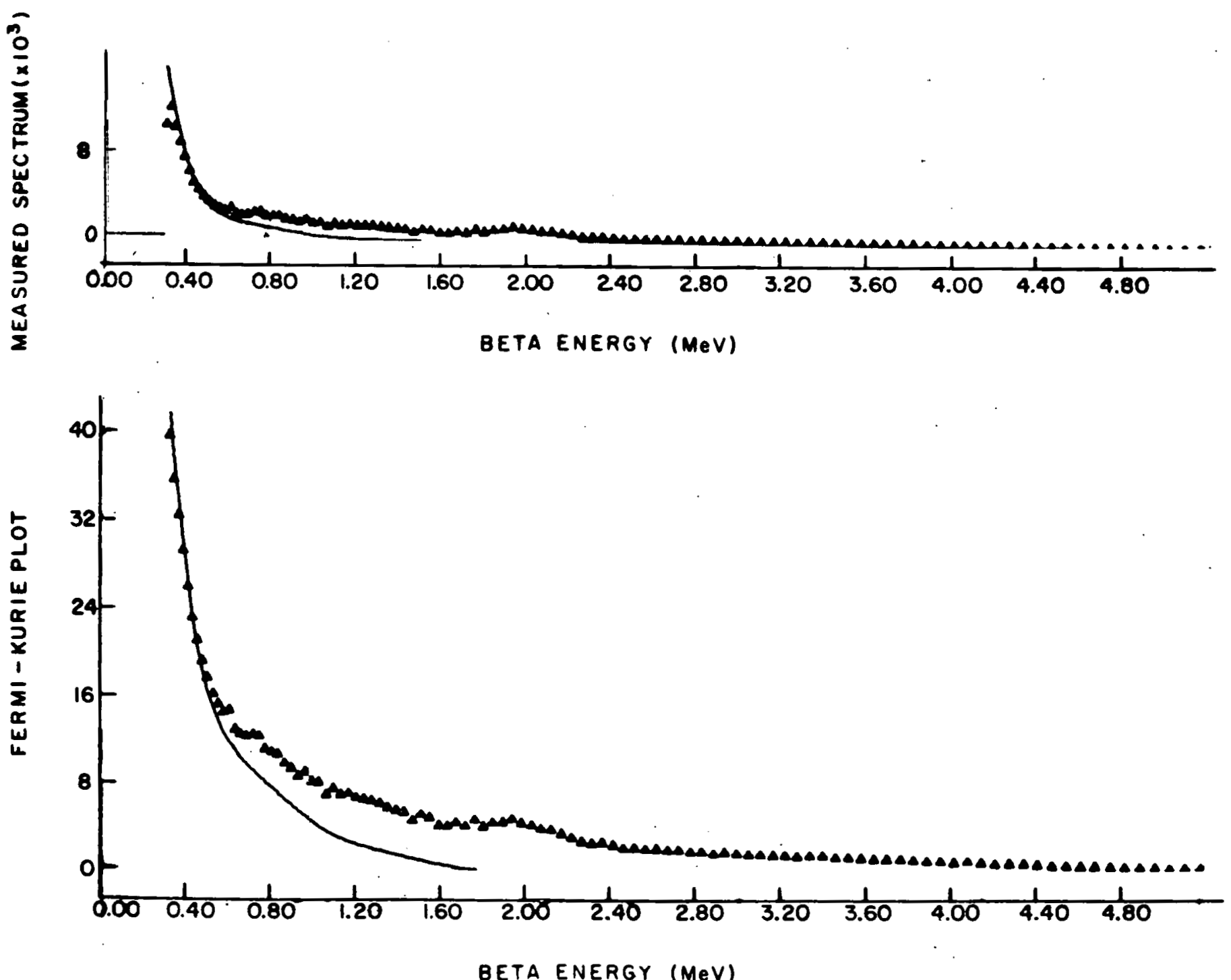

Figure 16. Fit to $0.196-\mathrm{MeV}$ transition gated beta-ray spectrum and Fermi plot for decay of $88_{\mathrm{Kr}}$ 


\section{${ }^{88} \mathrm{Rb}$ Decay}

Table 4 lists the gating transitions and the beta feeding for the 88 $\mathrm{Rb}$ decay, with the energy levels and gamma-ray intensities again supplied by R. L. Bunting (39). The beta-ray spectra in coincidence with three gamma-ray transitions in ${ }^{88} \mathrm{Rb}$ decay and the high-energy beta-ray spectrum in accidental coincidence with the $0.196-\mathrm{MeV}$ transition in ${ }^{88_{\mathrm{Rb}}}$ have end-point energies with a welghted average of $5.30 \pm 0.06 \mathrm{MeV}$. This Q-value is slightly higher than the $5.13 \pm 0.08 \mathrm{MeV}$ reported by Thulin (35) and the ${ }^{88} \mathrm{Rb}$ calibration energy of $5.17 \pm 0.08 \mathrm{MeV}$, which is a weighted average value determined from three previous measurements (34-36). However, the measurement is in good agreement with the adjusted value of $5.30 \pm 0.02 \mathrm{MeV}$ determined by Wapstra and Gove (8).

$$
{ }^{89} \mathrm{Kr} \text { Decay }
$$

Table 5 lists the Q-values determined for seven beta-ray spectra in coincidence with gamma-ray transitions in the decay of ${ }^{89} \mathrm{Kr}$. The energy levels and the percent beta feeding to these levels were determined by E. A. Henry (40): The 1.530- MeV and 1.534-MeV levels were included in one gate and their respective beta feedings were combined to obtain the percent contribution to the beta-ray spectrum from the six energy levels. The contributions to the $1.530-\mathrm{MeV}$ level were normalized using the intensity of 166 for the $1.530-\mathrm{MeV}$ transition relative to the intensity of 256. for the 1.534-MeV transition. The direct feeding to the $1.534-\mathrm{MeV}$ level was added to 0.6 of the direct feeding to the $1.530-\mathrm{MeV}$ level to produce an $18 \%$ contribution from the outer group to the theoretical betaray spectrum. Simllarly, in the $0.738-\mathrm{MeV}$ gate, the $2 \%$ contribution from 
Table 4. Values of beta decay energies for ${ }^{88}{ }_{R b}$

\begin{tabular}{|c|c|c|c|c|}
\hline $\begin{array}{c}\text { Gat ing } \\
\text { transit ion } \\
\cdot(\mathrm{MeV})\end{array}$ & $\begin{array}{c}\text { Level } \\
\text { depopulated } \\
(\mathrm{MeV})\end{array}$ & $\begin{array}{c}\text { Bet a decay } \\
\text { Q-value } \\
(\text { MeV })\end{array}$ & $\begin{array}{l}\text { Grou } \\
\text { Level } \\
\text { (MeV) }\end{array}$ & $\begin{array}{c}\text { ps included } \\
\text { Cont r ibut ion } \\
(\%)\end{array}$ \\
\hline \multicolumn{5}{|l|}{. . } \\
\hline 0.898 & 2.734 & $5.29 \pm 0.03$ & $\begin{array}{l}2.734 \\
4.846 \\
4.514\end{array}$ & $\begin{array}{r}94 \\
4 \\
2\end{array}$ \\
\hline 1.836 & 1.836 & $5.46 \pm 0.06$ & $\begin{array}{l}1.836 \\
2.734 \\
3.219 \\
4.514 \\
4.846\end{array}$ & $\begin{array}{r}28 \\
58 \\
3 \\
10 \\
1\end{array}$ \\
\hline \multirow[t]{2}{*}{2.678} & 4.514 & $5.26 \pm 0.03$ & $\begin{array}{l}4.514 \\
4.846\end{array}$ & $\begin{array}{r}98 \\
2\end{array}$ \\
\hline & weighted average & $5.30 \pm 0.06$ & & . \\
\hline
\end{tabular}


Table 5. Values of beta decay energies for ${ }^{89} \mathrm{Kr}$

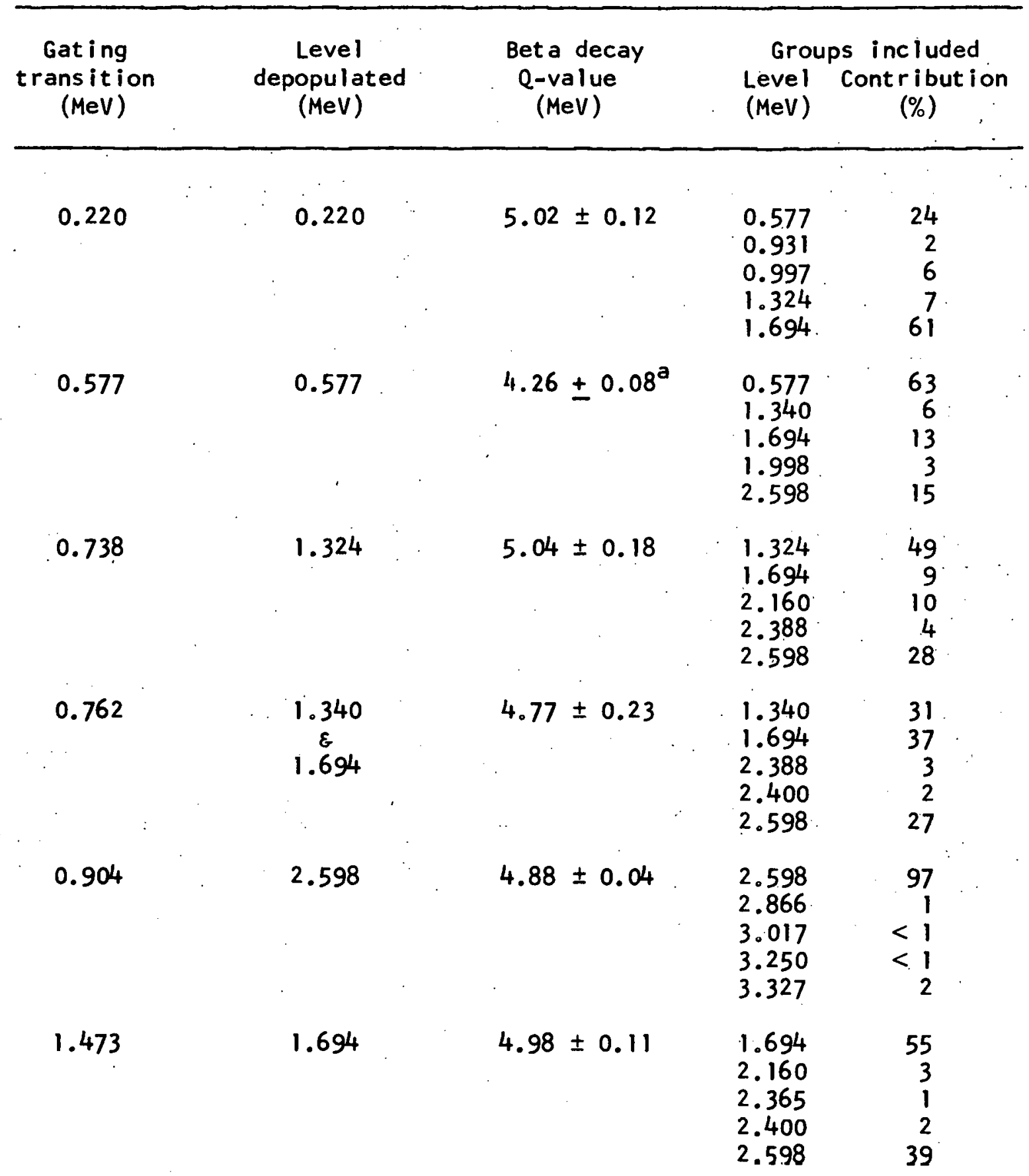

${ }^{a}$ Not used in determining weighted average. 
Table 5. Continued

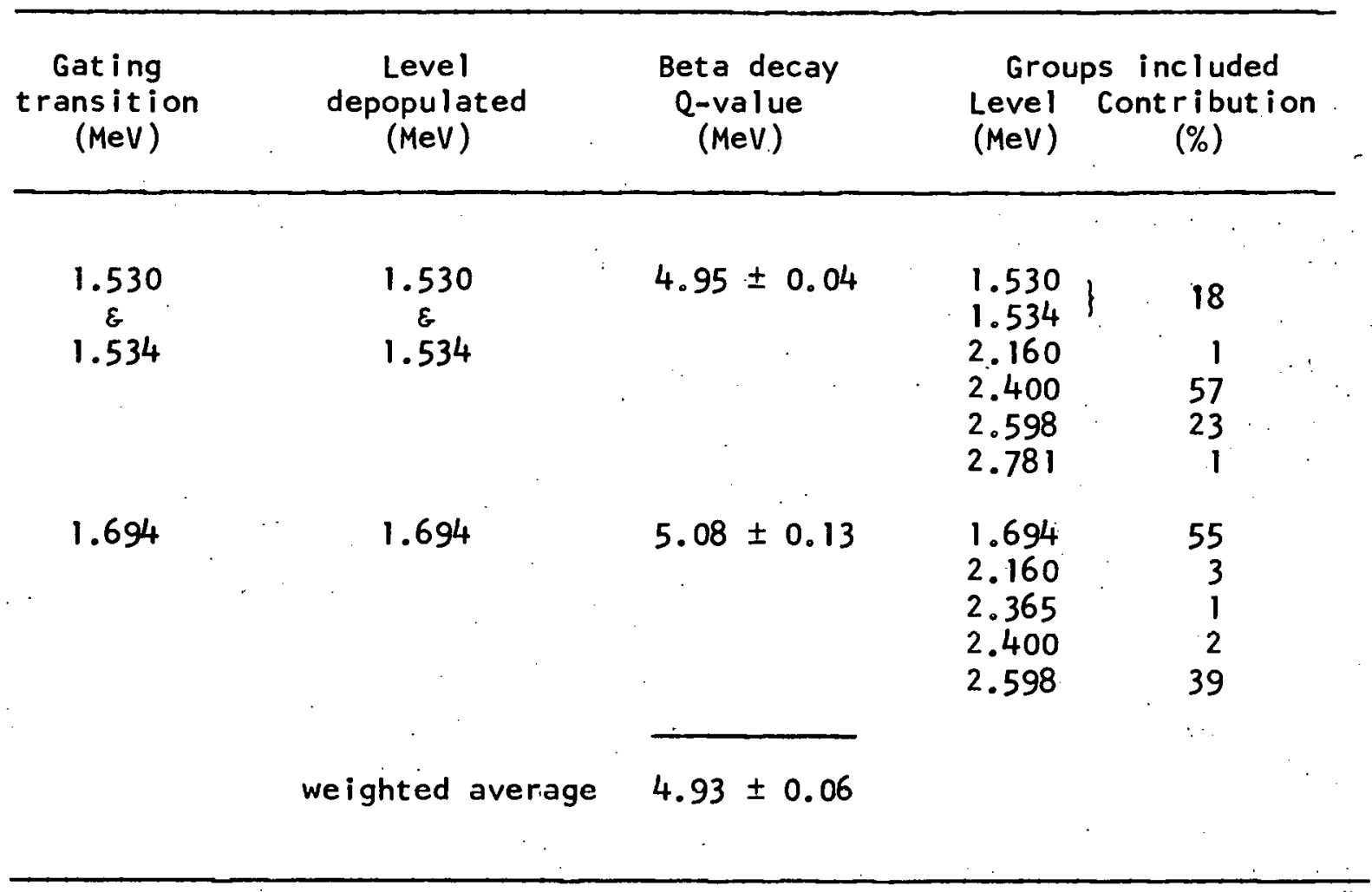


the $2.388-\mathrm{MeV}$ level and the $2 \%$ contribution from the $2.400-\mathrm{MeV}$ level were combined to obtain the $4 \%$ contribution shown for the $2.388-\mathrm{MeV}$ level. Two gates that have rather interesting results are the $0.220-\mathrm{MeV}$ gate and the $0.577-\mathrm{MeV}$ gate. This work shows that there is no feeding to the $0.220-\mathrm{MeV}$ level and the highest-energy beta group for that gate populates the $0.477-\mathrm{MeV}$ level. Kitching and Johns (41) report that a beta group of end-point energy $4.90 \pm 0.03 \mathrm{MeV}$ populates the $0.220-\mathrm{MeV}$ level, which would mean that the beta decay Q-value would be $5.12 \mathrm{MeV}$. This result is $0.2 \mathrm{MeV}$ higher than the Q-value of $4.93 \pm 0.16 \mathrm{MeV}$ determined from a beta singles experiment. The work of E. A. Henry (40) on the decay of ${ }^{89} \mathrm{Kr}$ is in agreement with this work in assigning zero beta feeding to the $0.220-\mathrm{MeV}$ level. The beta-ray spectrum in coincidence with the $0.577-$ MeV gamma ray, shown in Figure 17, has an end-point energy that is $0.6 \mathrm{MeV}$ below the Q-value. A possible explanation is that the percent beta feeding assumed to the $1.340-\mathrm{MeV}$ energy level is too small and should be a more significant contribution to the beta-ray spectrum. The percent beta feedings are quite well determined by Henry and any changes in the feedings to the $0.577-\mathrm{MeV}$ or $1.340-\mathrm{MeV}$ levels are not justified by the gamma-ray work. Because of this apparent discrepancy with the results of the other gated spectra, coupled with the firm nature of the $0.577-\mathrm{MeV}$ level, this result is not considered in the overall average.

\section{$90 \mathrm{Kr}$ Decay}

The weighted average of the beta decay energies from eight gamma-ray gates for the decay of $90 \mathrm{Kr}$ is $4.35 \pm 0.05 \mathrm{MeV}$, as listed in Table 6 . The singles beta-ray spectrum $Q$-value of $4.36 \pm 0.05$ agrees with the average 

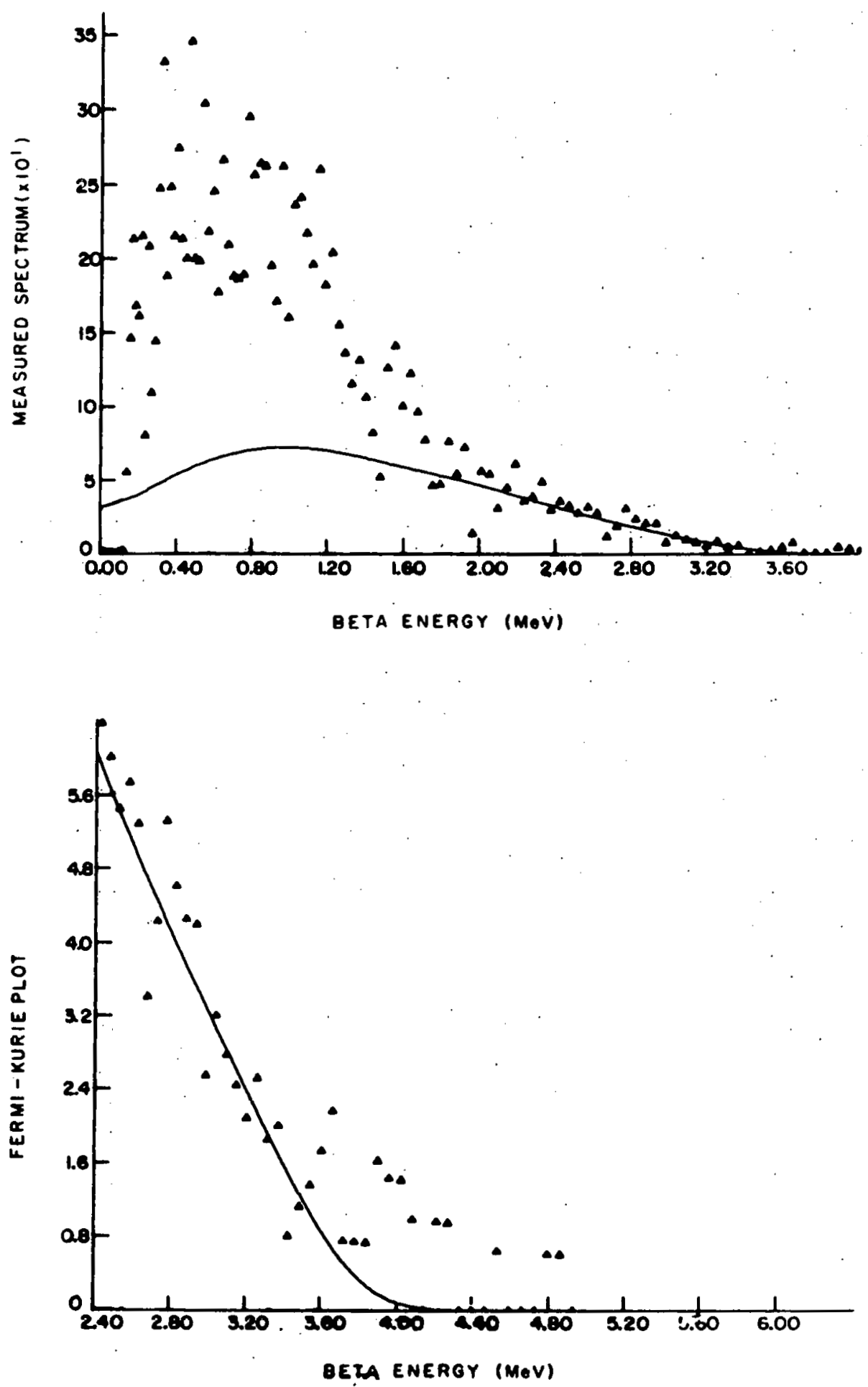

Figure 17. Fit to $0.577-\mathrm{MeV}$ transition gated beta-ray spectrum and Fermi plot for decay of $89_{\mathrm{Kr}}$ 
Table 6. Values of beta decay energies for ${ }^{90} \mathrm{Kr}$

\begin{tabular}{|c|c|c|c|c|}
\hline $\begin{array}{c}\text { Gating } \\
\text { transit ion } \\
(\mathrm{MeV})\end{array}$ & $\begin{array}{c}\text { Level } \\
\text { depopulated } \\
(\mathrm{MeV})\end{array}$ & $\begin{array}{l}\text { Beta. decay } \\
\text { Q-value } \\
(\mathrm{MeV})\end{array}$ & $\begin{array}{l}\text { Grouf } \\
\text { Level } \\
\text { (MeV) }\end{array}$ & $\begin{array}{l}\text { ps included } \\
\text { Cont } r \text { ibut ion } \\
(\%)\end{array}$ \\
\hline & . & & & \\
\hline 0.234 & 0.356 & $4.46 \pm 0.25$ & $\begin{array}{l}0.356 \\
1.780\end{array}$ & $\begin{array}{l}12 \\
88\end{array}$ \\
\hline $\begin{array}{c}0.242 \\
j\end{array}$ & 0.242 & $4.37 \pm 0.05$ & $\begin{array}{l}0.242 \\
0.661 \\
1.780 \\
2.261 \\
3.094\end{array}$ & $\begin{array}{r}3 \\
<1 \\
89 \\
1 \\
7\end{array}$ \\
\hline 0.540 & 1.780 & $4.42 \pm 0.04$ & 1.780 & 100 \\
\hline 0.554 & 0.661 & $4.41 \pm 0.09$ & $\begin{array}{l}0.661 \\
1.780 \\
2.126 \\
3.094\end{array}$ & $\begin{array}{r}6 \\
89 \\
3 \\
2\end{array}$ \\
\hline 1.119 & $\begin{array}{c}1.240 \\
\varepsilon \\
1.780\end{array}$ & $4.30 \pm 0.05$ & $\begin{array}{l}1.240 \\
1.674 \\
1.780\end{array}$ & $\begin{array}{r}1 \\
6 \\
93\end{array}$ \\
\hline 1.423 & 1.780 & $4.34 \pm 0.05$ & 1.780 & 100 \\
\hline 1.537 & 1.780 & $4.35 \pm 0.05$ & 1.780 & 100 \\
\hline \multirow[t]{2}{*}{1.780} & 1.780 & $4.29 \pm 0.05$ & 1.780 & 100 \\
\hline & weighted average & $4.35 \pm 0.05$ & & . \\
\hline
\end{tabular}


from the coincidence spectra, and with the former measurement of $4.41 \pm$ 0.03 by Mason and Johns (42). The $0.242-M e V$ transition gated beta-ray spectrum, shown In Figure 18, shows how well the FERMI program fits a multiple group spectrum with a weak outer beta group and a prominent lower-energy beta group. The $1.423-\mathrm{MeV}$ transition gated beta-ray spectrum is fit by a one-group theoretical spectrum whlch should reproduce the measured spectrum quite well, since the re is no other feeding to the 1.780-MeV level shown in the decay scheme of Mason and Johns. The spectrum appearance shown in Figure 19, however, displays considerable low-energy intensity in the measured spectrum that is not accounted for by the onegroup theoretical curve. This behavior, which is common to the four beta-ray spectra gated by transitions from the $1.780-\mathrm{MeV}$ level, indicates that there is significant beta feeding to an energy level at approximately 2.7 MeV which depopulates through the $1.780-\mathrm{MeV}$ level. Preliminary work by Duke et al. (43) on the decay of ${ }^{90} \mathrm{Rb}$ verifies that there is a level at $2.721 \mathrm{MeV}$ that is depopulated by a moderately intense $0.941-\mathrm{MeV}$ gamma ray to the $1.780-\mathrm{MeV}$ level.

\section{${ }^{90} \mathrm{Rb}$ Decay}

The ${ }^{90} \mathrm{Rb}$ beta decay end-point energy was determined from three gated beta-ray spectra to be $6.32 \pm 0.07 \mathrm{MeV}$, as illustrated in Table 7, whereas the singles measurement gives $6.28 \pm 0.08 \mathrm{MeV}$. In 1964, Johnson et al. (44) measured the Q-value to be $6.60 \pm 0.09 \mathrm{MeV}$, which is $0.3 \mathrm{MeV}$ higher than the present measurement. The agreement between the coincidence value determined using end-point energles having known calibration uncertainties and the singles value with an end-point energy beyond the 

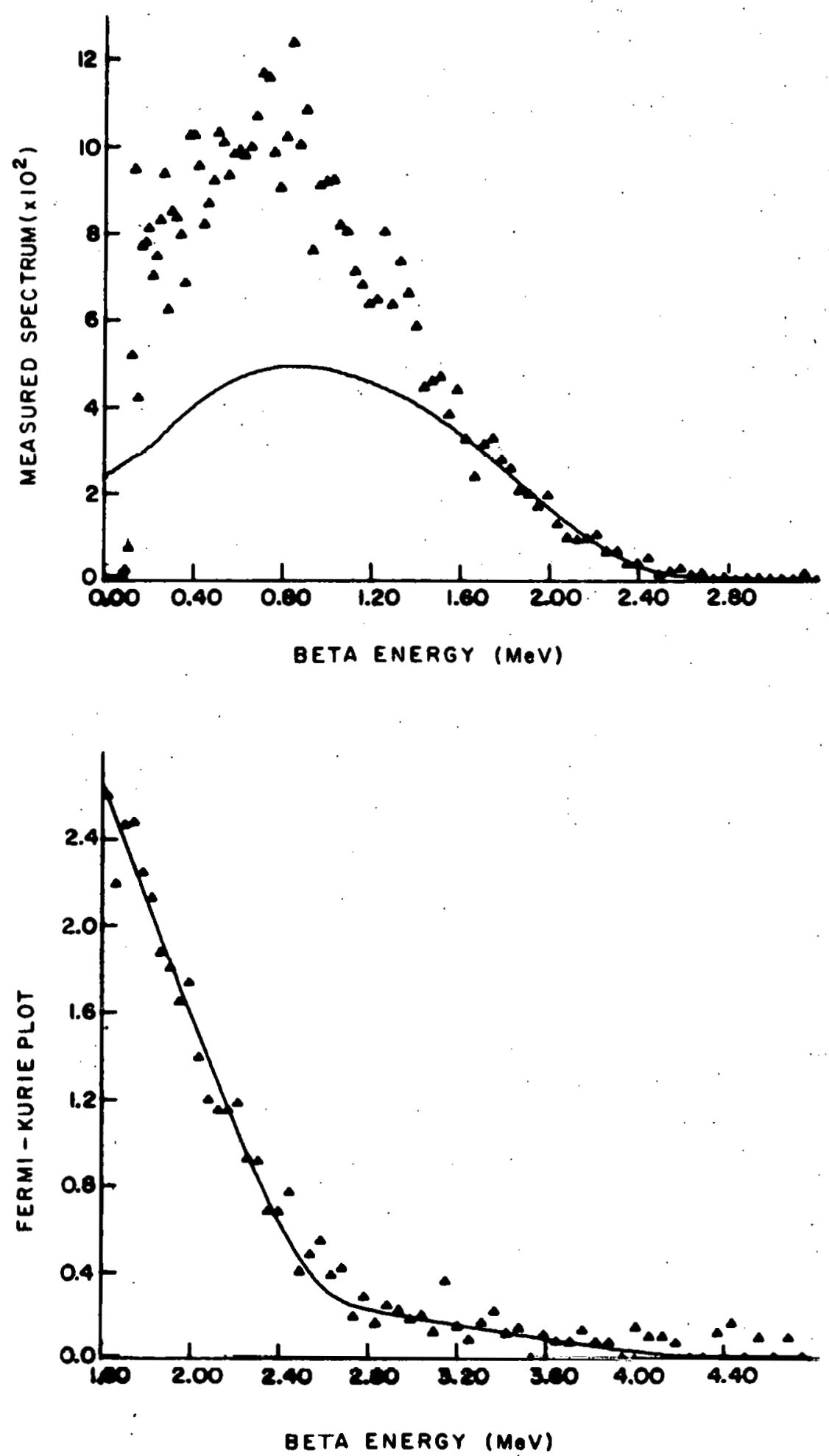

Figure 18. Fit to $0.242-\mathrm{MeV}$ transition gated beta-ray spectrum and Fermi plot for decay of $90 \mathrm{Kr}$ 

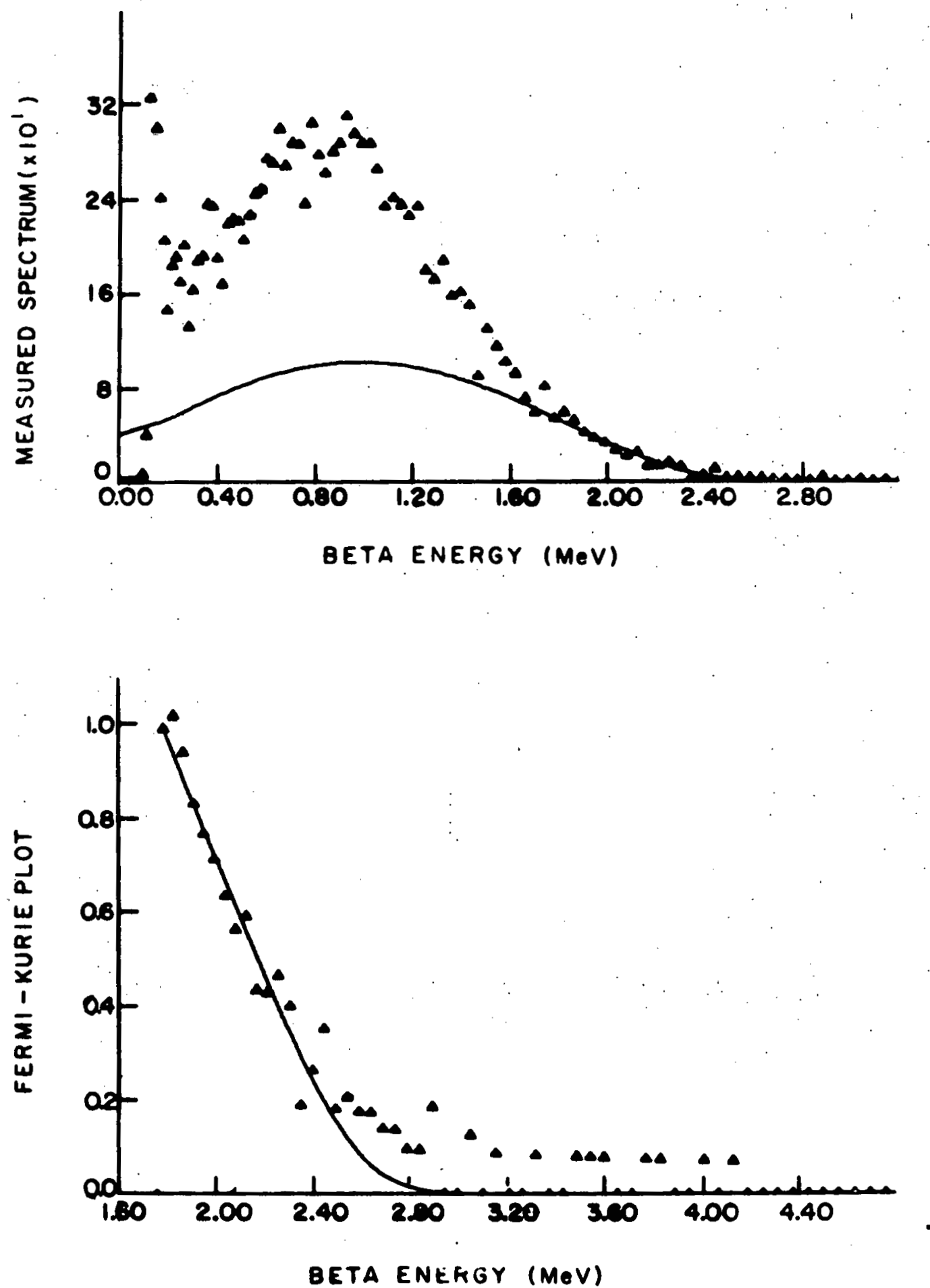

Figure 19. Fit to $1.423-\mathrm{MeV}$ transition gated beta-ray spectrum and Fermi plot for decay of ${ }^{90} \mathrm{Kr}$ 
Table 7. Values of beta decay energies for $90_{\mathrm{Rb}}$

\begin{tabular}{|c|c|c|c|c|}
\hline $\begin{array}{c}\text { Gat ing } \\
\text { trans it ion } \\
(\mathrm{MeV})\end{array}$ & $\begin{array}{c}\text { Level } \\
\text { depopulated } \\
(\mathrm{MeV})\end{array}$ & $\begin{array}{c}\text { Beta decay } \\
\text { Q-value } \\
(\mathrm{MeV})\end{array}$ & $\begin{array}{l}\text { Group } \\
\text { Level } \\
\text { (MeV) }\end{array}$ & $\begin{array}{l}\text { s included } \\
\text { Cont ribut ion } \\
(\%)\end{array}$ \\
\hline 0.832 & 0.832 & $6.26 \pm 0.03$ & $\begin{array}{l}0.832 \\
1.656 \\
1.892 \\
2.100 \\
3.383\end{array}$ & $\begin{array}{r}61 \\
2 \\
16 \\
1 \\
20\end{array}$ \\
\hline 1.061 & 1.892 & $6.38 \pm 0.05$ & $\begin{array}{l}1.892 \\
3.383 \\
4.032 \\
4.366 \\
4.647\end{array}$ & $\begin{array}{r}78 \\
2 \\
8 \\
10 \\
2\end{array}$ \\
\hline 1.119 & 5.254 & $\ldots-^{a}$ & 5.254 & 100 \\
\hline \multirow[t]{2}{*}{1.375} & 2.207 & $6.21 \pm 0.15$ & $\begin{array}{l}2.100 \\
2.821 \\
3.450 \\
3.477 \\
4.229\end{array}$ & $\begin{array}{r}23 \\
2 \\
57 \\
5 \\
13\end{array}$ \\
\hline & weighted average & $6.32 \pm 0.07$ & $\therefore$ & \\
\hline
\end{tabular}

${ }^{a}$-value in agreement with ${ }^{90} \mathrm{Kr}$ contaminant activity. 
calibration limit indicates that the calibration is valid up to at least 6.3 MeV. The 1.375-MeV transition gated beta-ray spectrum shows beta feeding from the ground state of ${ }^{90} \mathrm{Rb}$ to the $3.450-\mathrm{MeV}$ level in ${ }^{90} \mathrm{Sr}$ and from the isomeric $0.106-\mathrm{MeV}$ level to the other four contributing levels. Using the work of Johnison et al. (44), Mason and Johns (42) report that $16 \pm 3 \%$ of the ${ }^{90} \mathrm{Rb}$ beta transitions depopulate the $0.106-\mathrm{MeV}$ isomeric state. By varying the relative beta feeding to the $3.450-\mathrm{MeV}$ level, the present study shows that only about $2 \%$ of the beta transitions originate from the isomeric level. Figures 20 and 21 show the $1.375-\mathrm{MeV}$ transition gated beta-ray spectrum with $16 \%$ and $2 \%$ beta feeding, respectively, from the isomerlc level in ${ }^{90} \mathrm{Rb}$, with an obviously better fit in the latter case. Mason and Johns also report that there is a 1.119-MeV transition in ${ }^{90} \mathrm{Sr}$, which is also seen in $90_{\mathrm{Rb}}$. The Q-value determined from the beta-ray spectrum in coincidence with this $1.119-\mathrm{MeV}$ gamma ray verifies the work of Duke et al. (43), which explains the double presence of this transition as due to ${ }^{90} \mathrm{Kr}$ activity contaminating the ${ }^{90} \mathrm{Rb}$ decay data and favors the assignment of this gamma ray to the ${ }^{90} \mathrm{Kr}$ decay alone.

\section{Kr Decay}

Using the preliminary decay scheme of Duke et al. (43), the beta feedings to levels in the ${ }^{91_{R b}}$ nucleus were calculated. The resultant contributions to the five gated-beta-ray spectra are shown in Table 8 . Some corrections had to be made to the assumed feedings in order to fit the measured spectra. An example of such a correction is the reported $36 \%$ contribution to the $1.136-\mathrm{MeV}$ level for the $0.630-\mathrm{MeV}$ transition gated 
64
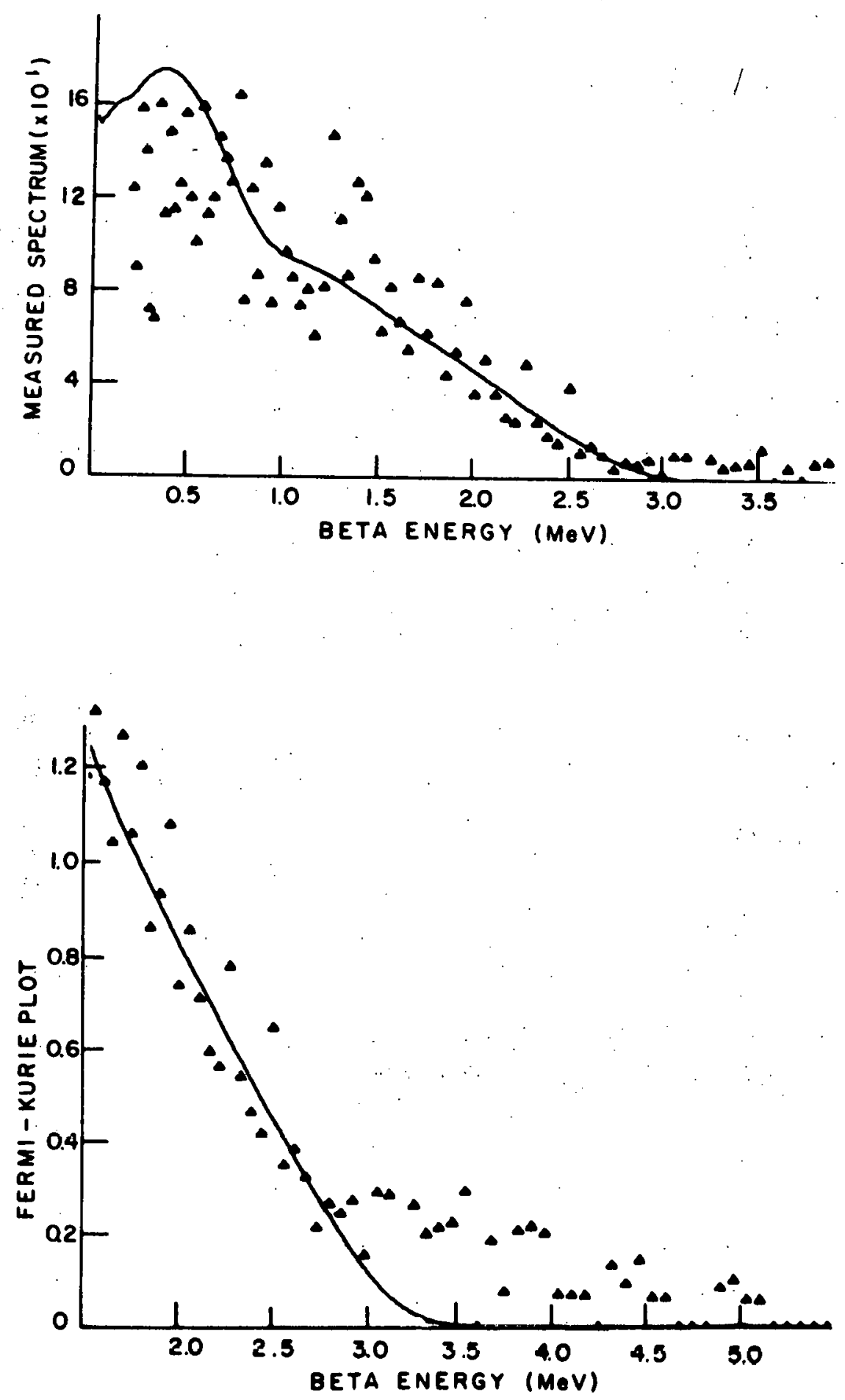

Figure 20. Fit to 1.375-MeV transition gated beta-ray spectrum and FermI plot for decay of ${ }^{90} \mathrm{Rb}$ with $16 \%$ beta feeding from $0.106-\mathrm{MeV}$ isomeric level in $90_{\mathrm{Rb}}$ 

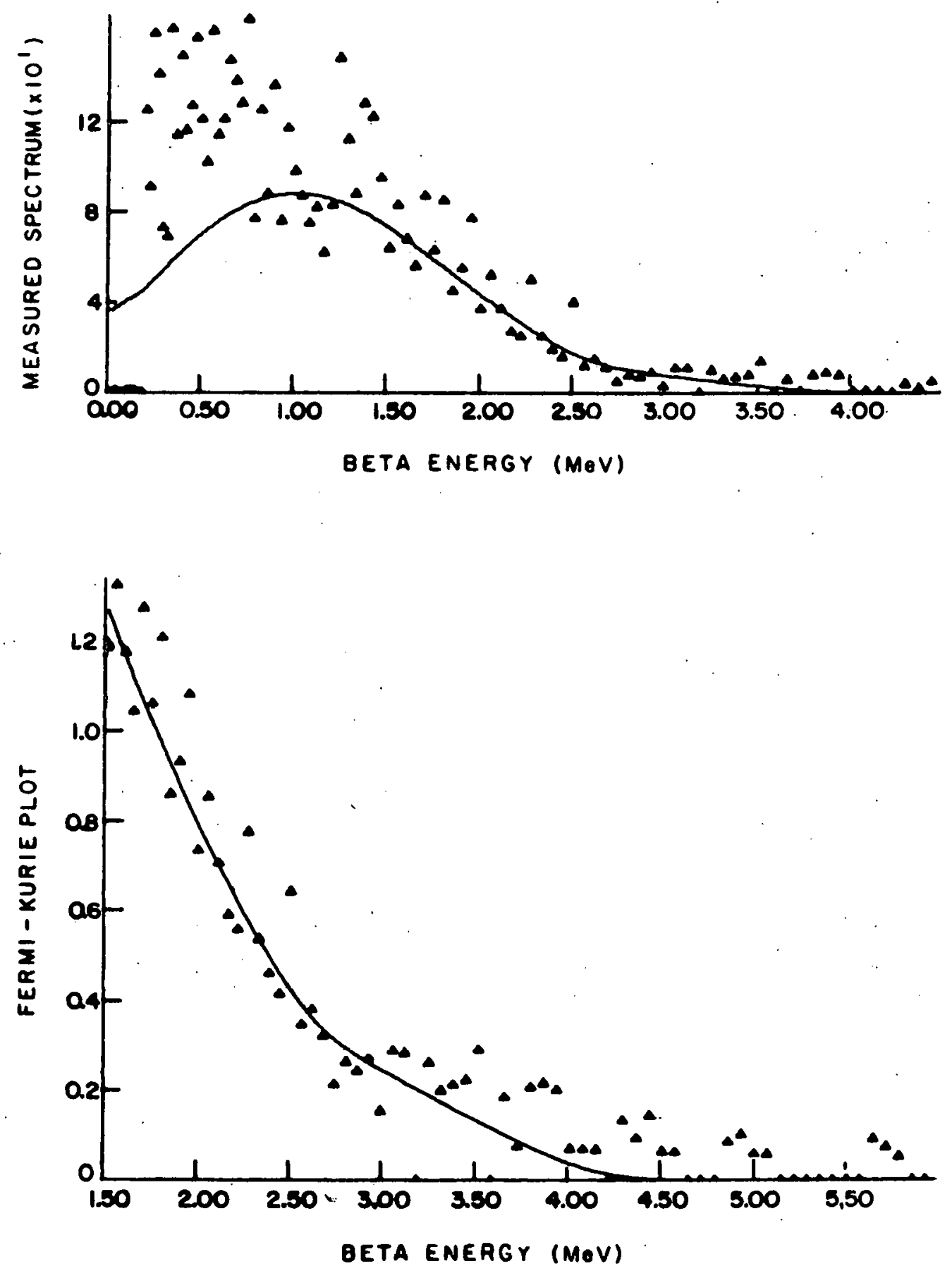

rigure 21. Fit to 1.375-MeV transition gated beta-ray spectrum and Fermi plot for decay of ${ }^{90} \mathrm{Rb}$ with $2 \%$ beta feeding from $0.106-\mathrm{MeV}$ isomeric level in ${ }^{90} \mathrm{Rb}$ 
Table 8. Values of beta decay energies for ${ }^{91} \mathrm{Kr}$.

\begin{tabular}{|c|c|c|c|c|}
\hline $\begin{array}{c}\text { Gat ing } \\
\text { transition } \\
(\mathrm{MeV})\end{array}$ & $\begin{array}{c}\text { Level } \\
\text { depopulated } \\
(\mathrm{MeV})\end{array}$ & $\begin{array}{c}\text { Beta decay } \\
\text { Q-value } \\
\text { (MeV) }\end{array}$ & $\begin{array}{l}\text { Grou } \\
\text { Level } \\
\text { (MeV) }\end{array}$ & $\begin{array}{l}\text { ps included } \\
\text { Cont ribution } \\
(\%)\end{array}$ \\
\hline 0.109 & 0.109 & $6.14 \pm 0.09$ & $\begin{array}{l}0.109 \\
0.507 \\
0.556 \\
0.722 \\
1.136\end{array}$ & $\begin{array}{r}64 \\
4 \\
4 \\
24 \\
4\end{array}$ \\
\hline 0.613 & 0.722 & $6.15 \pm 0.10$ & $\begin{array}{l}1.268 \\
1.529 \\
2.250 \\
2.593 \\
2.964\end{array}$ & $\begin{array}{l}12 \\
23 \\
45 \\
10 \\
10\end{array}$ \\
\hline 0.630 & 1.136 & $6.24 \pm 0.14$ & $\begin{array}{l}1.136 \\
2.470 \\
2.496 \\
2.964\end{array}$ & $\begin{array}{l}36 \\
26 \\
26 \\
12\end{array}$ \\
\hline 1.109 & 1.109 & $5.88 \pm 0.06^{a}$ & $\begin{array}{l}1.109 \\
1.881 \\
2.664 \\
3.377\end{array}$ & $\begin{array}{r}79 \\
4 \\
13 \\
4\end{array}$ \\
\hline \multirow[t]{2}{*}{1.501} & 1.501 & $6.06 \pm 0.08$ & $\begin{array}{l}1.501 \\
2.250\end{array}$ & $\begin{array}{r}93 \\
7\end{array}$ \\
\hline & weighted average & $6.12 \pm 0.07$ & . & \\
\hline
\end{tabular}

$a_{\text {Not used in determining weighted average. }}$ 
beta-ray spectrum, which is shown in Figure 22. The calculations using the gamma-ray intensities in the preliminary decay scheme gives a percent beta feeding of $73 \%$, which produces a poorer fit to the beta-ray spectrum, which is shown in Figure 23, and gives a $Q$-value that is not consistent with the other three values. It is apparent that further study on the gamma-ray decay scheme is needed to produce an acceptable fit to the beta-ray spectra. The beta decay Q-value averaged from the analysis of the four gated spectra is $6.12 \pm 0.07 \mathrm{MeV}$. The beta singles end-point energy measurement of $6.25 \pm 0.08 \mathrm{MeV}$ is within the uncertainty of the beta-gamma average decay energy. In 1970, Eidens et al. (45) reported the Q-value to be $5.7 \pm 0.4 \mathrm{MeV}$, and Wapstra and Gove (8) report a value of $6.5 \mathrm{MeV}$, determined from systematics. Mason and Johns (46) report a decay energy of $5.08 \pm 0.10 \mathrm{MeV}$, which is not consistent with these other values nor with the predictions of the Way-Wood diagrams (7).

The 1.109-MeV transition gated beta-ray spectrum has an end-point energy that does not give the correct $Q$-value when added to the energy of the major populated level. Duke et al. report that the 1.109-MeV transition depopulates a 1.109-MeV level; Mason and Johns report that the gamma ray depopulates the 1.615-MeV level, but the $1.109-M e V$ level is not included in their decay scheme; the present study. suggests that the gamma ray depopulates a level around $1.3 \mathrm{MeV}$. Further study is under way by Duke et al. to complete the decay scheme of ${ }^{91} \mathrm{Kr}$, which should eliminate some of the disagreement for this case as well as the beta branching intensity to the $1.136-\mathrm{MeV}$ level in $91_{\mathrm{Rb}}$. 

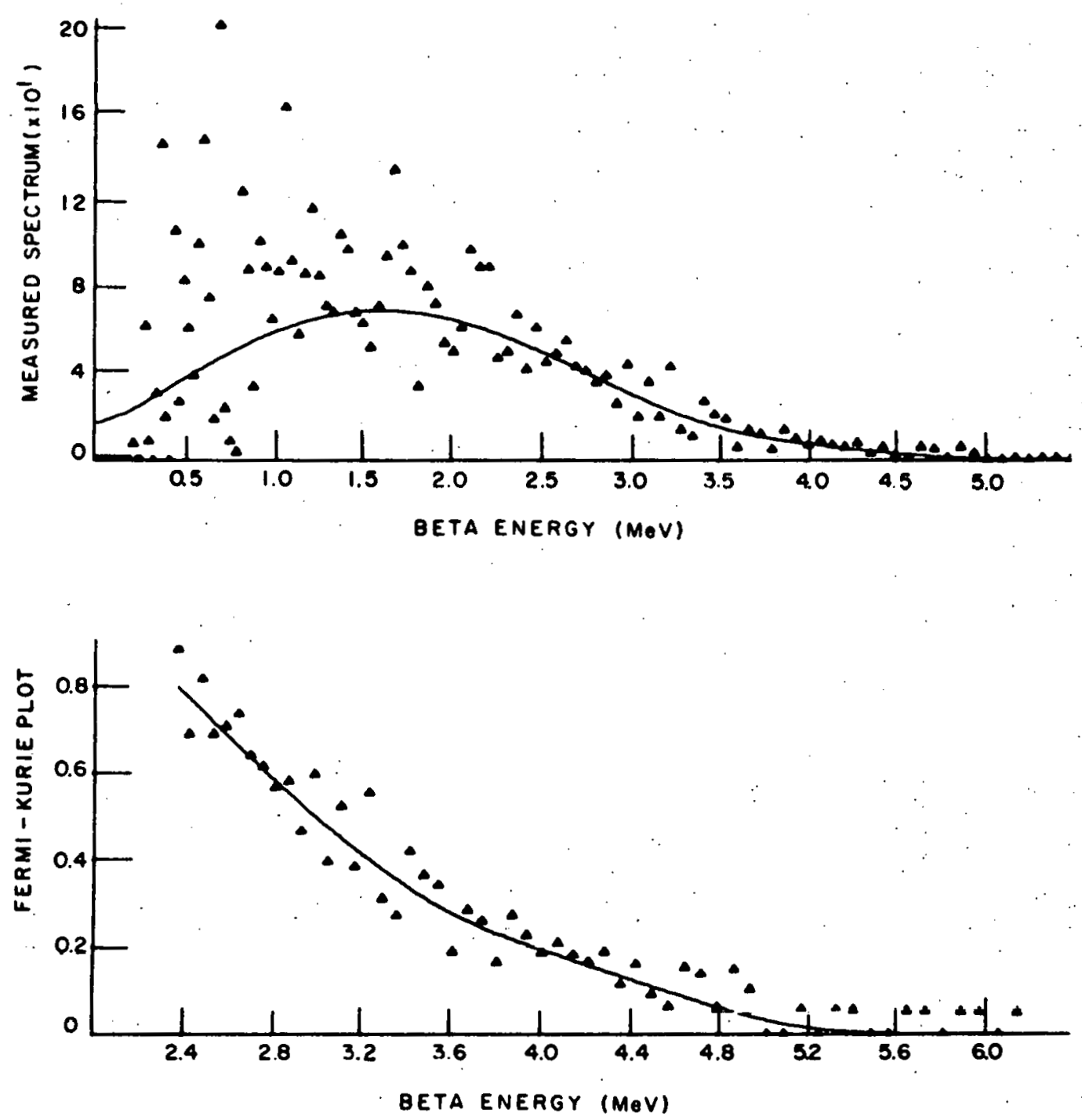

Figure 22. Fit to $0.630-\mathrm{MeV}$ transition gated beta-ray spectrum and Fermi plot for decay of ${ }^{91} \mathrm{Kr}$ wi th $36 \%$ beta feeding to $1.136-\mathrm{MeV}$ level of ${ }^{91} \mathrm{Rb}$ 

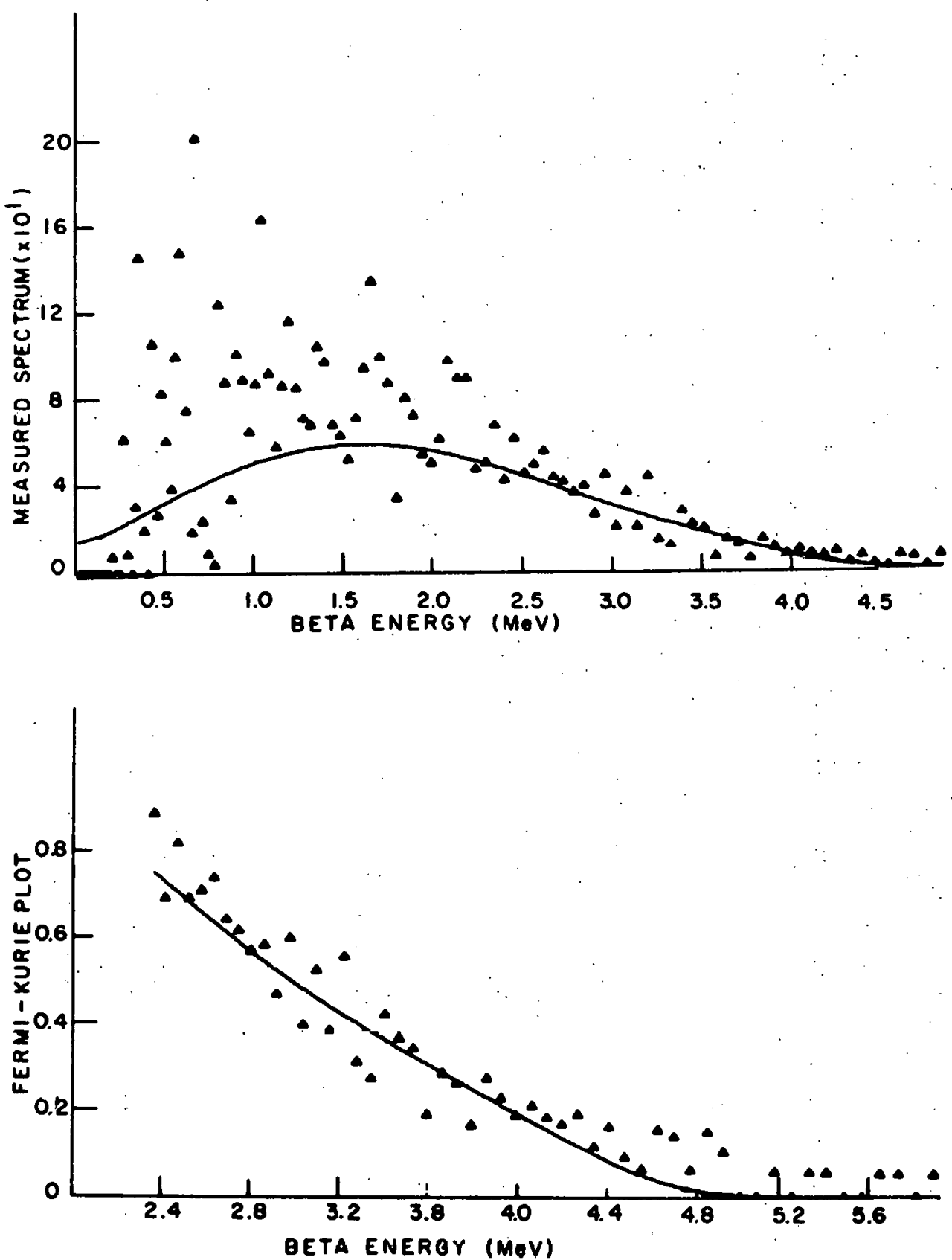

Figure 23. Fit to $0.630-\mathrm{MeV}$ transition gated beta-ray spectrum and Fermi plot for decay of ${ }^{91} \mathrm{Kr}$ with $73 \%$ beta feeding to $1.136-\mathrm{MeV}$ level of ${ }^{91} \mathrm{Rb}$ 


\section{$91_{\text {Rb Decay }}$}

The $Q$-value for the decay of ${ }^{91} \mathrm{Rb}$ was determined, using six coincidence beta-ray spectra, to be $5.68 \pm 0.04 \mathrm{MeV}$, as detailed in Table 9 . This is in excellent agreement with the work in 1968 by Zherebin et al. (47), which reported a value of $5.68 \pm 0.15 \mathrm{MeV}$. Mason and Johns (46) developed a level scheme with the 1.041-MeV level populated by $5.8 \%$ of the beta transitions from ${ }^{91} \mathrm{Rb}$. The beta-ray spectrum colncident with the $0.603-M e V$ gamma ray depopulating this level is shown in Figure 24. The present work obtained a value of $0.6 \%$ beta feeding to the 1.041 MeV level, which gives a better fit to the spectrum, as shown in Figure 25. A better fit to the $0.439-\mathrm{MeV}$ gated beta-ray spectrum with lower feeding to the $1.041-\mathrm{MeV}$ level is further evidence that the percent beta feeding to this level, as assigned by Mason and Johns, is too high.

\section{${ }^{92} \mathrm{Kr}$ Decay}

The previously unmeasured beta-decay $Q$-value for the ${ }^{92} \mathrm{Kr}$ decay was determined using both coincidence beta-ray spectra and a singles betaray spectrum. The eight gated spectra give an average Q-value of $5.97 \pm$ $0.08 \mathrm{MeV}$ and the singles spectrum end-point energy was $5.95 \pm 0.08 \mathrm{MeV}$. The eight gated spectra, from the transitions listed in Table 10, have very good statistics and are extremely well fit by the theoretical functions. Though there are no other values with which to compare these results, the agreement between the colncidence and singles values is evidence for the accuracy of the measurements, and of the previously determined gamma-ray decay scheme. The energy levels and the percent beta feeding for the decay of ${ }^{92} \mathrm{Kr}$ were taken from the study of $\mathrm{R}$. J. 01 son 
Table 9. Values of beta decay energies for ${ }^{91} \mathrm{Rb}$

\begin{tabular}{|c|c|c|c|c|}
\hline $\begin{array}{c}\text { Gating } \\
\text { transition } \\
(\mathrm{MeV})\end{array}$ & $\begin{array}{c}\text { Level } \\
\text { depopulated } \\
(\mathrm{MeV})\end{array}$ & $\begin{array}{c}\text { Beta decay } \\
\text { Q-value } \\
\text { (MeV) }\end{array}$ & $\begin{array}{l}\text { Group } \\
\text { Level } \\
\text { (MeV) }\end{array}$ & $\begin{array}{l}\text { s included } \\
\text { Cont ribution } \\
(\%)\end{array}$ \\
\hline 0.346 & 0.439 & $5.66 \pm 0.13$ & $\begin{array}{l}0.439 \\
2.064 \\
2.344 \\
2.657\end{array}$ & $\begin{array}{l}51 \\
14 \\
16 \\
19\end{array}$ \\
\hline 0.439 & 0.439 & $5.71 \pm 0.15$ & $\begin{array}{l}0.439 \\
1.041 \\
2.064 \\
2.344 \\
2.657\end{array}$ & $\begin{array}{c}51 \\
1 \\
15 \\
15 \\
18\end{array}$ \\
\hline 0.593 & 2.657 & $5.67 \pm 0.04$ & 2.6577 & 100 \\
\hline 0.603 & 1.041 & $5.78 \pm 0.13$ & $\begin{array}{l}1.041 \\
2.344 \\
2.657 \\
3.752\end{array}$ & $\begin{array}{l}16 \\
13 \\
55 \\
16\end{array}$ \\
\hline 1.616 & 2.657 & $5.63 \pm 0.07$ & 2.657 & 100 \\
\hline \multirow[t]{2}{*}{2.564} & 2.657 & $5: 70 \pm 0.04$ & 2.657 & 100 \\
\hline & weighted average & $5.68 \pm 0.04$ & & \\
\hline
\end{tabular}



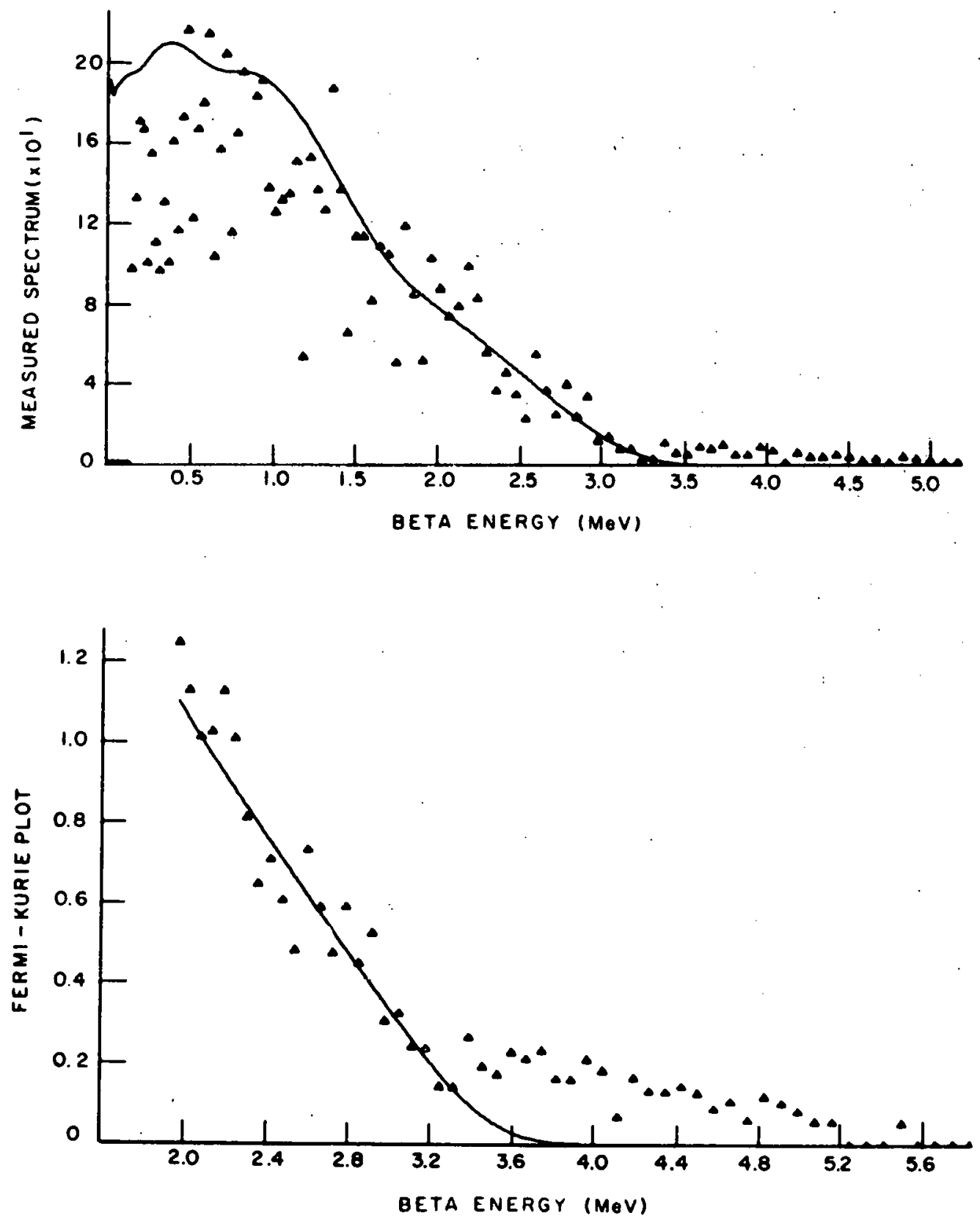

Figure 24. Fit to $0.603-\mathrm{MeV}$ transition gated beta-ray spectrum and Fermi plot for decay of ${ }^{91} \mathrm{Rb}$ with $5.8 \%$ beta feeding to $1.041-\mathrm{MeV}$ level of ${ }^{91} \mathrm{Sr}$ 

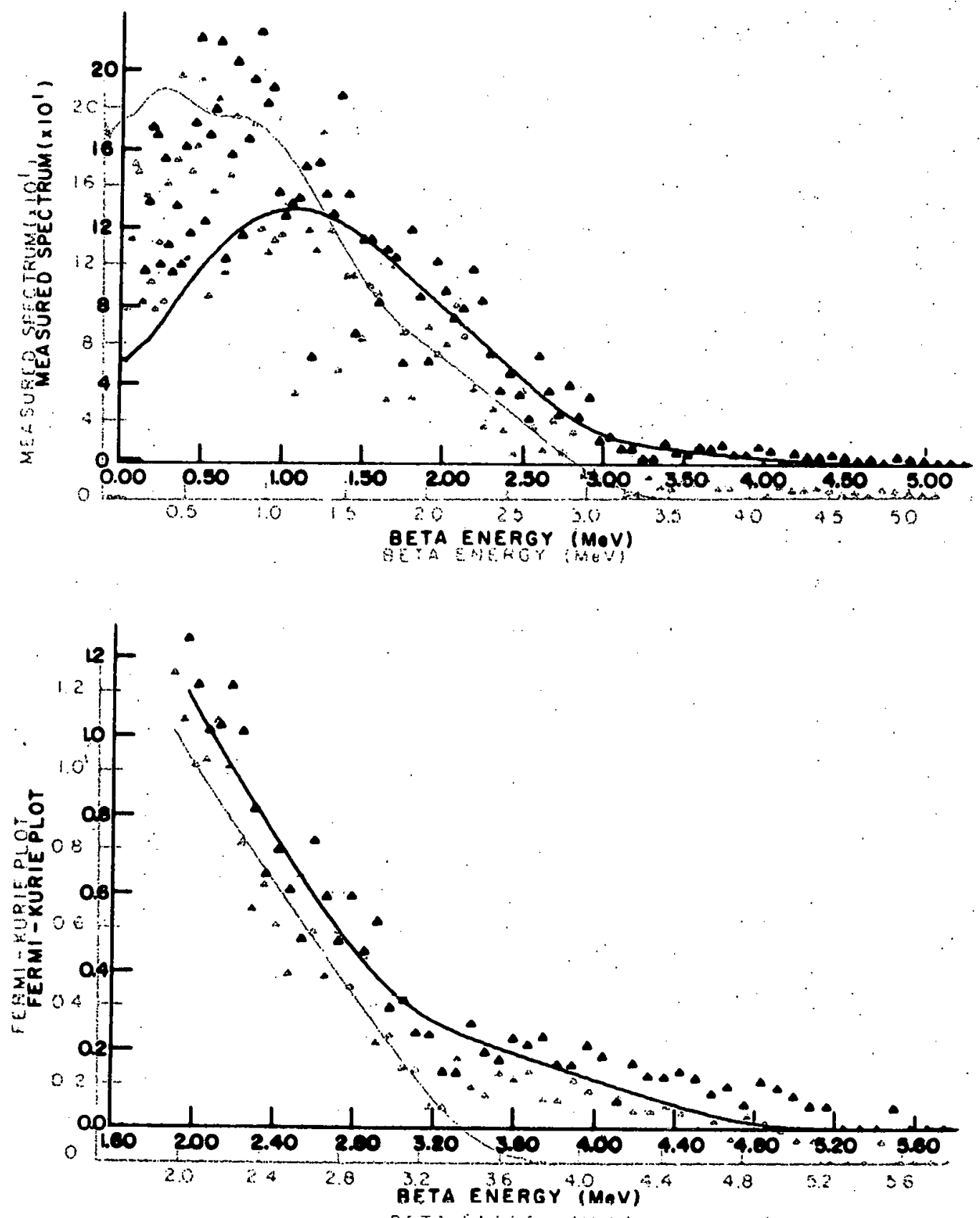

Figure 25. Fit to $0.603-\mathrm{MeV}$ transition gated beta-ray spectrum and Fermi Figure 24. plot for decay of 9.86 with $0.6 \%$ beta feeding to $1.041-M e v i$

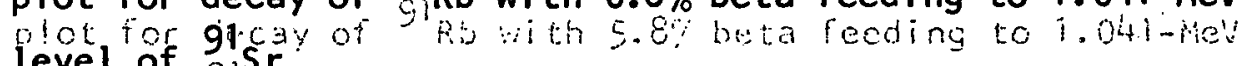

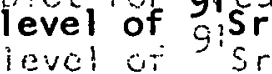


Table 10. Values of beta decay energies for ${ }^{92} \mathrm{Kr}$

\begin{tabular}{|c|c|c|c|c|}
\hline $\begin{array}{c}\text { Gating } \\
\text { transition } \\
(\mathrm{MeV})\end{array}$ & $\begin{array}{c}\text { Level } \\
\text { depopulated } \\
(\mathrm{MeV})\end{array}$ & $\begin{array}{c}\text { Beta decay } \\
\text { Q-value } \\
(\mathrm{MeV})\end{array}$ & $\begin{array}{l}\text { Groul } \\
\text { Level } \\
(\mathrm{MeV})\end{array}$ & $\begin{array}{l}\text { ps Included } \\
\text { Contribution } \\
(\%)\end{array}$ \\
\hline 0.142 & 0.142 & $6.00 \pm 0.10$ & $\begin{array}{l}0.493 \\
0.728 \\
0.928 \\
1.361 \\
2.039\end{array}$ & $\begin{array}{r}1 \\
<1 \\
1 \\
96 \\
2\end{array}$ \\
\hline 0.317 & 0.317 & $5.89 \pm 0.10$ & $\begin{array}{l}1.361 \\
1.664\end{array}$ & $\begin{array}{r}99 \\
1\end{array}$ \\
\hline 0.342 & 0.485 & $5.95 \pm 0.23$ & $\begin{array}{l}1.361 \\
1.664 \\
2.039\end{array}$ & $\begin{array}{r}89 \\
2 \\
9\end{array}$ \\
\hline 0.548 & 0.548 & $6.01 \pm 0.10$ & $\begin{array}{l}1.361 \\
1.664 \\
2.039\end{array}$ & $\begin{array}{l}99 \\
<1 \\
<1\end{array}$ \\
\hline 0.813 & 1.361 & $6.12 \pm 0.09$ & 1.361 & 100 \\
\hline 0.876 & 1.361 & $5.89 \pm 0.09$ & 1.361 & 100 \\
\hline 1.044 & 1.361 & $5.88 \pm 0.08$ & 1.361 & 100 \\
\hline 1.219 & 1.361 & $5.95 \pm 0.08$ & 1.361 & 100 \\
\hline & weighted average & $5.97 \pm 0.08$ & & \\
\hline
\end{tabular}


(15). The only discrepancy found between this work and that of olson is between his calculated percent beta feeding to the ground state of ${ }^{92} \mathrm{Rb}$ and that determined by fitting the singles beta-ray spectrum. Using the ground-state feeding of $50 \%$ assigned by 01 son, the calculated beta-ray spectrum, shown in Figure 26 , is a much poorer fit to the measured singles spectrum than that obtalned using a ground-state beta feeding on the order of $2 \%$, which results in the beta-ray spectrum fit shown in Figure 27 . In addition, the lower beta feeding to the ground state gives rise to better $\log \mathrm{ft}$ values for the expected first-forbidden beta-ray transition (15). In both analyses of the singles spectrum, significant contamination from the decay of ${ }^{92} \mathrm{Rb}$ appears. which has an end-point energy of $7.5 \mathrm{MeV}$.

\section{${ }^{92}$ Rb Decay}

For the decay of ${ }^{92} \mathrm{Rb}$, a beta singles measurement only was made, giving a beta decay end-point energy of $7.58 \pm 0.15 \mathrm{MeV}$. The high uncertainty in the measured value is due to the fact that the calibration function is not well known above the fit region, $4.0 \mathrm{MeV}$ to $6.4 \mathrm{MeV}$. The comparison between coincidence and singles measurements for ${ }^{90} \mathrm{Rb}$ is evidence, however, that the calibration function is linear from $3.0 \mathrm{MeV}$ to $6.3 \mathrm{MeV}$. The area under the spectrum above $7 \mathrm{MeV}$ could be slightly reduced by incomplete absorption of electron energies, but the addition of these counts to the lower-energy portion of the spectrum should be negligible in comparison to the counts belonging below $7 \mathrm{MeV}$. The beta singles spectrum, shown in Figure 28, was fit using two groups from the determination by 01 son (15) that the gound-state beta feeding to ${ }^{92} \mathrm{Sr}$ is $94 \%$ and the beta branch to the $0.814-\mathrm{MeV}$ state is $1.3 \%$. The beta-decay 

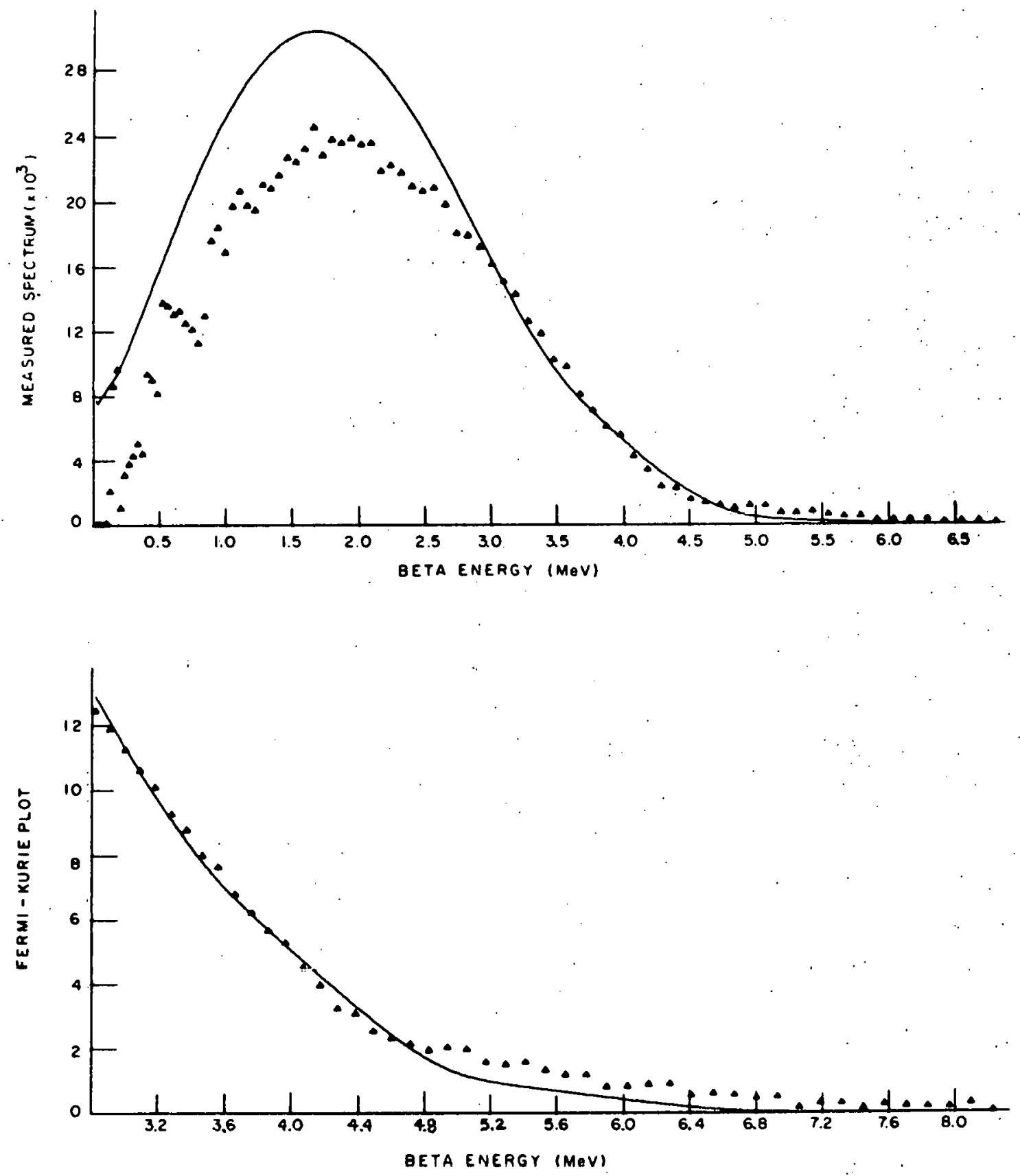

Figure 26. Fit to beta-singles spectrum and Fermi plot for decay of $92 \mathrm{Kr}$ with $50 \%$ beta feeding to ground state of ${ }^{92} \mathrm{Rb}$ 

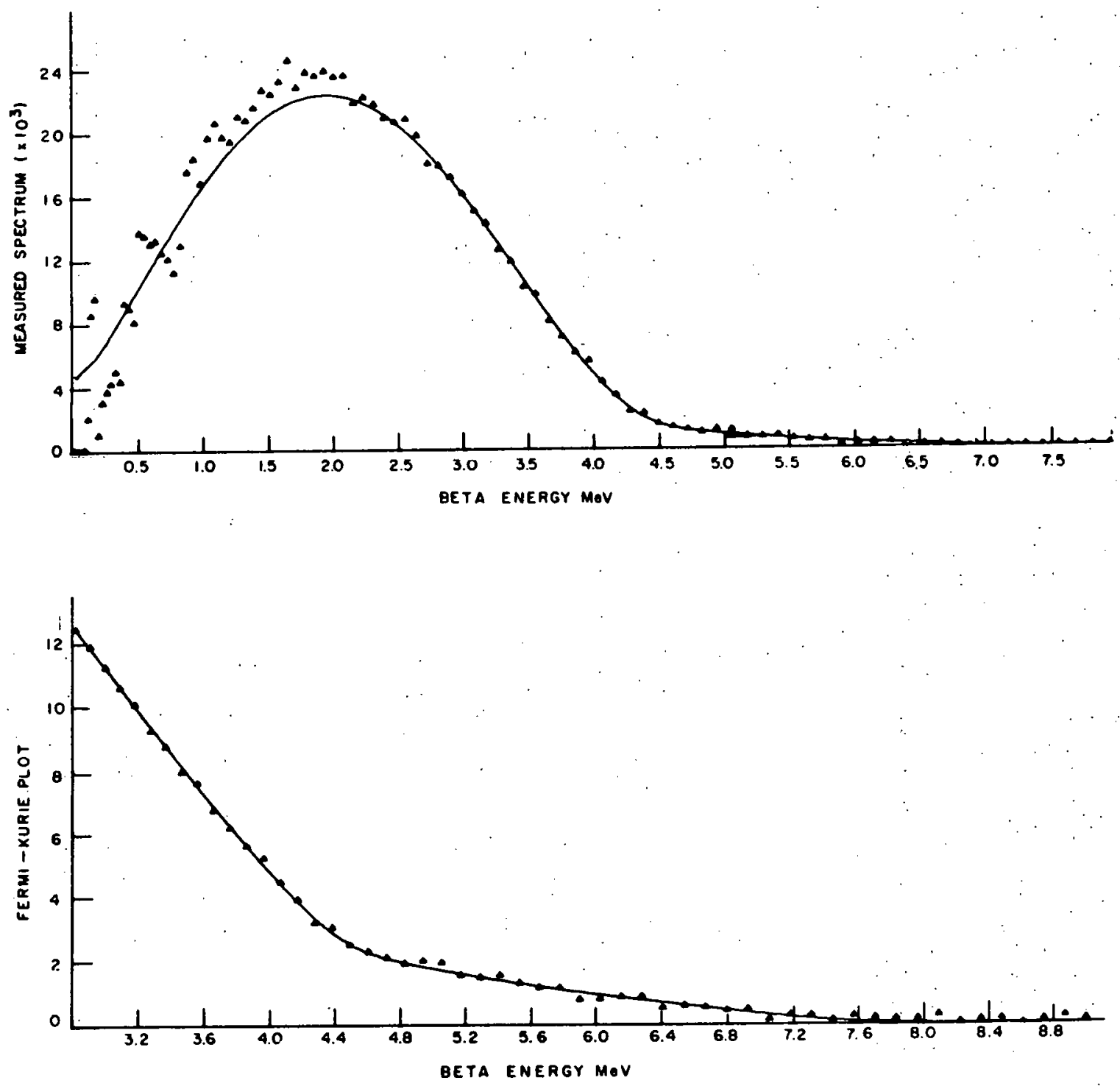

Figure 27. Fit to beta-singles spectrum and Fermi plot for decay of ${ }^{92} \mathrm{Kr}$ with $2 \%$ beta feeding to ground state of ${ }^{92} \mathrm{Rb}$ 

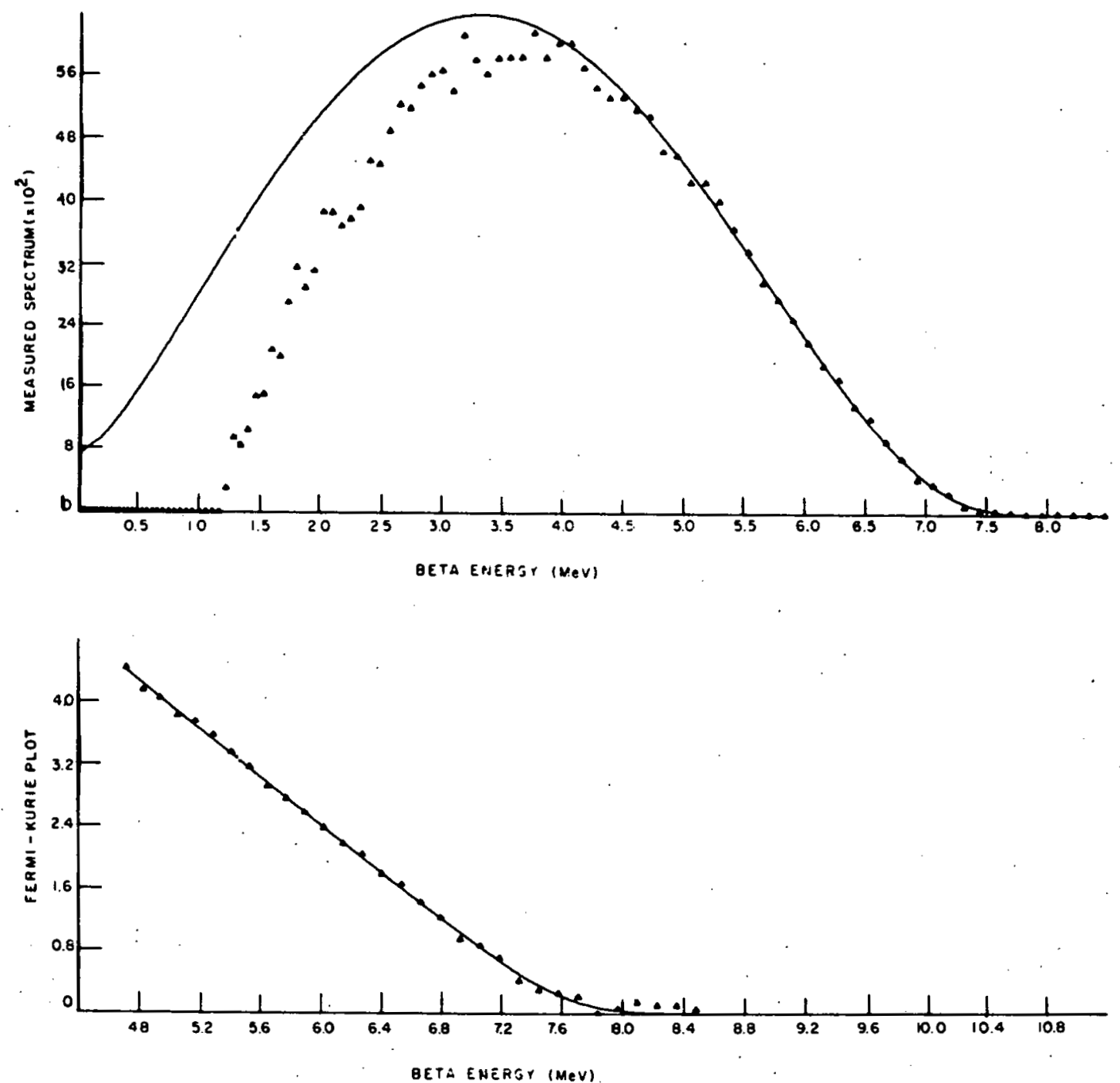

Figure 28. Fit to beta-singles spectrum and Fermi plot for decay of ${ }^{92} \mathrm{Rb}$ 
Q-value reported here does not agree with the $8.18 \pm 0.13 \mathrm{MeV}$ reported by Macias-Marques et al. (48), who claims that a beta group having an end-polnt energy of $7.4 \mathrm{MeV}$ populates the $0.815-\mathrm{MeV}$ level. If Marques et al. are correct, then a prominent hlgher-energy group should have been seen in a singles spectrum, since the work of 0lson showed that the upper limit to the beta feeding to the $0.815-\mathrm{MeV}$ level is $25 \%$, compared to the ground-state beta branching. This was not reported in the work of Macias-Marques et al., nor is it seen in the present work.

$$
93 \mathrm{Kr} \text { and }{ }^{93} \mathrm{Rb} \text { Decays }
$$

The decay schemes for ${ }^{93} \mathrm{Rb}$ and ${ }^{93} \mathrm{Sr}$ have not been determined, hence no Q-value can be determined using beta-gama coincidence spectra endpoint energles. The gated beta-ray spectra, however, do provide a lower limit to the beta-decay end-point energy. The four end-point energies determined from gating transitions in the ${ }^{93} \mathrm{Kr}$ decay listed in Table 11 are around $7.1 \mathrm{MeV}$. The similarity of all the end-point energies for the gated spectra suggest that the chosen transitions arise from the depopulation of a single level that is heavily beta fed. The statistics for the four spectra are quite good and they are fit well by the theoretical function at the high-energy end of the spectra. An example of such a spectrum is the $0.323-M e V$ transition gated beta-ray spectrum shown in Figure 29. A singles spectrum was also taken but the lever arm for the highest-energy group is not long enough to give an accurate measurement of the $Q$-value. The outer group end-point energy from the singles spectrum analysis is $8.3 \pm 0.5 \mathrm{MeV}$. There is also some evidence in the singles spectrum of strong branching by a group having an end-point energy of 
Table 11. Values of beta decay energies for ${ }^{93} \mathrm{Kr}$ and ${ }^{93} \mathrm{Rb}^{\mathrm{a}}$

\begin{tabular}{ccc}
$\begin{array}{c}\text { Gating } \\
\text { transition } \\
(\mathrm{MeV})\end{array}$ & $\begin{array}{c}\text { Beta decay } \\
\text { end-point energy } \\
(\mathrm{MeV})\end{array}$ & $\begin{array}{c}\text { Isobaric } \\
\text { identification }\end{array}$ \\
\hline 0.182 & $7.02 \pm 0.10$ & $\mathrm{Kr}$ \\
0.253 & $7.23 \pm 0.10$ & $\mathrm{Kr}$ \\
0.267 & $7.02 \pm 0.10$ & $\mathrm{Kr}$ \\
0.323 & $7.12 \pm 0.10$ & $\mathrm{Kr}$ \\
0.431 & $5.32 \pm 0.11$ & $\mathrm{Rb}$ \\
\hline
\end{tabular}

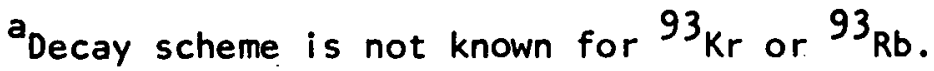



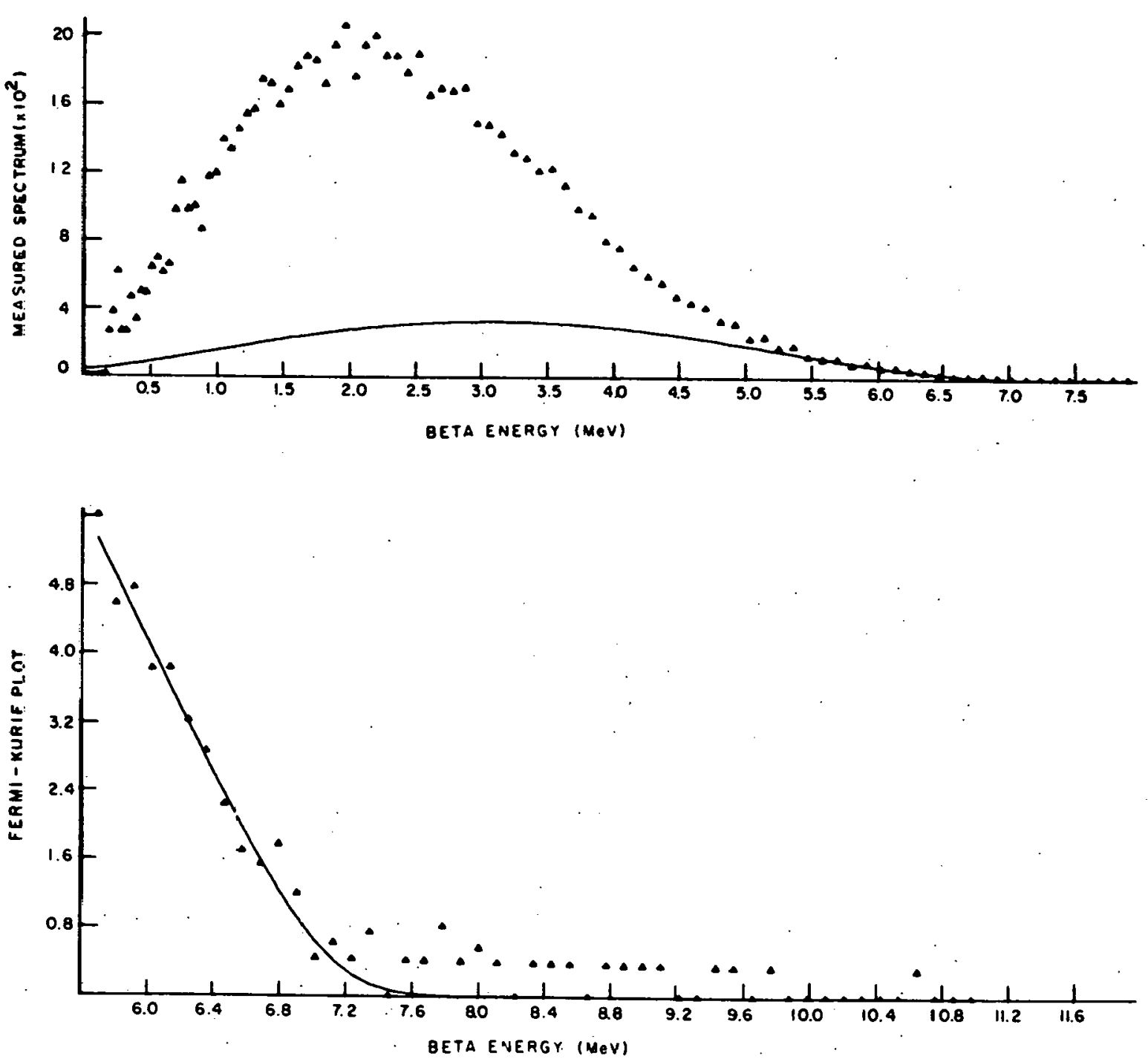

Figure 29. Fit to $0.323-\mathrm{MeV}$ transition gated beta-ray spectrum and Fermi plot for decay of $93 \mathrm{Kr}$ 
$6.2 \pm 0.1 \mathrm{MeV}$. The singles spectrum, however, does not show the $7.1 \mathrm{MeV}$ end-point energy which seems to be prevalent for the gated spectra.

The one gated beta-ray spectrum for the decay of ${ }^{93} \mathrm{Rb}$, which is also listed in Table 11, has an end-point energy of $5.32 \pm 0.11 \mathrm{MeV}$. The beta singles spectrum, shown in Figure 30 , gives a good measurement of the betadecay $Q$-value, $7.23 \pm 0.10 \mathrm{MeV}$. When the decay schemes have been determined, the beta-gamma colncidence spectra end-point energies presented here should provide better Q-value determinations, as well as prove useful in the construction of the decay schemes. 

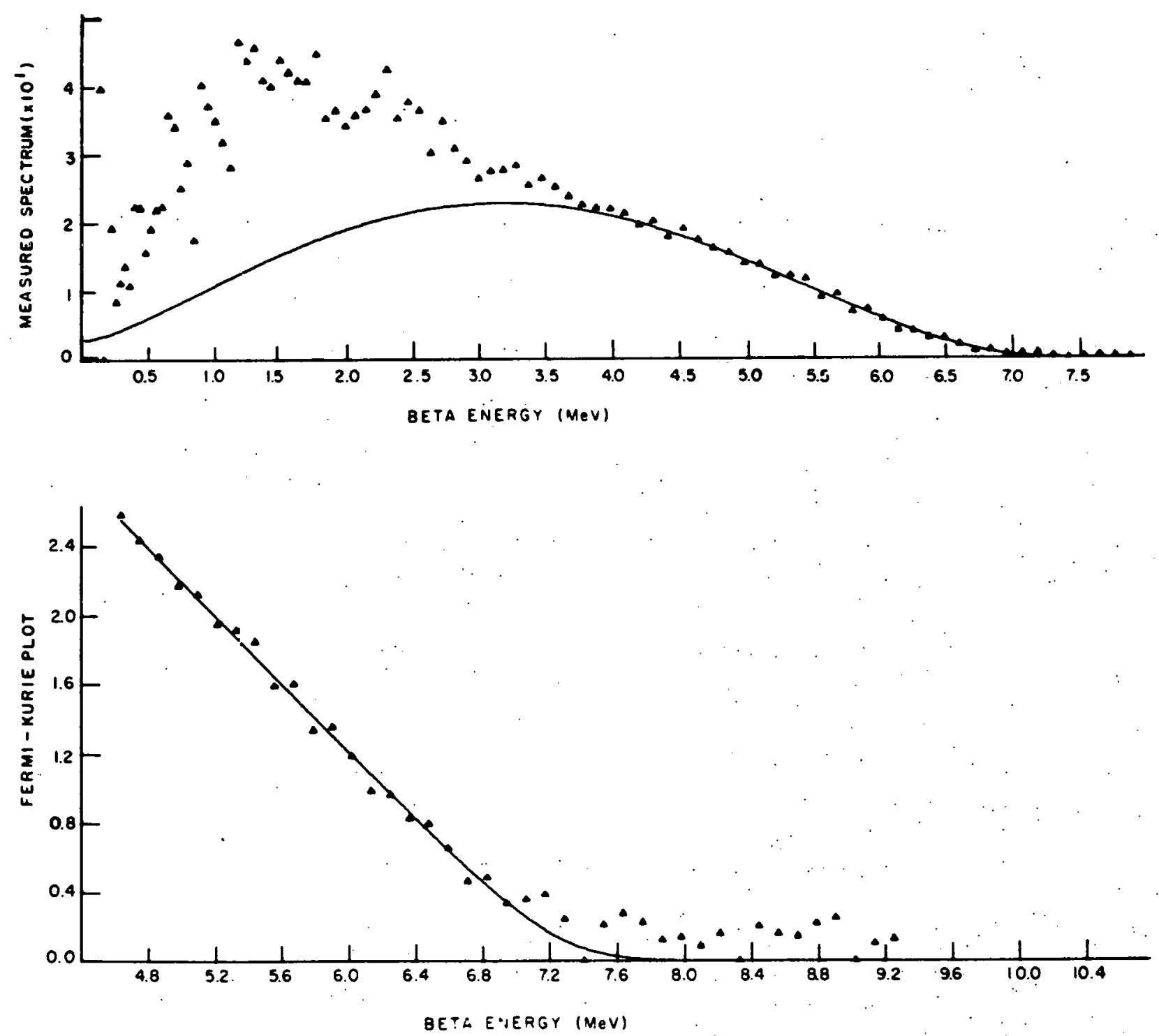

Figure 30. Fit to beta-singles spectrum and Fermi plot for decay of ${ }^{93} \mathrm{Rb}$ 


\section{DISCUSSION}

A summary of the results of this work is given in Table 12, which lists the average $Q$-values from the gated coincidence beta-ray spectra with the associated uncertainties, the number of gates used in determining the average values; and the Q-values resulting from the analysis of the singles beta-ray spectra. Also included in the table are the $Q$-values predicted by the Garvey et al. (4) and Seeger (3) formalisms as well as the experimental results and systematic predictions reported in the compilation by Wapstra and Gove (8). The predicted energies according to Garvey et al. are considerably closer to those measured in this work than are those of Seeger. Figure 31 illustrates how the two calculations deviate from the experimental Q-values of this work, with the Garvey et al. predictions shown as open circles and the Seeger predictions shown as open squares. The weighted rms deviation for the Garvey mass relation is $0.22 \mathrm{MeV}$, while that for the Seeger mass formula is $1.46 \mathrm{MeV}$.

It is dangerous to conjecture whether the Garvey et al mass relation is better than the Seeger mass formula, in general. The Garvey relation was developed using mass differences between adjacent nuclei as a means for predicting nuclidic masses far from the line of beta-stability. The Seeger equation was developed using the masses of the known nuclei as a means of predicting masses very far from stability for the r-process calculations of the abundance of elements in astrophysical processes. It is not surprising that the predictions of Garvey et al. are better than those of Seeger for the region studied since the "boot-strapping" technique used by Garvey et al. accounts for local fluctuations in the mass surface 
Table 12. Beta decay energy results

\begin{tabular}{|c|c|c|c|c|c|c|}
\hline \multirow{2}{*}{$\begin{array}{l}\text { Decaying } \\
\text { Nucleus }\end{array}$} & \multicolumn{3}{|c|}{ Predicted Energy } & \multicolumn{3}{|c|}{ Results this Work } \\
\hline & $\begin{array}{c}\text { Garvey } \\
\text { et al (4) } \\
(\mathrm{MeV})\end{array}$ & $\begin{array}{c}\text { Seeger } \\
(3) \\
(\mathrm{MeV})\end{array}$ & $\begin{array}{l}\text { Wapstra } \\
\text { and Gove (8) } \\
\text { (MeV) }\end{array}$ & $\begin{array}{c}\text { Coincidence } \\
\text { Determination } \\
(\mathrm{MeV})\end{array}$ & $\begin{array}{l}\text { Gates } \\
\text { Used }\end{array}$ & $\begin{array}{c}\text { Singles } \\
\text { Determination } \\
(\mathrm{MeV})\end{array}$ \\
\hline${ }^{88} 8_{K r}$ & 2.81 & 1.3 & $2.90 \pm 0.10$ & $2.93 \pm 0.03$ & 7 & --- \\
\hline${ }^{88} \mathrm{Rb}$ & 5.07 & 4.4 & $5.30 \pm 0.02$ & $5.30 \pm 0.06$ & 4 & -- \\
\hline${ }^{89}{ }_{\mathrm{Kr}}$ & 5.11 & 4.3 & $5.15 \pm 0.03$ & $4.93 \pm 0.06$ & 7 & $4.84 \pm 0.16$ \\
\hline $90 \mathrm{Kr}$ & 4.18 & 2.9 & $4.41 \pm 0.03$ & $4.35 \pm 0.05$ & 8 & $4.40 \pm 0.06$ \\
\hline $90_{\mathrm{Rb}}$ & 6.41 & 5.6 & $6.63 \pm 0.09$ & $6.32 \pm 0.07$ & 3 & $6.34 \pm 0.08$ \\
\hline $91_{K r}$ & 6.46 & 6.0 & $6.5^{\mathrm{a}}$ & $6.12 \pm 0.07$ & 4 & $6.25 \pm 0.08$ \\
\hline $91_{R b}$ & 5.49 & 4.2 & $5.68 \pm 0.15$ & $5.68 \pm 0.04$ & 6 & $-\cdots$ \\
\hline${ }^{92} \mathrm{Kr}$ & 5.31 & 4.3 & $\therefore$ & $5.97 \pm 0.08$ & 8 & $5.95 \pm 0.08$ \\
\hline${ }^{92} \mathrm{Rb}$ & 7.78 & 7.2 & $7.9^{a}$ & $\cdots$ & & $7.58 \pm 0.15$ \\
\hline${ }^{92} \mathrm{Sr}$ & 1.82 & 0.2 & $1.92 \pm 0.07$ & $1.93 \pm 0.03$ & 1 & --- \\
\hline $93 \mathrm{Kr}$ & 8.15 & 7.8 & --- & -- & 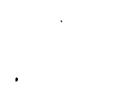 & $8.30 \pm 0.50$ \\
\hline${ }^{93} \mathrm{Rb}$ & 6.62 & 5.6 & $6.9^{a}$ & -- & 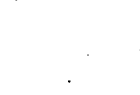 & $7.23 \pm 0.10$ \\
\hline
\end{tabular}

apredicted by systematics. 


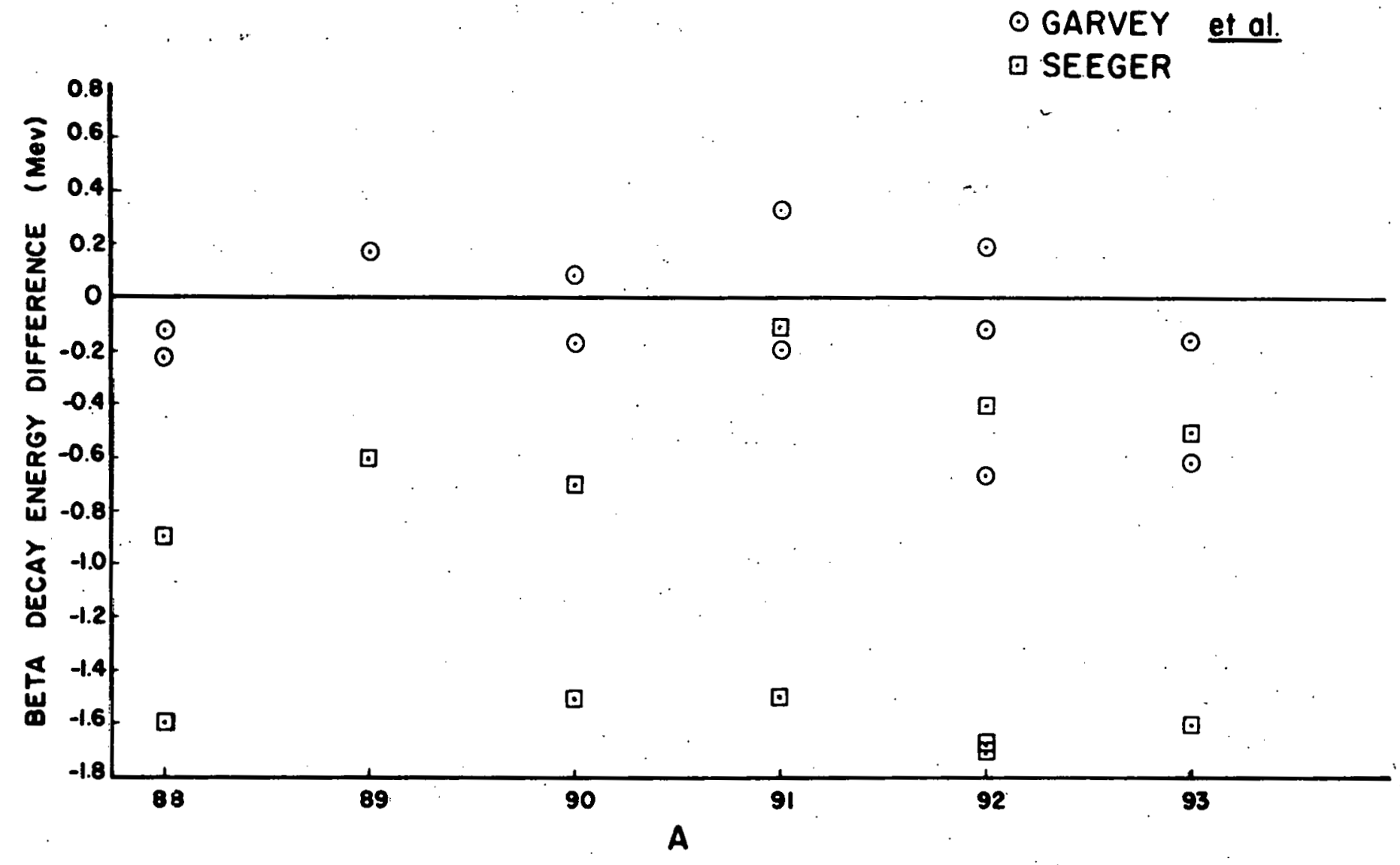

Figure 31. Deviations from beta decay Q-values measured in this work for predictions of Garvey et al. and Seeger 
while the equation used by Seeger rigidly constrains the results to a general determination of the known mass values.

Garvey et al. quote an average deviation of $0.20 \mathrm{MeV}$ for their fit to all the known masses, which is slightly less than the rms deviation of their predictions for the beta decay energies measured in this work. This small increase in the rms deviation for the nuclei in this study could indicate the onset of a breakdown for this relation in the regions far. from beta stability. J. P. Adams (49) noticed a similar but more drastic increase in the rms deviation for beta decay energles predicted by Garvey et al. in the neutron rich mass region around $A=140$. Seeger quotes an average deviation of $0.78 \mathrm{MeV}$ to the known masses, which is considerably less than the rms deviation of $h i s$ predictions for the Q-values measured in this work. It appears, on the basis of these comparisons, that the mass relation of Garvey et al. would be used to advantage to predict beta decay energies for short-lived radioactive nuclei likely to be studied in the reasonable future. The mass formula of Seeger, however, is perhaps uncontested, although untested directly, for use in the extreme neutron-rich region traversed in nucleo-genesis calculations.:

The systematic approach to determining beta decay energies established by Way and Wood (7) is a "boot-strapping" technique used for extrapolating to unexplored nuclear mass regions and for predicting unknown beta decay energles from the beta decay energies of the adjacent nuclei. The Way-Wood formalism, which is based on the semi-empirical mass formula of von Weizsycker (1) portrays the general features of the mass surface. The Way-Wood diagrams Illustrate the three simple relations that are 
Implied in the semi-empirical formula between beta decay energies and nuclear parameters, $A, N$, and 2 . The most famlliar of these relations is the linear relation between beta decay energies and $N$ for constant $A$, which follows from the parabolic expression for the mass surface. The two other relations show approximately linear behavior between beta decay energies and $A$ for nuclei with constant $Z$ or $N$. There are deviatlons from linearity that occur in the regions near shell closures, which are expected since the mass formula contains no shell-model dependence. It has been found empirically, however; that even when the linearity breaks down, adjacent 1 ines of constant $Z$ or $N$ remain remarkably parallel.

The Way-Wood diagrams for even A-even $Z$, even $A$-odd $Z$, odd $A$-even $Z$, and odd A-odd $Z$ which illustrate the two approximately linear relationships for the decay energles of the masses studied in this work are shown in figures 32-35. The open circles mark the previously measured beta decay Q-values, the open squares mark the Q-values measured in this study, and the open triangles mark the beta decay energies predicted on the basis of the parallelogram structure. The 1 ines of constant $Z$ and $N$ are labeled and dashed lines connect the predicted Q-values with the measured ones. At the major shell closure for $\mathrm{N}=50$ a significant discontinuity in the slope of the constant $-Z$ lines is apparent, but the slope change is independent of $Z$ for neighboring lines. The weighted rms deviation of the Way-Wood systematics predictions for the nuclei studied in this work is $0.46 \mathrm{MeV}$.

The Way-Wood systematics appear to work well at predicting beta decay energies by "boot-strapping" from one parallelogram to the next. 


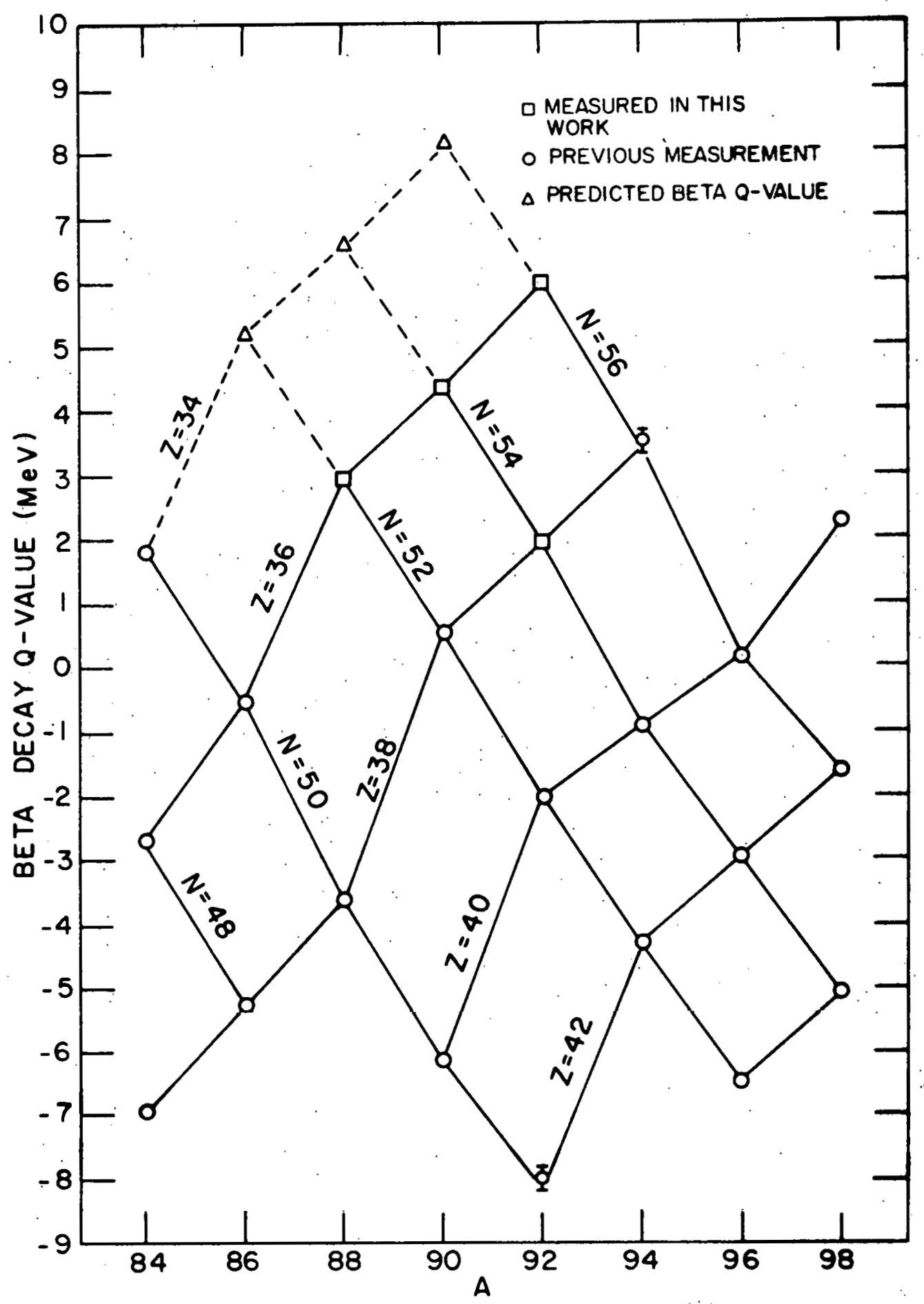

Figure 32. Way-Wood diagram for even $A$-even $Z$ in mass region $A=90$ 


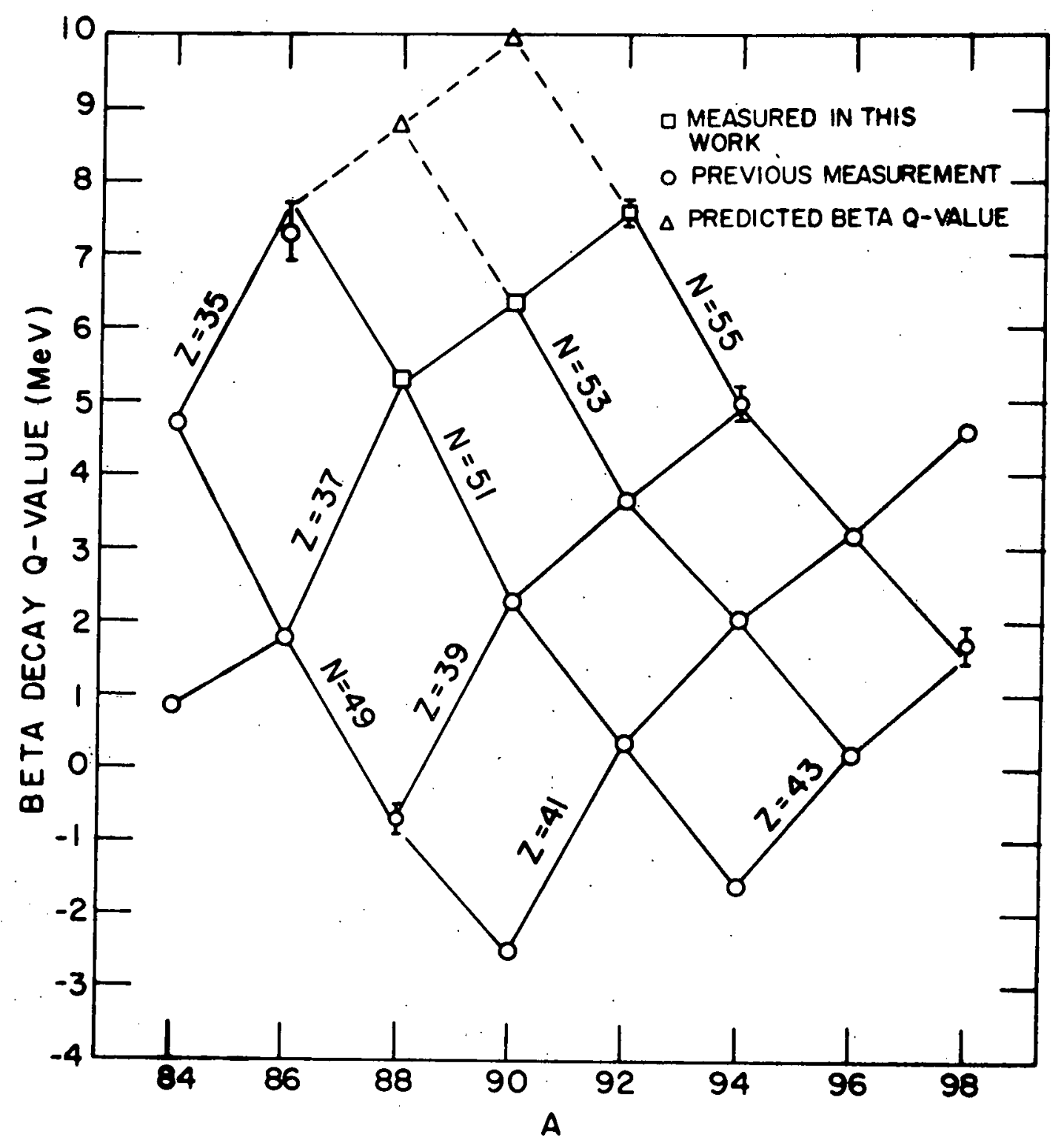

Figure 33. Way-Wood diagram for even $A$-odd $Z$ in mass region $A=90$ 


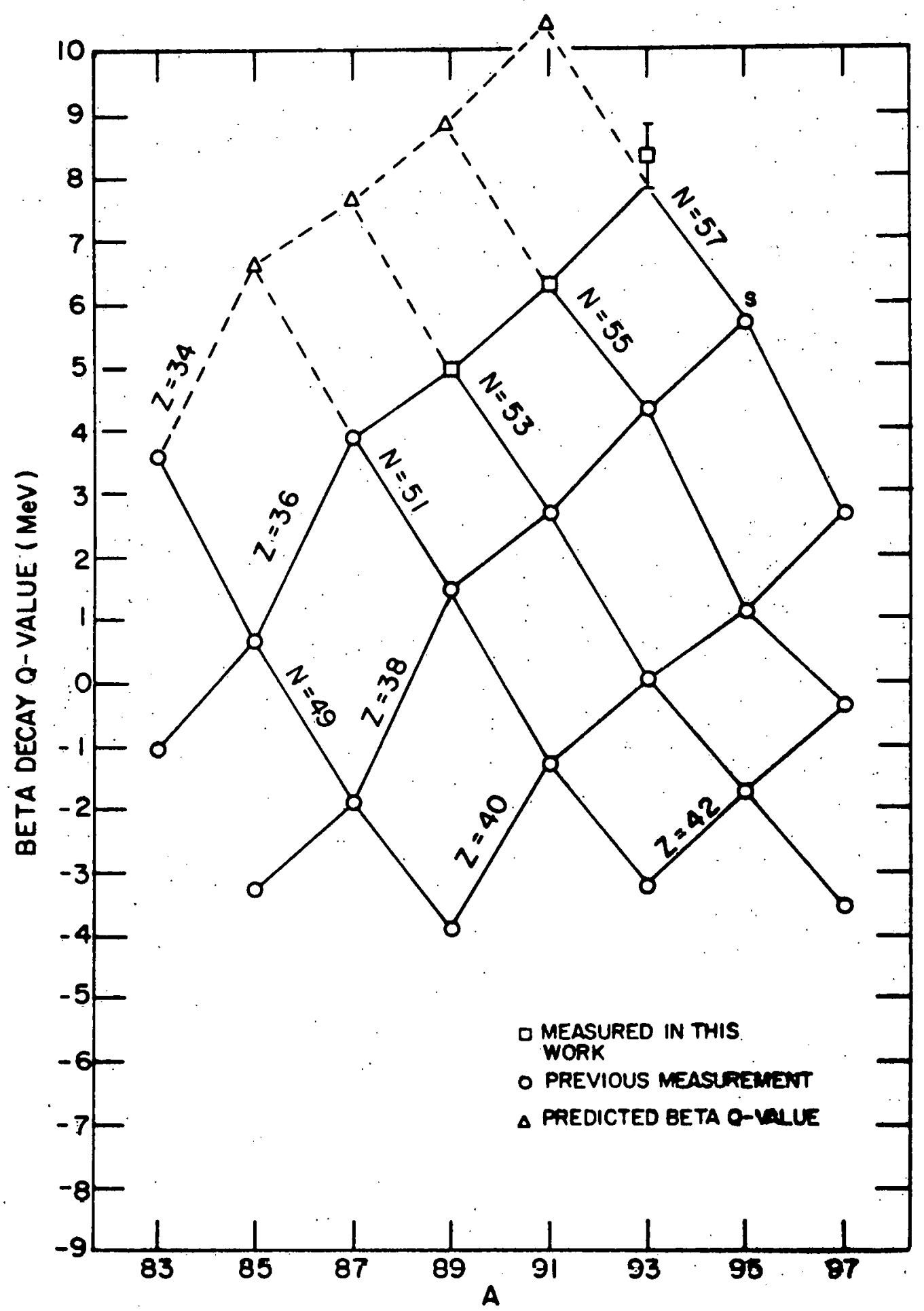

Figure 34. Way-Wood diagram for odd $A$-even $Z$ in mass region $A=90$ 


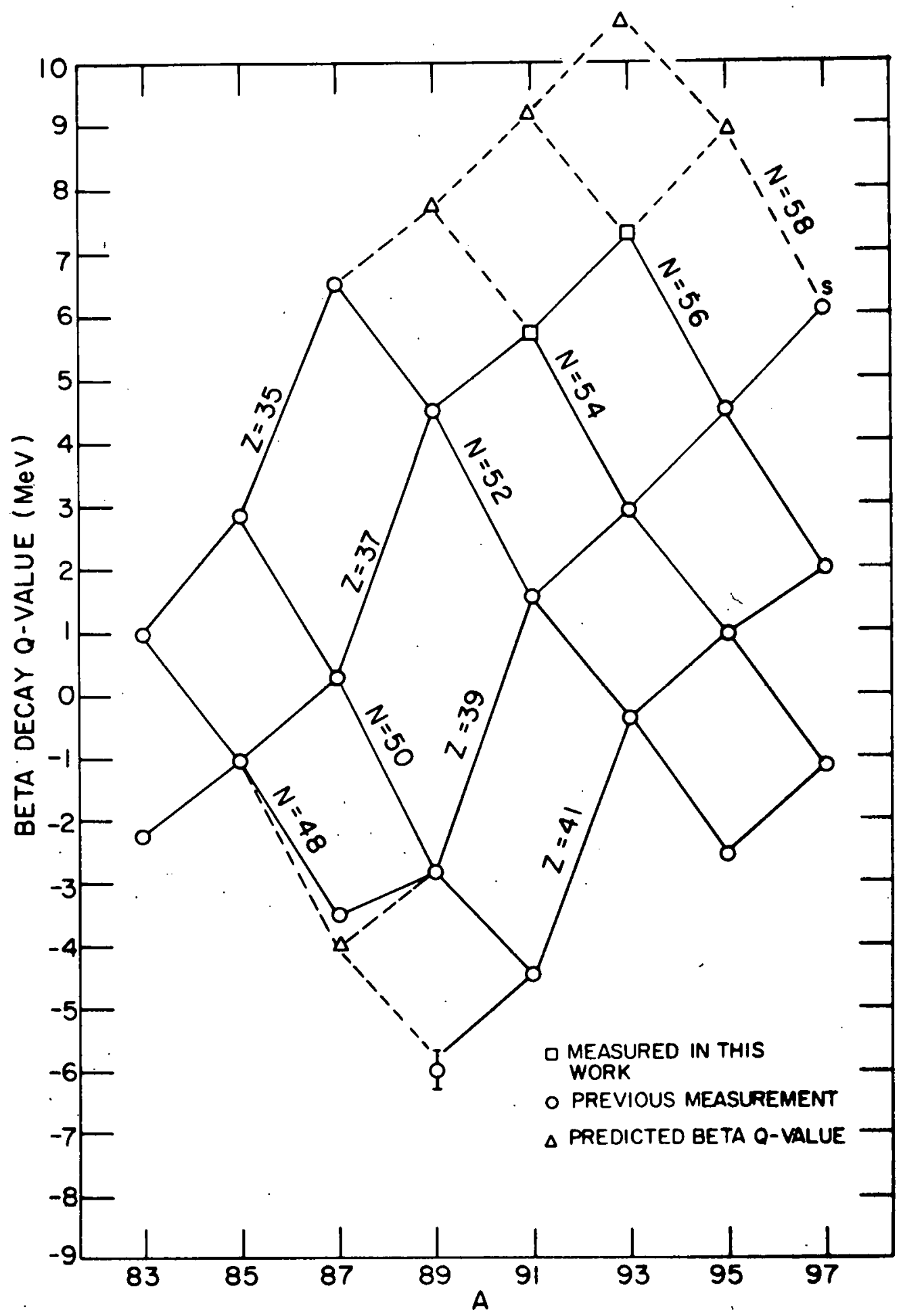

Figure 35. Way-Wood diagram for odd $A$-odd $Z$ in mass region $A=90$ 
Extending these systematics by using the new measurements reported here, thirteen beta decay end-point energies were determined and are listed in Table 13, along with the calculations of Garvey et al. and Seeger. The Way-Wood technique of predicting the Q-values is probably no more accurate: than $0.5 \mathrm{MeV}$ when extrapolating from experimentally determined values. The errors compound when the predictions are partially based on other systematically determined values. A comparison between the systematic predictions and the Garvey et al. or Seeger calculations shows discrepancles which are larger than those clted for the mass relations. Which, if any, of these is accurate will have to be determined by future experiments:

The beta decay end-point energles reported in this work have been a good test of the Garvey et al. mass relation and the Seeger mass formula in the region far from the line of beta stabllity, where their validity is most cruclally tested. For nuclei far from stability but experimentally approachable, the decay energy predictlons of Garvey et al. are more accurate than those of Seeger. It is unknown at this time whether the inability of the Seeger predictions for nuclel studied in this work to stay within the overall precision claimed in his work is an indication of possible limitations in the application of his formula. Where systematic predictions of the type developed by Way and Wood are possible, these seem to give reasonable accuracy and may indlcate where experimental. measurements need to be improved. 
Table 13. Predicted beta decay energies

\begin{tabular}{lccc}
\hline $\begin{array}{l}\text { Decaying } \\
\text { Nucleus }\end{array}$ & $\begin{array}{c}\text { Systematic } \\
\text { Predictions } \\
(\text { MeV })\end{array}$ & $\begin{array}{c}\text { Garvey } \\
\text { et } \frac{\text { al. }}{(M e V)}\end{array}$ & $\begin{array}{c}\text { Seeger } \\
(3) \\
(\mathrm{MeV})\end{array}$ \\
\hline${ }^{85} \mathrm{Se}$ & 6.8 & 5.9 & 5.5 \\
${ }^{86} \mathrm{Se}$ & 5.3 & 5.0 & 3.7 \\
${ }^{87} \mathrm{Se}$ & 7.9 & 7.3 & 6.7 \\
${ }^{88} \mathrm{Se}$ & 6.7 & 6.3 & 5.4 \\
${ }^{89} \mathrm{Se}$ & 9.2 & 8.6 & 8.4 \\
$90_{\mathrm{Se}}$ & 8.4 & 7.5 & 6.6 \\
$91_{\mathrm{Se}}$ & 10.8 & 10.3 & 10.1 \\
${ }^{88_{\mathrm{Br}}}$ & 8.7 & 9.0 & 7.6 \\
${ }^{89}$ & 7.7 & 8.0 & 6.2 \\
$99_{\mathrm{Br}}$ & 9.9 & 10.3 & 9.3 \\
$90_{\mathrm{Br}}$ & 9.3 & 9.2 & 7.5 \\
$93_{\mathrm{Br}}$ & 11.0 & 10.4 & 9.2 \\
$95_{\mathrm{Rb}}$ & & 7.9 & 7.1 \\
\hline
\end{tabular}




\section{CONCLUSIONS}

In this work, eleven beta decay energles were measured using betagamma and beta-singles techniques. The results compare favorably with previous measurements and with mass-relation and systematics predictions. There are several areas in which significant improvements can be made to the present work. The energy calibration of the plastic scintillator could be improved by a more accurate determination of the beta decay energies of the calibration sources. Currently, the end-point energy for ${ }^{88_{R b}}$ is being measured using a magnetic beta-ray spectrometer on-line. with the TRISTAN Isotope separator. WI th the new measurement the discrepancies in the values quoted in the literature should be resolved allowing the uncertainty in the energy calibration at higher energles to be reduced. More accurate measurements of beta decay energies and beta branching ratios could be made using the high resolution beta-ray spectrometer. Plans are now in progress to verify the $2 \%$ ground state branching for the decay of ${ }^{92} \mathrm{Kr}$ and the beta decay energy and beta feeding to the $0.814-\mathrm{MeV}$ level in ${ }^{92} \mathrm{Sr}$ for the decay of ${ }^{92} \mathrm{Rb}$ reported in this study. Discrepancies in the Q-value determinations using certain gated beta-ray spectra could be resolved with more complete decay schemes, especially for the decays of ${ }^{90} \mathrm{Rb}$ and ${ }^{91} \mathrm{Kr}$ which have gated beta-ray spectra that were not used to determine the respective Q-values. It would also be possible to determine the beta decay energies for ${ }^{93} \mathrm{Kr}$ and $93_{\text {Rb }}$ if decay schemes were known. Continued work in beta decay energy determinations is planned for the TRISTAN facllity with improved tape 
collectors, new detectors, and different types of samples greatly expanding the possibllity of further study for the neutron-rich nuclei far from the line of beta stability. 


\section{REFERENCES}

1. von Weizsăcker, C. F. Zur theorie der kernmassen. Z. Physik 96: 431. 1935.

2. Konopinski, E. J. and Rose, M. E. The theory of nuclear beta-decay. In Siegbahn, K., ed. Alpha-, Beta- and Gamma-ray Spectroscopy.

P. 1327. Amsterdam, North-Hol land Publishing Company. 1965.

3. Seeger, P. A. Semi-empirical atomic mass law. Nucl. Phys. 25: 1 . 1961.

4. Garvey, G. T., Kelson, I., Gerace, W. J., Jaffe, R. L., and Talmi, I. Set of nuclear-mass relations and a resultant mass table. Rev. Mod. Phys. 41: S1. 1969.

5. Talbert, W. L., Jr., Tucker, A. B., and Day, G. M. Delayed neutron emission in the decays of short-lived separated isotopes of gaseous fission products. Phys. Rev. 177: 1805. 1969.

6. Talbert, W. L., Jr. Addendum to delayed neutron emission in the decays of short-lived separated isotopes of gaseous fission products. Phys. Rev. Cl: 1135. 1970.

7. Way, K. and Wood, M. A beta-decay energy systematics. Phys. Rev. 94: 119. 1954.

8. Wapstra, A. H. and Gove, N. B. The 1971 atomic mass evaluation. Nuclear Data Tables 9: 265. 1971.

9. Talbert, W. L., Jr., and. Thomas, D. Design considerations for a system to investigate short-lived nuclei produced at a reactor. Nucl. Instr. Methods 38: 306. 1965.

10. Talbert, W. L., Jr. and McConnell, J. R. Preparat ion for on-line studies of short-lived nuclei produced by a reactor. Ark. Fys. 36: $99 . \cdot 1967$.

11. AMF Atomics. Final Hazards Summary Report for Ames Laboratory Research Reactor. Greenwich, Connecticut, American Machine and Foundry Company. 1964.

12. Brown, F. Electromagnetic separators and associated techniques. In Yaffe, L., ed. Nuclear Chemistry. Vol. 2. P. 295. New York, Academic Press. 1968. 
13. Wahl, A. C., Ferguson, R. L., Nethway, D. R., Troutner, D. E., and Wolfsberg, Z. K. Nuclear-charge distribution in low-energy fission. Phys. Rev. 126: 1112. 1962.

14. Norman, J. H. and Hull, D. L. Private communication. 1971.

15. Olson, R. J. Gamma-ray decay schemes for ${ }^{92} \mathrm{Kr},{ }^{92} \mathrm{Rb}$, and ${ }^{92} \mathrm{Sr}$. Unpublished Ph.D. thesis. Ames, lowa, Library, lowa State University of Science and Technology. 1971.

16. Norman, J. H., Talbert, W. L., Jr., and Roberts, D. M. Optimizing act ivity separation in fission product decay chains. U. S. Atomic Energy Commission Report IS-1893 (Iowa State Univ., Ames) 1968.

17. Wohn, F. K., Clifford, J. R., Carlson, G. H., and Talbert, W. L., Jr. A plastic scintillation detector for beta-ray spectrum measurements. Nucl. Instr. Methods (In press) ca. 1972.

18. Nichols, R. T., Pohm, A. V., Talboy, J. H., Jr., and Jensen, E. N. Beta-ray spectrometer for coincidence measurements. Rev. Sci. Instr. 26: 580.1955.

19. Turner, C. E., Jr. Private communication. 1970.

20. Lederer, C. M., Hollander, J. M., and Perlman, I. Table of Isotopes. 6th ed. New York, New York, Wi ley and Sons. 1967.

21. Wolfson, J. L. and Collier, A. J. Precision measurements of betaray end-point energies: $60 \mathrm{Co}, 13 \mathrm{C}_{\mathrm{Cs}}$, and $204 \mathrm{Tl}$. Nucl. Phys. Al 12: 156.1968.

22. Whn, F. K., Talbert, W. L., Jr., and Halbig, J. K. The decay of $85 \mathrm{~m}_{\mathrm{kr}}$. Nucl. Phys. Al52: 561.1970.

23. KIm, M. U. The beta spectrum investigations in decays of ${ }^{134} \mathrm{Cs}$, $122 \mathrm{Sb}$, and $32 \mathrm{P}$. Unpublished Ph.D. thesis. Bloomington, Indlana, Library, Indiana University. 1968.

24. Booij, H. M. W., Van Hock, E. A., Van der Molen, H., Slot, W. E., and Block, J. Shapes of the non-unique and unique first-forbidden beta-spectra of $84 \mathrm{Rb}, 74 \mathrm{As}$, and $124 \%$. Nucl. Phys. A160: 337. 1971.

25. Persson, B. I., Plesser, I., and Sunier, J.W. Beta decay of ${ }^{32} \mathrm{P}$, ${ }^{206} \mathrm{Tl}$ and 209Pb. Nucl. Phys. A167: 470. 1971.

26. Duffiend, R. B. and Langer, L. M. The beta-spectrum of ${ }^{141}$ La. Phys. Rév. 84: 1065. 195i. 
27. Schuman, R. P., Turk, E. H., and Heath, R. L. Decay of shortlived Barium and Lanthanum fission products. Phys. Rev. 115: 185. 1959.

28. Porter, F. T. and Day, P. P. $0^{-}$to $0^{+}$beta transition ${ }^{144} \mathrm{Pr}$ 144Nd. Phys. Rev. 114: 1286. 1959.

29. Graham, R. L., Geiger, J. S., and Eastwood, T. A. Experimental evidence for axial vector interaction in the disintegration of $144 \mathrm{Pr}$. Can. J. Phys. 36: 1084. 1958.

30. Holm, G. B., Fygerquist, U., and Bergstrom, 1. Decay of 3.9-min $\mathrm{Xe}-137$. Phys. Lett. 6: 324. 1963.

31. Onega, R. J. and Pratt, W. W. Decay of Xe-137. Phys. Rev. 136: 365. 1964 .

32. Holm, G. B. Energy levels in the single closed shell nucleus ${ }^{137} \mathrm{Cs}$ populated in the decay of 4-min. ${ }^{137} \mathrm{Xe}$. Ark. Fys. 37: 1. 1968.

33. Van Klinken, J., Pleiter, F., and Dljkstra, H. T., Beta and gamma-ray measurements on decay of $38 \mathrm{Cl}$. Nucl. Phys. Al12: 372 . 1968.

34. Lycklama, $\mathrm{H}_{8}$, Archer, N. P., and Kennett, T. J. Beta decay of ${ }^{87} \mathrm{Kr}$,

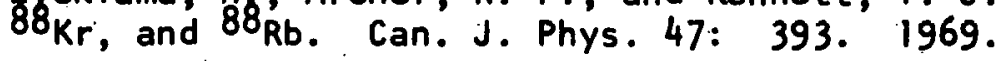

35. Thulln, S. Studies in nuclear spectroscopy with electromagnetically separated gaseous isotopes 11: disintegration of some Krypton and Xenon isotopes. Ark. Fys. 9: 137. 1955.

36. Bunker, M. E.. Langer, L. M., and Moffat, R. D. The disintegration of $88_{\mathrm{Rb}}$. Phys. Rev. 81: 30. 1951 .

37. Rogers, P. C. and Gordon, G. E. Computer analysis of beta-ray and conversion-electron speetra observed with low-resolution detectors. Nucl. Instr. 37: 259. 1965.

38. Bevington, P. R. Data Reduction and Error Analysis for the Physical Sclences. New York, New York, McGraw-Hill Book Company. 1969.

39. Bunting, R. L. Private communication. 1972.

40. Henry, E. A. Gamma-ray decay schemes for ${ }^{89} \mathrm{Kr}$ and ${ }^{89} \mathrm{Rb}$. Unpublished Ph.D. thesis. Ames, lowa, Library, lowa State University of Science and Technology. 1972.

41. KItching, J. E, and Johns, M. W. The decay of $3.2-\mathrm{min}{ }^{89} \mathrm{Kr}$. Nucl. Phys. A98: 337.1967. 
42. Mason, J. F. and Johns, M. W. Decay of $90_{\mathrm{Kr}}$ and ${ }^{90} \mathrm{Rb}$. Can J. Phys. 48: 2056. 1970 .

43. Duke, C. L., Erdal, B. R., Nielsen, K. B., Olson, R. J., and Talbert, W. L., Jr. Private communication with C. L. Duke. 1972.

44. Johnson, N. R., O'Kelly, G. D., and Eichler, E. Decay of ${ }^{90}$ Rb. Phys. Rev. B135: 36.1964.

45. Eidens, J., Roeckl, E., and Armbruster, P. On-line separation and identifjcatigh of several short-lived fission products:- decay of

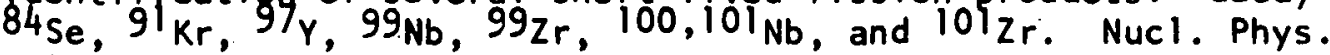
Al41: 289. 1970.

46. Mason, J. F. and Johns, M. W. Level structures of ${ }^{91} \mathrm{Rb}$ and ${ }^{91} \mathrm{Sr}$ as populated in beta-decay. Can. J. Phys. 48: 2895. 1970.

47. Zherebin, E. A., Krylov, A. I., Polikarpov, V, J., and Yuzyuk, M. N. Investigation of beta and gamma radiation of $\mathcal{S l}_{\mathrm{Rb}}$. Yadernaya Fizika 7: 3. 1968.

48. Macias-Marques, M. 1., Foucher, R., Caillian, M., and Belhassen, J. Mass differences in the neutron-rich Sr region. Int. Conf. on Properties of Nuclei far from the Region of Beta-Stability. Cern 70-30: 321. 1970 .

49. Adams, J. P. Study of electron emissions of some mass-separated fission product activities. Unpublished Ph.D. thesis. Ames, lowa, Library, lowa State University of Science and Technology. 1972 . 


\section{ACKNOWLEDGMENTS}

This author wishes to acknowledge and thank the many people who have given invaluable support and encouragement during this study:

Dr. Willard L. Talbert, Jr., who, as thesis advisor, guided this project to completion. He is responsible for the development of the TRISTAN facility which made this study possible. His insight and knowledge of physics were invaluable for the interpretation of the results. $H$ is long hours of aid in guiding the writing of this thes is are greatly appreciated.

Dr. Fred $K$. Wohn for his help in the development of the experimental and analytical techniques employed in this project. He suggested the project undertaken and initiated much of the work which was continued by this author.

James $P$. Adams for his ever present help and cooperation throughout the duration of this experiment. His aid, advice, and encouragement have been exceptionally valuable to the completion of this work.

John R. McConnell, who has worked to make TRISTAN a notable experimental facility. I wish to particularly thank him for his help as teacher and his willingness to be of assistance at any time.

The rest of the members of Group VII, for experimental assistance and many fruitful discussions.

Dr. Fred T. Phelps, Jr., who kindled my interest in physics with his infectious enthusiasm.

My parents, Mr. and Mrs. Edward J. Skillin, for their encouragement throughout my education. 